\title{
The Earth and Her Roots: Above + Below Place-Thought
}

by

Brooke Zacharuk

\begin{abstract}
A thesis submitted to the Faculty of Graduate and Post Doctoral Affairs in partial fulfillment of the requirements for the degree of
\end{abstract}

Master of Architecture

Carleton University

Ottawa, Ontario

\author{
(C) 2021 \\ Brooke Zacharuk
}


Odawa(Ottawa), Turtle Island 


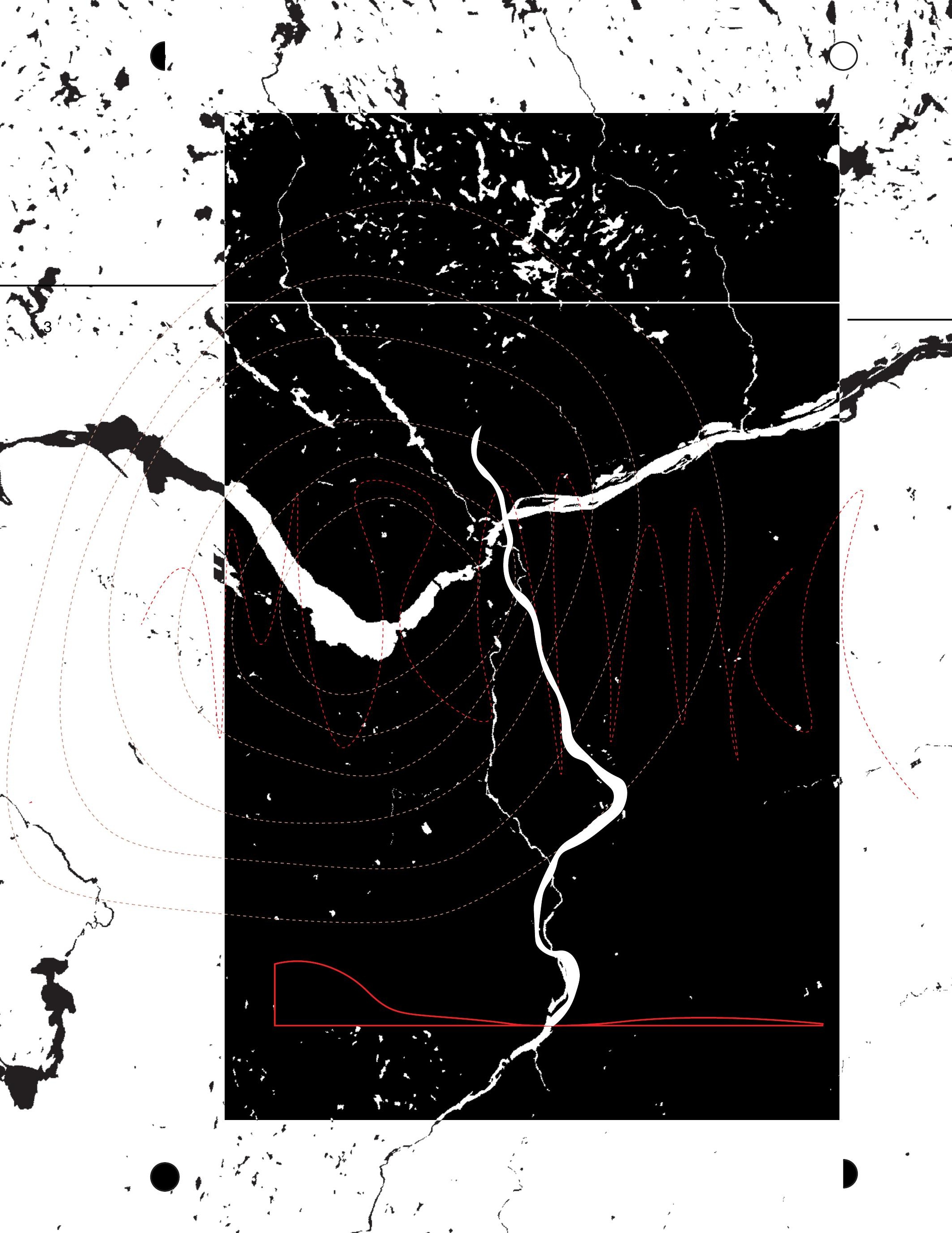


Earth as a paradigm for architecture questions languages of design drawing/thinking. Studying Odawa pastures' potential to challenge national building codes and worldviews revealed the return of repressed design processes made of metaphysical, cosmological, and socio-political strings woven from rhythm and flows in hybrid realities. A proposal to unify agriculture/architecture policy, pedagogy, and practice through product/labour creation manifests in liminal negotiations within residential building envelopes surrounding the Tunney's Pasture post-war government campus.

Speculative fabulation/feminism and radical Indigenism support intersectional justice by working with architectural methodologies founded on nondualism. Advocacy for ancestral practices, neo-materialism, Place-Thought, and care-work expands ontologies centered on unity to unsettle Archi-tecture's dualisms. Adopting a transcendent viewpoint towards polarities dissolves the boundaries of Earth/Architecture across time, scale, space, and the pluriverse. Flowing between ways of knowing/being presents growing(++), harvesting(-+), living(--), and rooting(+-) into geo-cycles through archetypal mythologies of place, culture, bodies, and folds. 
I acknowledge the Algonquin nation whose traditional and unceded territory we gathered upon for my education. I recognize that Indigenous communities and teachings are essential in supporting biodiversity and am committing to unlearning colonial mindsets held personally and advocating for the dismantling of these systems collectively. I seek to honour the land of Turtle Island.

Situated within the national epicenter of colonial enterprise, the seat of the government of Canada in Odawa signifies settler colonialist practices and relations across the country/ globe. Being here now presents an opportunity to challenge the foundations of industrial building practices that negatively impact the environment and humanity.

Negotiations for Ontario's first modern-day treaty, which would include Odawa territory, are currently in process. ${ }^{1}$ "If successful, it will be the province's first modern-day constitutionally protected treaty." ${ }^{2}$ Simultaneously, the City of Ottawa's New Official Plan currently under development largely supports an expansion model of constructing new housing from extracted material on greenspace with undiversified urban planning strategies. ${ }^{3}$ In this moment of rapid biodiversity loss, I aim to work collectively with communities to act on the changes that need to be made to protect the planet for future generations.

1 Ontario, Map of Ontario Treaties and Reserves, (2021).

2 Ontario, The Algonquin Land Claim, (2020).

3 City of Ottawa, The New Official Plan, (2021). 
Thank you to the many mentors I have been so

fortunate to meet along my journey to creating

\section{this work.}

I would like to thank my advisor, Zachary Colbert,

for encouraging me to run with the multiverse. Lisa

Moffitt's graduate seminar Miniaturising the Gigantic

was an essential course to support explorations

on above + below - many of the readings from this

course appear throughout. Thank you to Jill Stoner,

for instilling a spirit of literature in architecture

pedagogy and supporting the foundation for the

Thank you Ozayr

Saloojee, Tom

Carruthers, Piper

Bernbaum, and Natalia

Escobar Castrillón for

their comments and

wonderful conversation

at my defence.

Thank you Suzanne

Harris-Brandts, Jerry

Hacker, Leah Meisterlin,

Lisa Moffitt, and Stephan

Kowal for their feedback

and thoughts during my

colloquiums.

I am exceptionally

grateful to my partner,

Marc Vincent, for

supporting me in my

career and beyond

- The Earth and Her

Roots thank you for

showing this thesis the

Rolleiflex.

+ Britney Zacharuk's

Environmental Science/

Sister Conversations

++ my parents,

for everything! etymological studies employed in this work. Jerry

Hacker, for embracing the optimism required to seek

a world that is protected for the next generations.

Ozayr Saloojee, for reminding me to find mirrors and always credit excellent questions. Yvan Cazabon, for opening my eyes to the spirit of Carleton's architecture archives. Catherine Bonier, for the honour of participating in the Cities course as your Teaching Assistant. Adriana Ross, for helping me learn how to draw. Neil Spiller, for showing me the world of Leonora Carrington and surrealist women. loana Teodorescu, for providing personal and professional mentorship as I face the discipline of Architecture. Bobby llg, for first showing me the transformative capacity of natural architecture. Kurt Espersen-Peters, for mentoring my undergraduate thesis in Interior Design and encouraging me to pursue my Master of Architecture. And last but certainly not least, thank you to all my family and friends who supported me throughout my pursuits. 


\title{
7 Table of Contents
}

\author{
4 Abstract \\ 5 (Land) Acknowledgement $[\mathrm{s}]$ \\ $7 \quad$ Table of Contents \\ $9 \quad$ List of Illustrations \\ 10 Appendix List \\ 11 Glossary of Terms \\ 12 Prologue \\ Part I \\ 18 Gratitude \\ 19 Theory \\ 21 Method \\ 22 structure \\ 1 \\ Part II \\ 28 Earth (nature) \\ 31 Consequences \\ 37 Embodied Energy (Material Agency) \\ 40 Indigenous [vernacular] (ancestral)
}




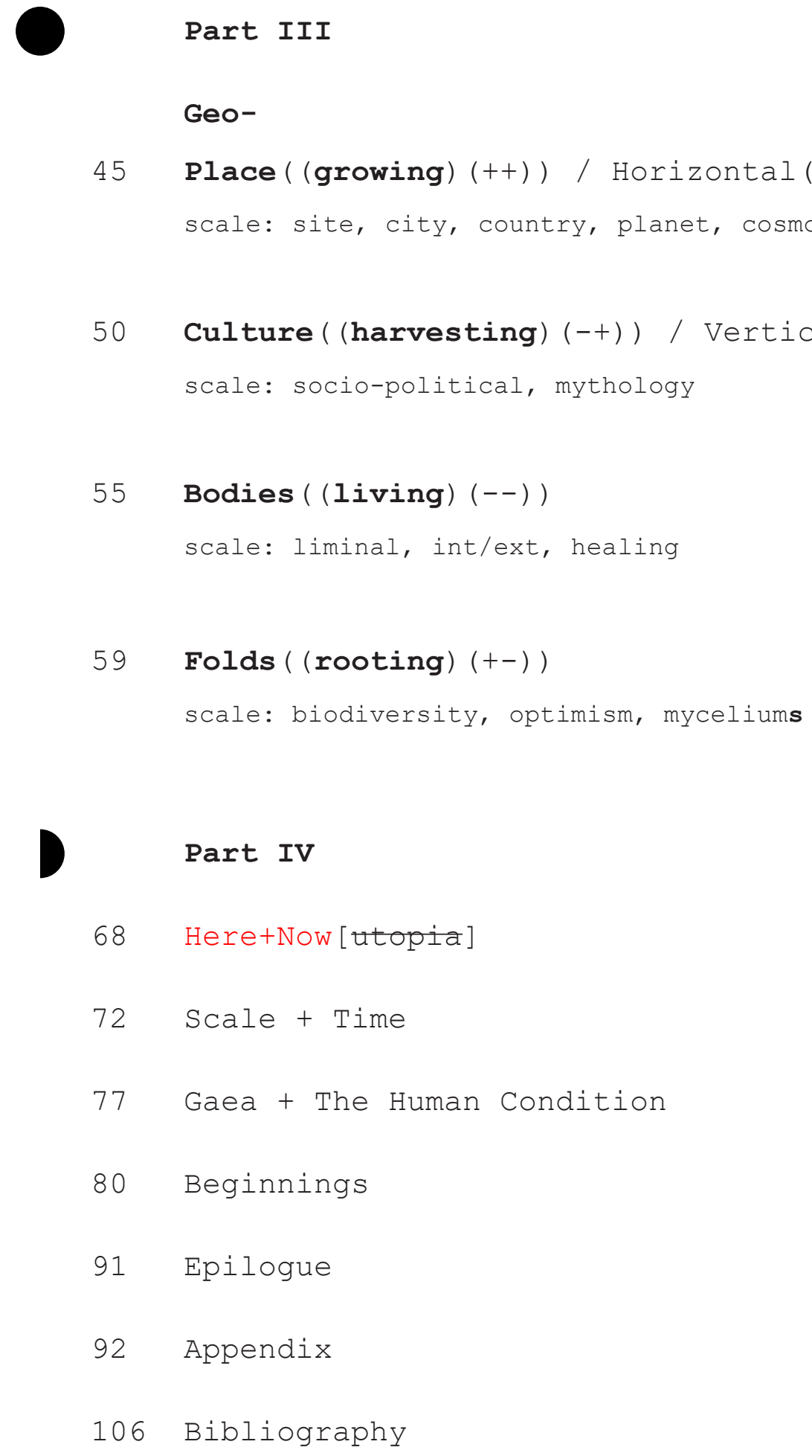




\section{Images}

$\begin{array}{lll}3 & \text { Fig } 1 . & \text { space-time } \\ 17 & \text { Fig 2. } & \text { The Return of the Represed:Earth } \\ 24 & \text { Fig 3. } & \text { standards } \\ 32 & \text { Fig 4. } & \text { psycho-metric } \\ 33 & \text { Fig. } 5 & \text { oil cities } \\ 38 & \text { Fig. } 6 & \text { Algonquin Nation } \\ 39 & \text { Fig. } 7 & \text { Odawa }\end{array}$

\section{Material Studies}

$\begin{array}{ll}14 & 1 \\ 15 & 2 \\ 26 & 3 \\ 27 & 4 \\ 42 & 5 \\ 43 & 6 \\ 66 & 7 \\ 67 & 8\end{array}$

\section{Drawings}

$\begin{array}{ll}82 & \text { materials (embodied) energy } \\ 83 & \text { geo-place } \\ 84 & \text { geo-culture } \\ 85 & \text { geo-bodies } \\ 86 & \text { geo-folds } \\ 87 & \text { becoming soil } \\ 88 & \text { mind map } \\ 89 & \text { knowing/being } \\ 90 & \text { being care-ful }\end{array}$


10 Appendix List

p. Site Documentation

$\begin{array}{ll}93 & 1 \\ 94 & 2 \\ 95 & 3 \\ 96 & 4 \\ 97 & 5 \\ 98 & 6 \\ 99 & 7 \\ 100 & 8 \\ 101 & 9 \\ 102 & 10 \\ 103 & 11 \\ 104 & 12\end{array}$

1051000 
Neo-Materialist / giving material agency

Post-dualist / embracing diversity

Pluriverse / a world of pluralism; see plurality + multiverse

Plurality / being plurals

Polarity / poles of the same thing, unity

Multiverse / multiple universes

Ontological / nature of being (a soul)

Transition-Oriented / beyond colonialism + extractivism

Ecozoic / radical optimism

Radical / from the root up

Quadrants / coordinate system graphing points on $x, y, z$ axis - or 1/4 of a circle

Intersectional / Relationship between forms of oppression (Race, Gender, Class, Religion, Environment, +)

Blackfoot Dictionary / Algonquin Dictionaries Project

Architect $=$ no definition provided

Nature $=$ no definition provided

Earth $=$ Earth, dirt, land (ksááhko, personified) (ksaahkomm)

Home = going home day (a day midway between summer solstice + winter solstice) (aahkiáapiksistsiko) 


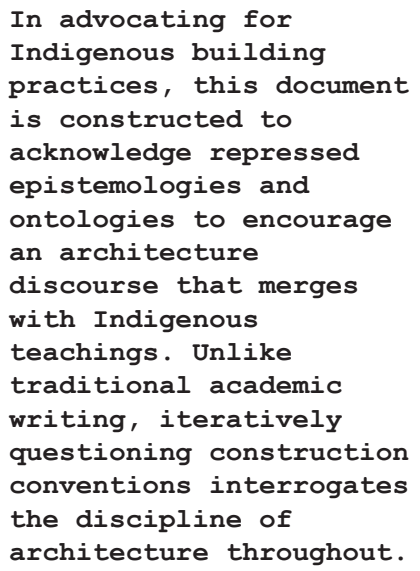

Red text proposes the return of repressed language(s).

[Square brackets with a strikethrough suggest reconciling perspectives].

(Round brackets are multipliers, implying a multiplicity of meanings).

Bold text narrates the design.

Work with a circle and miniaturized text signifies work done in collaboration with Lisa Moffitt's graduate seminar: Miniaturizing the Gigantic.

The intention of this method is to expose the importance of language as an emotional, visual, and perceptual tool to encourage placebased design that acquires spatial. tectonic, and material realities from the ancestry of the regional climate and soil. The drawings suggest a re-interpretation of construction documents that do not adhere to dominant industry conventions of scale and time.

Author's Note:

Please consider the counterclockwise motion of the quadrants reading, which signifies the un-learning aspect of this project.
New languages of design are required. Industry conventions - such as plans, sections, elevations, axonometry, and maps - and conventional conceptions of space - such as typologies, programs, and cities - are tools of architecture and urbanism entangled within dominant economic, political, and social power structures. As a result, the built environment currently perpetuates "dispossession, attempted assimilation, and displacement."4 In response, this work uses intersectional environmentalism to advocate for Indigenous knowledge to be brought to architecture in alliance with anti-racist and feminist agendas to build justice and equity for humanity and the planet.

Situated within conversations of settler colonialism and decolonization, it is necessary to recognize that settler colonialist ideology can produce "colonial fatalism", which undermines or silences "well-established traditions of decolonial knowledge production in the field of Indigenous studies." Furthermore, settler colonialism can neglect the "violence on Indigenous bodies sustained by white supremacist heteropatriarchal social order," 6 and omit to reference longstanding Indigenous resistance. ${ }^{7}$ The seminal article "Decolonization is not a metaphor" highlights the importance of realizing the goal of decolonization as "repatriation of Indigenous land and life; it is not a metaphor for other things we want to do to improve our societies or schools." ${ }^{8}$ Contextualizing settler colonialist and decolonization frameworks reveals the need for more meaningful alliances to address the role of architecture and the climate crisis.

4 Julie Tomiak, et al. Introduction in Settler City Limits: Indigenous Resurgence and Colonial Violence in the Urban Prairie West (Winnipeg: University of Manitoba Press, 2019), 11.

$5 \mathrm{lbid}, 13$.

6 Ibid.

7 Ibid, 17.

8 Eve Tuck and Wayne Yang. "Decolonization is not a Metaphor," Decolonization, Indigeneity, Education \& Society 1, no. 1 (2012): 1-40. 
Part I 


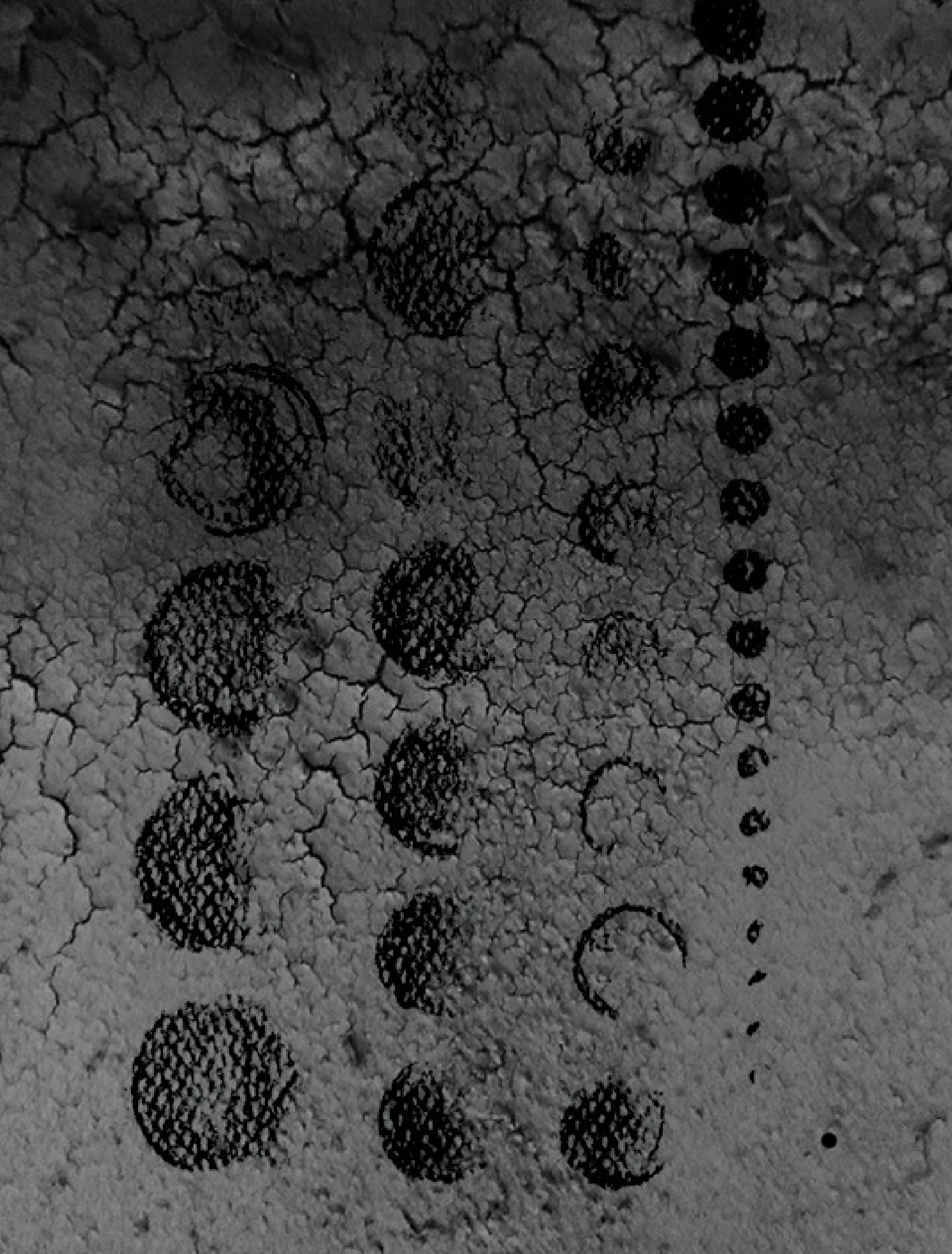





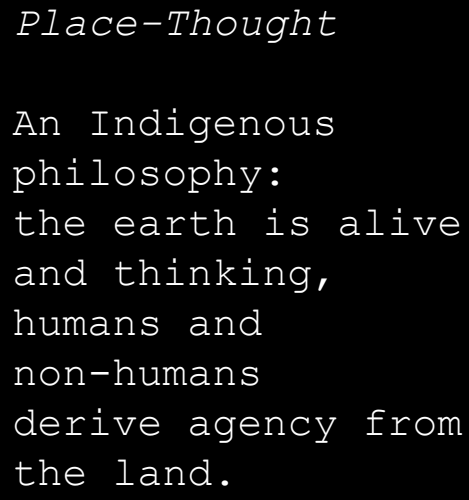

Vanessa Watts, "Indigenous place-thought \& agency amongst humans and nonhumans (First Woman and Sky Woman go on a European world tour!)," Decolonization: Indigeneity, Education \& Society 2: no.1 (2013): 24. 


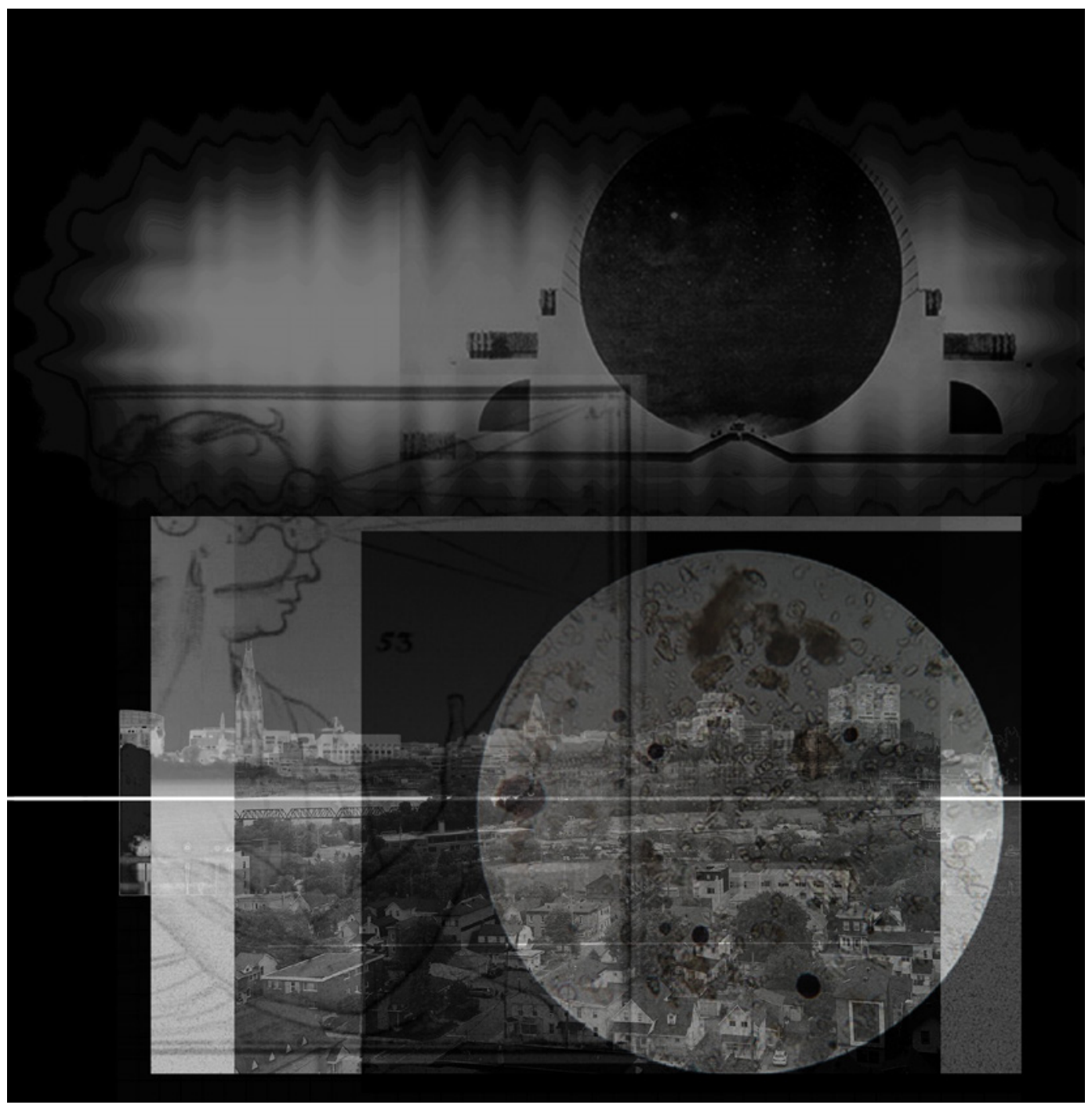

Fig. 2

The Return of the

Repressed:Earth

The Soil Microbial Carbon

Pump seen through the

Microscope given the

Architectural Significance of the Cenotaph for Newton 
Gratitude

I extend gratitude to Vanessa Watt's - Mohawk (Bear Clan, Six Nations) and Anishinaabe - for the article on Place-Thought, Zoe Todd - (Métis/ otipemisiw) from Amiskwaciwâskahikan (Edmonton) - and Heather Davis for their article on Decolonizing the Anthropocene, and Robin Wall Kimmerer, for teaching me that Wiingaashk (Sweetgrass) "belongs to herself." I am grateful to Rupi Kaur's poetry: specifically, the collection The Sun and Her Flowers published in 2017, which inspired the title and structure of this work. 
Donna Haraway writes, "our task is to make trouble, to stir up potent response to devastating events, as well as to settle troubled waters and rebuild quiet places."9 Staying with the trouble, as Haraway tells us, could also be interpreted as unifying dualities to elevate seemingly opposing positions to transcendent wholes. The practice of transcending duality has ancient roots in philosophies and religions and may offer clues to settle our troubled waters today. ${ }^{10}$ Bruno Latour's recent book Down to Earth(2018) highlights the local action and worldview required to address the Climate Regime : unifying the duality of local/global. ${ }^{11}$ In this way, Latour's work engages with the Chthulucene and Speculative fabulations/ feminisms, presented in Donna Haraway's Staying with the Trouble(2016), where we begin to learn to live well with human/non-human, living/nonliving (life/death)(+/-). ${ }^{12}$

Bernard Rudofsky's seminal exhibition and book Architecture without Architects(1964) $)^{13}$ and Marcel Vellinga and Lindsay Asquith's Vernacular Architecture in the $21^{\text {st }}$ Century: Theory, Education and Practice(2005) ${ }^{14}$ situate this thesis within the epistemological context of contemporary advocacy for vernacular construction based on Indigenous building

9 Donna Haraway, Staying with the Trouble: Making Kin in the Chthlucene (Durham: Duke University Press, 2016), 1.

10 Joseph Campbell, The Power of Myth with Bill Moyers (New York: Anchor Books, 1988).

11 Bruno Latour, Down to Earth: Politics in the New Climatic Regime (Cambridge: Polity Press, 2018).

12 Haraway, “Making Kin: Anthropocene, Capitalocene, Plantationocene, Chthulucene,"in Staying With the Trouble, 99-103.

13 Bernard Rudofsky, Architecture Without Architects: An Introduction to Non-Pedigreed Architecture (New York: The Museum of Modern Art, 1964).

14 Marcel Vellinga, and Lindsay Asquith, Vernacular Architecture in the $21^{\text {st }}$ Century: Theory, Education and Practice (London: Taylor \& Francis, 2006). 

supports the ontological connection between Indigenous agricultural and architectural practices based on regional soil and climate. ${ }^{15}$

A combination of architectural theory, anthropology, mythology, and philosophy accompanies the study of Indigenous building cultures. Diana Agrest's work Architecture of Nature:Nature of Architecture(2018) and Architecture from Without(1991) place this work within criticisms of modernist theory through advocacy for Nature/Earth as an independent subject of study in Architecture. Arturo Escobar's Designs for the Pluriverse: Radical Interdependence, Autonomy, and the Making of Worlds(2018) defines the ontological transition-oriented design employed throughout. Joseph Campbell's The Power of Myth(1988) supports the psychospiritual and mythological dimensions of this research. Lastly, Hannah Arendt's work The Human Condition(1958) encourages the philosophical inquiry into the nature of labour, work, and action to support the premise that lessons from millennia challenge modernist beliefs on progress. $^{16}$

An emphasis on materiality is the connecting thread that weaves the intersecting theoretical frameworks. David Benjamin's work on architecture's material impact at Columbia University GSAPP, published in the book Embodied Energy and Design: Making Architecture Between Metrics and Narratives(2017), reinforces the premise that biofabrication can help address architecture's role in climate change. ${ }^{17}$ In dialogue with contemporary discourse's pursuit of addressing architecture's impact 
21 on the environment, an ontological exploration of embodied energy's etymology reveals material Spirit. Therefore, neo-materialism becomes the prevalent theoretical position that blends ancient histories with new approaches to design. As a result, the predominant theoretical framework for this work proposes that material agency can support the collective journey toward decolonization through the Indigenous philosophy of PlaceThought.

\section{Method}

I began this work with The Operative History and Theory methodology developed by Manfredo Tafuri that supports the "systemic criticism of the ideologies accompanying the history of capitalist development."18 Cited as a general reference in Kenneth Frampton's seminal text Modern Architecture: A Critical History(1980), Tafuri is situated within the Arts + Crafts movement, which catalyzed Louis Sullivan and Frank Lloyd Wright's explorations on the manifestation of Nature in architecture..$^{19}$ However, as this thesis aims to advocate for histories beyond euro-centric and fossilcapitalist ideals, the work sought alternatives to Western histories of Nature and architecture. Such sought histories advocate for Indigenous knowledge to heal the Earth. Studying with deep time shows natural assemblies that dwell in union with Earth and proposes that Earthen envelopes require new methods of academic inquiry. The work responds to deep time studies by narrating speculative architectural fabulations and feminisms, inspired by Donna Haraway, focused on ontological transition-oriented design, inspired by Arturo Escobar. Considerations

18 Manfredo Tafuri, Architecture and Utopia: Design and Capitalist Development (Cambridge: MIT Press, 1977), 182.

19 Kenneth Frampton, Modern Architecture: A Critical History (London: Thames and Hudson, 1985). 
22 emphasize the programmatic, linguistic, and representational implications of a decolonial geo-place paradigm for architecture manifest in scale and across time.

Investigating the deep history of architecture as it manifests across drawing, language, and space revealed alternative vocabularies focused on emotion and unity. As a result, the drawings developed for this work can be read as maps that explore a range of forces, which could be interpreted as legends. Additionally, the drawings are hybridized (photography, models, painting, and digital) to reflect the complexities of the transition beyond extractivism. Proposed nomenclature and drawing conventions seek to identify opportunities to design through transcending polarities. Archetypes attempt to merge ways of knowing with ways of being to seek hybrids that operate in a multiverse of plurality. Ultimately, the intention is to inform architectural methods with earth-based mythologies.

\section{Structure}

Part II / Limiting the focus of design to a single point of materialization led to architecture's negative impact on the environment, which ultimately traces to contemporary discourse claiming that nature no longer exists. In response to this claim, the concept of "Nature" is used interchangeably with "Earth" in an exploration of Descartes/Cartesian logic and the creation of the term Anthropocene alongside investigations into modernist architecture and urbanism theories and methods. The history and consequences of industrial materials are presented to expose contemporary industry greenwashing produced through logocentrism. In response, a proposal to unify agriculture/architecture is presented, and 
23 the natural building movement is situated within political, economic, and social contexts. The study of embodied energy's relation to the theory of neo-materialism (material agency/spirit) and Place-Thought present Indigenous[vernaeular] building as a repressed practice.

Part III / Expansion in conversation with Darwinism's impact on the built environment encourages organism-based readings of cities and architecture (growing/++). Exploring architecture as culture allows the work to engage with a de-growth economy, the socio-political, and mythology through urban prefabrication facilities (harvesting/-+). Building envelopes discussed as the liminal negotiator between interior/exterior realities and psychological internal/external conditions explores the role of Earth in healing (living/--). An intersectional eco-feminist lens investigates labour and work in the creation, maintenance, and decomposition of the built environment to support the proposal of using mycelium(roots) to turn materials into soil (rooting/+-). These quadrants/realms (++/-+/-I+-) are narrated with an adaptive re-use proposal for Tunney's Pasture post-war government campus and the diversification of the surrounding residential neighbourhood in Odawa, Turtle Island. Simultaneous rhythms of [geo(place, culture, bodies, and folds)] attempt to unify dualities of logic/intuition and science/mythology.

Part IV / Explorations on utopias, scales, time, nowness, oneness, beings, Gaea, the human condition, and plurality in the multiverse set the stage for the concluding drawings. 

I

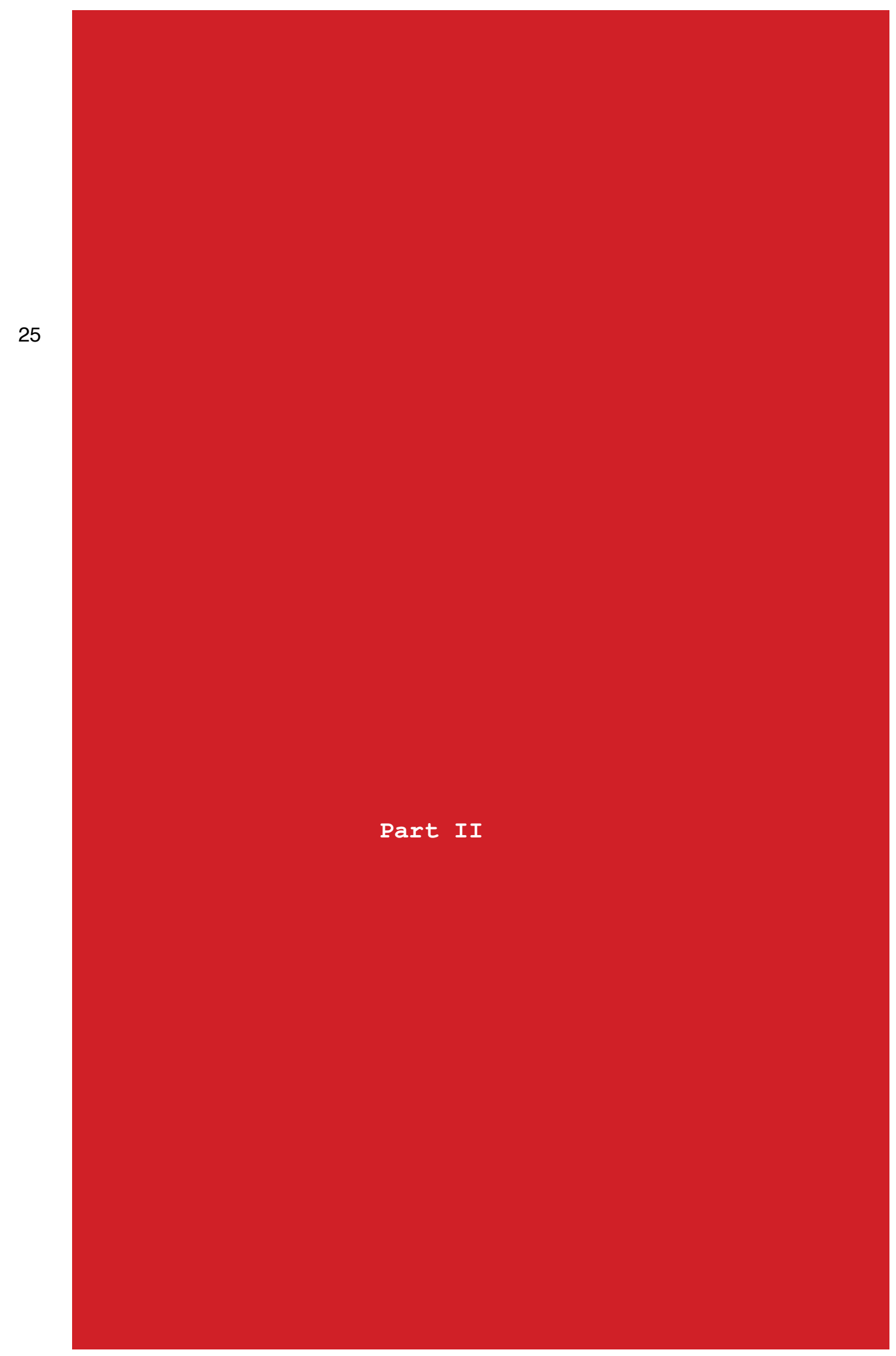


-

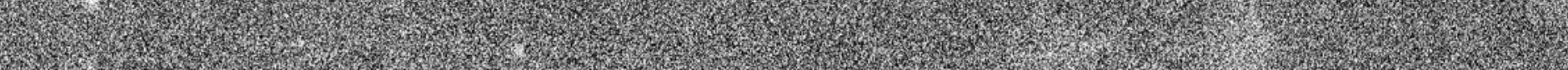

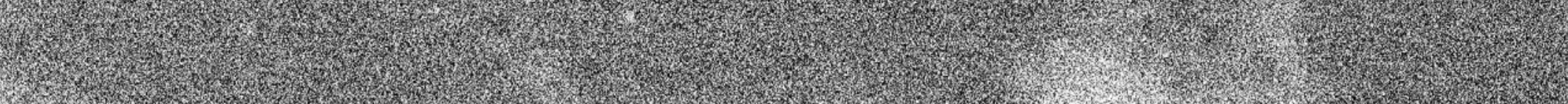

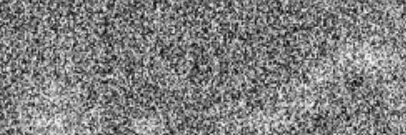

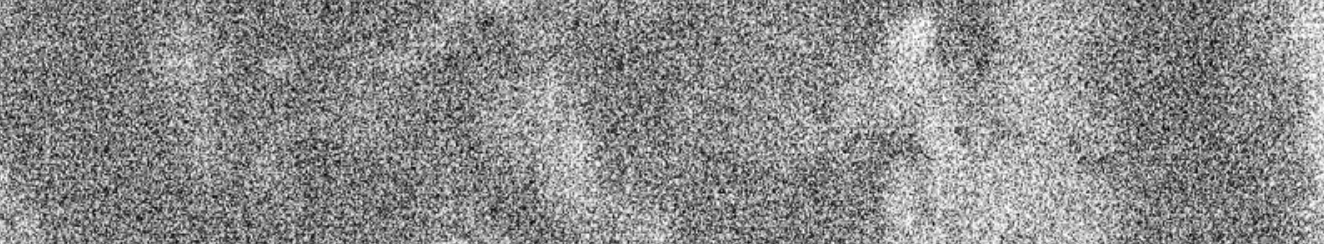
1.7.

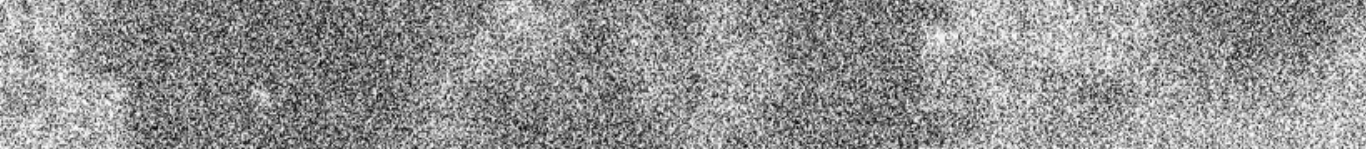

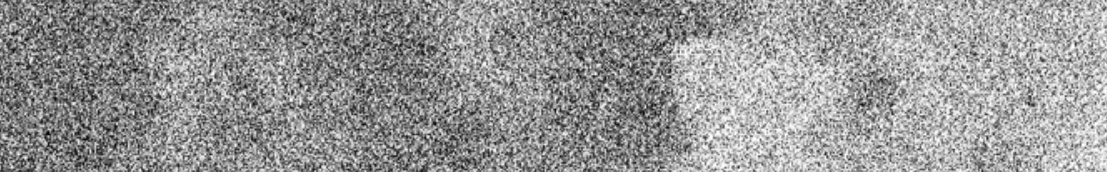

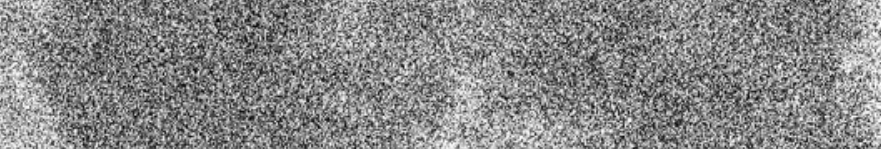

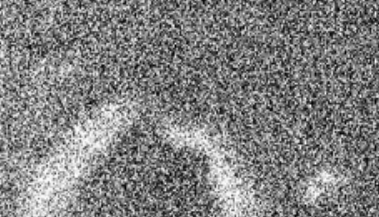

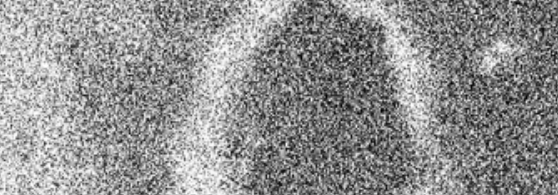

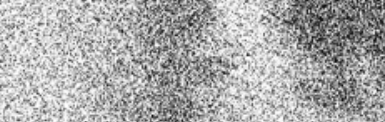

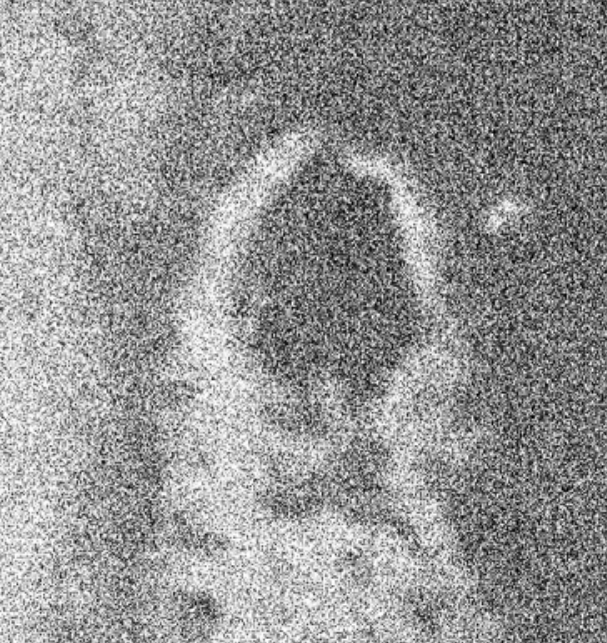
17.

a)

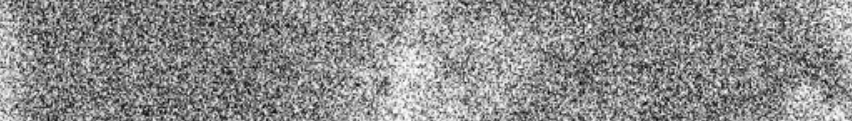

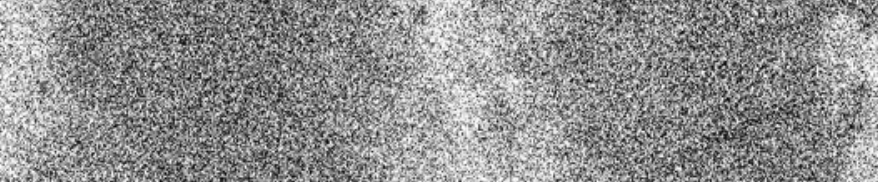

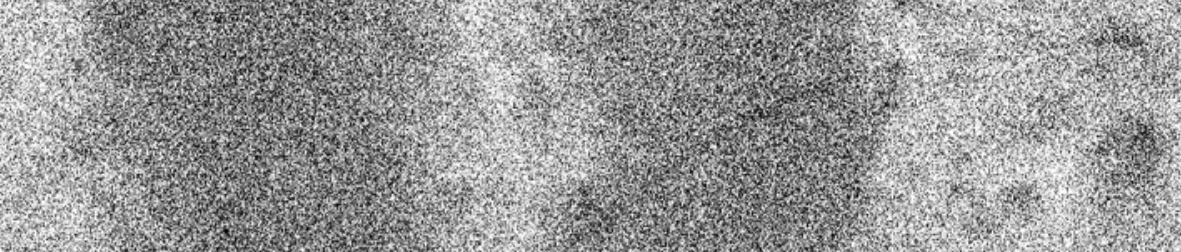

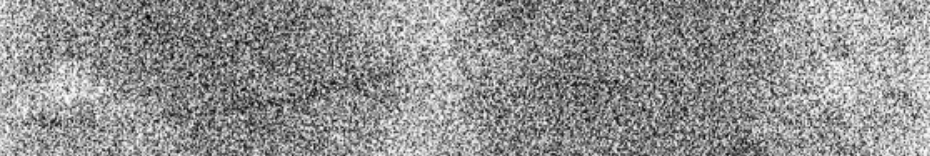

Hiting

1.

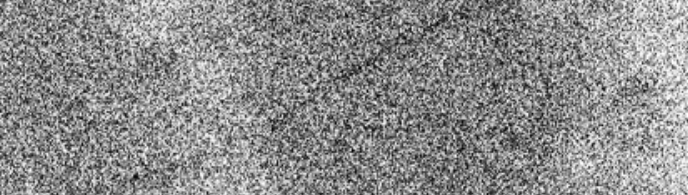

3.t.

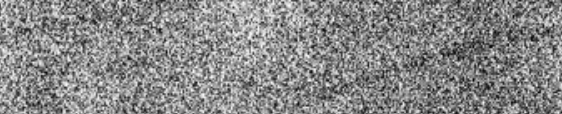

1.

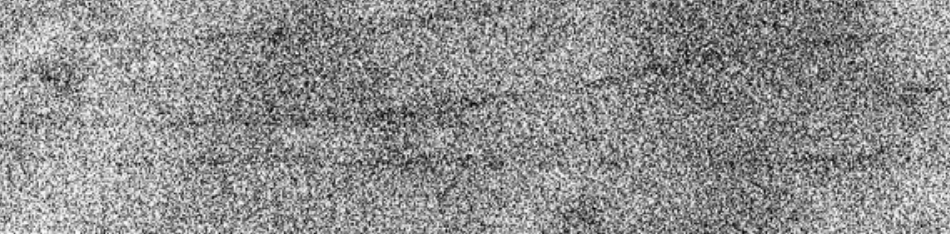

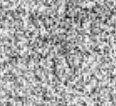

r

$$
\begin{aligned}
& -1 \\
& \hline
\end{aligned}
$$

1. 3.
1.
1.

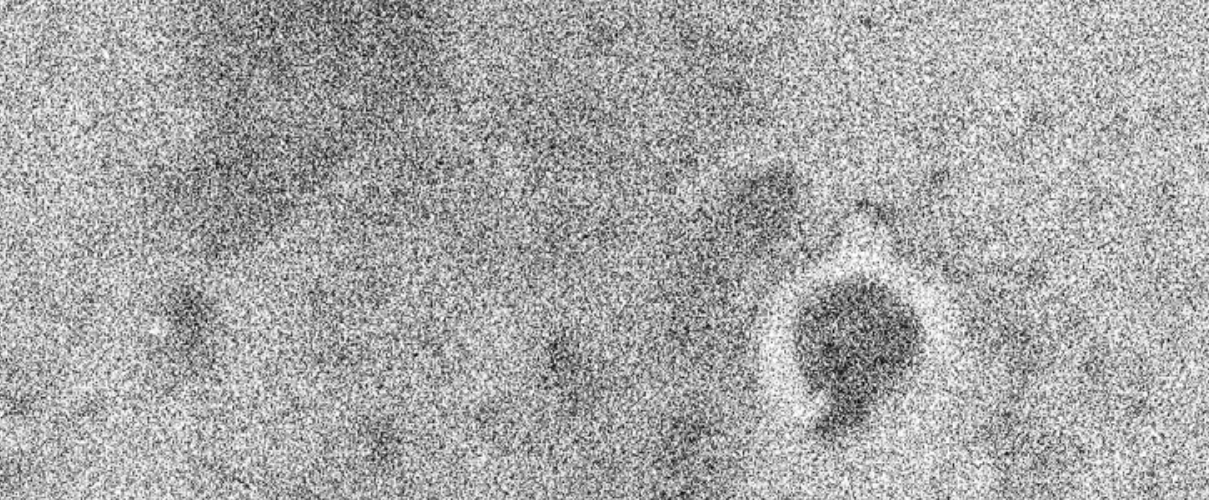



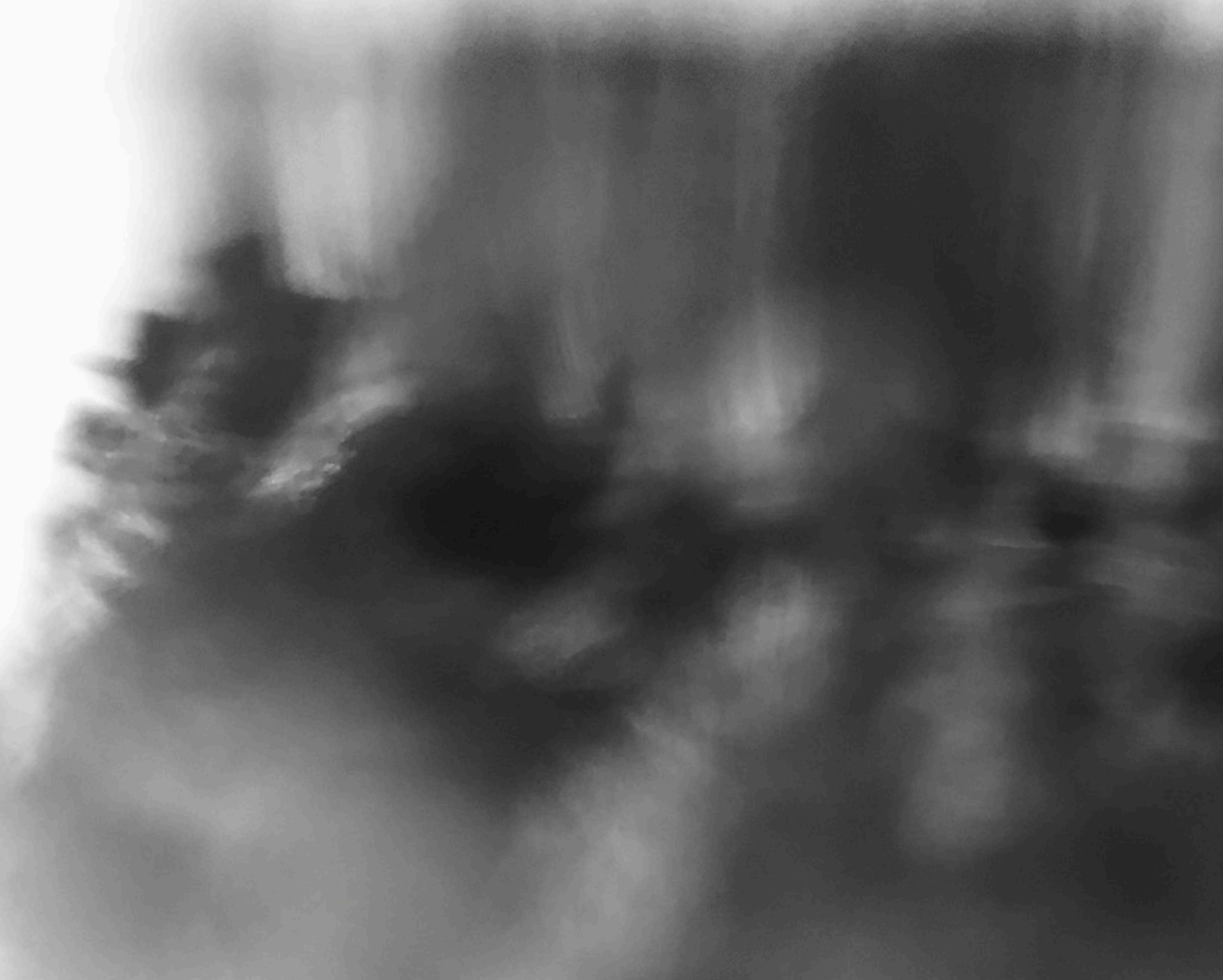

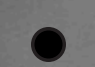


Epistemological and ontological division - knowledge as separate from being - is fundamental in defining the destructive dichotomies at play in our world today. As a result of the identification with polarity, "nature", as conceptualized by contemporary discourse, is racialized, gendered, and dead. "The death of nature" or the "non-existence" of nature prescribed by Bill McKibben in the 1989 book The End of Nature, ${ }^{20}$ is a denial of the self from a perspective of unity. But who is the Self? Descartes argued, "I think, therefore I am."21 Barbara Kruger responded, "I shop, therefore I am." 22 Descarte's proclamation supports a Cartesian mode of rationalism that prioritizes reason through a mind-body dualism. The emphasis on thought - or epistemology - highlights logic based on a mechanistic understanding of reality. It could be said this logic became the bedrock for neo-liberal capitalism, industrialization, and colonization[globalization].

The Anthropocene, Oliganthropocene, Capitalocene...the cene Timothy James LeCan asserts that from a neo-materialist perspective, the prevalent discourse on climate change engaging with anthropogenic activity reinforces conventional modernist beliefs between humanity and Earth(nature), framing Nature/Earth as "a largely passive natural world."23 Critics argue the Anthropocene is not holistically representative of the inequalities present within contributions to climate change, as large-scale corporations are more responsible for the pollution in the environment compared to individuals (Oliganthropocene/Capitalocene). ${ }^{24}$ Donna

20 Bill McKibben, The End of Nature (New York: Penguin Random House, 1989).

21 René Descartes, A Discourse on the Method Translated by John Veitch (Project Gutenberg, 1937).

22 Barbara Kruger, I Shop Therefore I am. (New York: MoMA, 1990).

23 Timothy James LeCain, "Against the Anthropocene: A Neo-Materlialist Perspective," International Journal for History, Culture and Modernity 3, no.1 (2015): 1.

24 Ashley Dawson, Extreme Cities: The Peril and Promise of Urban Life in the Age of Climate Change (London: Version, 2019). 
Haraway criticizes the Anthropocene's connection to pessimism, which could lead to cynicism and inaction (Chutulucene). ${ }^{25}$ Heather Davis and Zoe Todd's article "On the Importance of a Date, or Decolonizing the Anthropocene" equates the failure to address the Anthropocene to the disassociation from unity. Seeking the context of the Anthropocene is itself a questioning of duality based on human logic of epistemic and ontological paradigms, where human perception is distinct from the world, removing "the how and why from the what. ${ }^{26}$ The what is the Sixth Extinction" ${ }^{27}$, the how and why are arguably due to the rejection of our interdependence. In other words, the climate crisis traces to seeing ourselves as separate to the natural world. If Nature does not exist, neither can we/l.

Architecture and urban theorist, practitioner, and educator, Diana Agrest, reflects on the relationship between architecture, Nature, and sociology throughout her career by focusing on themes of repression. The reprint of her 1991 essay "The Return of the Repressed:Nature" at the end of her recent book Architecture of Nature, Nature of Architecture(2018) epitomizes her ecofeminist critique of modernist urbanism's conceptions of nature. The essay originally published in 1996 (but written in 1991), relates the repression of nature/feminine and sets the basis for her continual explorations on the binaries relating to Nature (nature/culture, nature/urban). "Nature, identified with the female sex, was to be enslaved, inquisitioned, dissected, and exploited, an identification that justifies the

25 Haraway, "Making Kin: Anthropocene, Capitalocene, Plantationocene, Chthulucene,"in Staying With the Trouble, 99-103.

26 Heather Davis and Zoe Todd, "On the Importance of a Date, or Decolonizing the Anthropocene," An International Journal for Critical Geographies 16, no. 4 (2017): 769.

27 Elizabeth Colbert, The Sixth Extinction: An Unnatural History (New York: Henry Holt and Company, 2014). 
search for power over nature and over women."28 Earth(Nature), "adored as a virgin, or burned as a witch." ${ }^{29}$ Intersectionality expands the logic of oppression to any rejection of "other" to the constructed "norm," reinforcing nature as gendered and racialized. Agrest's work is situated within criticisms of Descarte's emphasis on rationalism, as she explores the prioritization of logic and mechanization which caused the environmental crisis and its devastating accompanying social consequences.

Agrest's analysis of our dislocation from Nature connects to her studies on the methods employed by architectural modernism. ${ }^{30}$ Her earlier book Architecture from Without(1991) operates as a critique of the philosophical position of architecture and urbanism theory/method, as she explores the signification of form/function. Diachronic (language/time) and synchronic (language/now) show the dichotomy between past (heterotopia) and future (utopia). ${ }^{31}$ Typological urban planning is examined as a combination of social sciences, systems theory, ${ }^{32}$ and the "death of nature." As a result, Agrest's analysis caused this work to search beyond Western approaches to design such as systems theory and typological program, as these methods of thought are found to be connected to the philosophical rejection of Nature.

Agrest's study of modernist urbanism/architecture deepens as psychoanalysis presents cities as the unconscious with mirror/glass destroying the object and the mental construct. ${ }^{33}$ "Now, the focus of architecture is image rather than language. In the mirrored buildings the articulation seems to be established

28 Diana Agrest, "The Return of the Repressed: Nature" from 1989 in Architecture of Nature: Nature of Architecture (New York: Applied Research and Design Publishing, 2018), 262. 29 Ibid.

30 Diana Agrest, Architecture from Without (Cambridge: MIT Press, 1993).

$31 \mathrm{lbid}, 124$.

32 Ibid.

$33 \mathrm{Ibid}, 152$. 
31 with the arts of the image, such as photography and film." ${ }^{34}$ The birth of chronovisualisation coincides with the destruction of the image of architecture as a fixed object and seeks to dissolve inside/outside (glass symmetry) to outside/inside (mirrors) in pursuit of meeting ourselves. "In this sense, the architecture of the mirror is not very different from the decorated shed." ${ }^{35}$ Agrest's study allows for the reprioritization of cities/architecture as subjects(being) of Nature, in contrast to modernity's objectification of an externalized environment. Cumulatively, Agrest equates photography to the printing press in its ability to challenge representation, perspective, and language ${ }^{36}$ As a result, photography is used throughout to explore new methods for architectural drawing, language, and being that challenge modernist beliefs founded on rejecting our codependence with Earth.

\section{Consequences}

Due to lobbied policy intervention positioned to uphold the fossil capitalist system, much of the industry's sustainable construction goals developed in response to the oil crisis of the 1970s are insufficient in addressing the planetary global warming crisis. The emphasis on energy efficiency (operational energy) prioritized by most new construction is "detrimental to human health, as airtight buildings made of synthetic materials contribute to environmental illness and other health problems." ${ }^{37}$ As a result, industrial architecture's mode of production and tectonics perpetuate the planned obsolescence of the fossil-capitalist system.

34 Ibid.

$35 \mathrm{Ibid}$.

36 Ibid, 165.

37 Catherine Wanek, Michael Smith, and Joseph F. Kennedy, The Art of Natural Building: Design, Construction, Resources Second Edition (Gabriola Island: New Society Publishers, 2005), 10. 


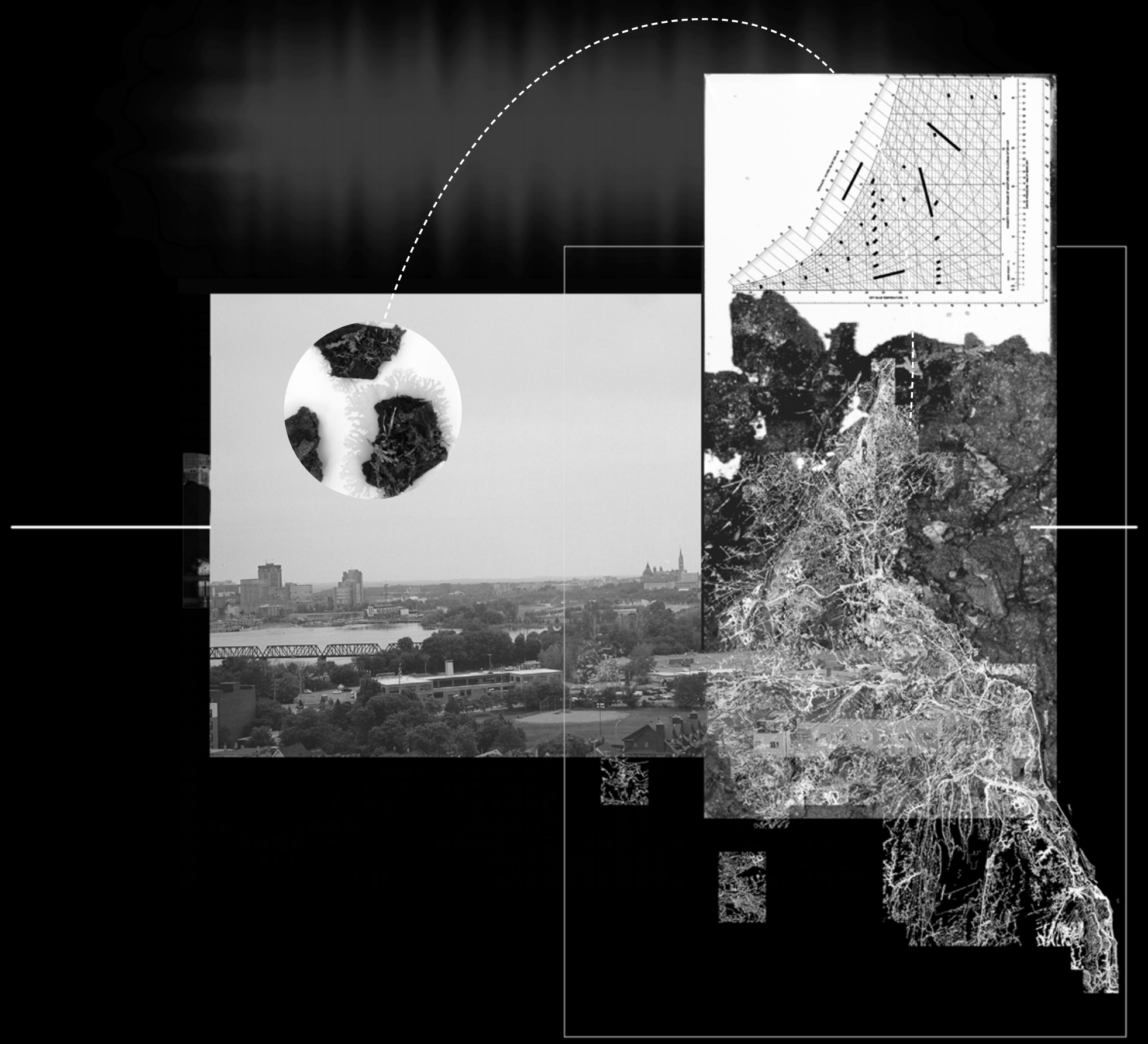

Fig. 4

psycho-metric 


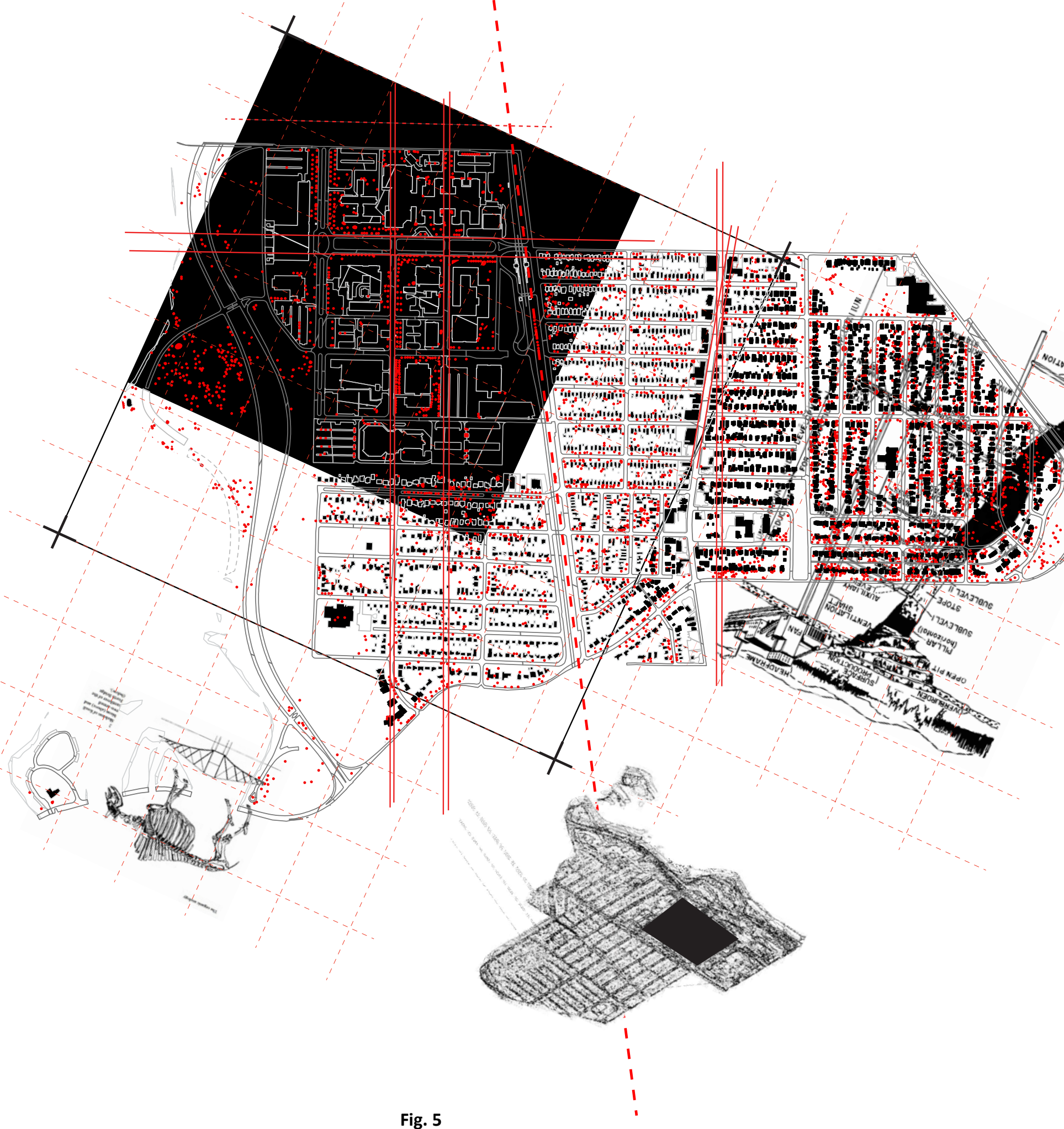

oil cities 
34 The technological fallacy of the industrial revolution and European Enlightenment ideals colonized mythology to deem local wisdom and Indigenous knowledge 'primitive. ${ }^{38}$ This dynamic is still present in architectural education and practice through the prioritization of eurocentric values compounded by the influence of fossil-capitalism. As a result, developers and large industrial corporations seeking to profit from city building dominate the built environment, causing an imbalance in our ecologies and society. The North American construction industry is controlled by private interest and exploits the public's confirmation bias to propagate the norm of industrial materials. Consequently, the building industry is responsible for approximately $30 \%$ of global carbon emissions, energy consumption, and waste,$^{39}$ arguably caused by the extractivist paradigm (assaulting the Earth). The United Nations states material extraction is responsible for $90 \%$ of global biodiversity loss, $90 \%$ of global water stress, and approximately $50 \%$ of global greenhouse emissions. ${ }^{40}$

While current architecture practices are undoubtedly associated with the pollution of our environment, it is important to be cautious not to become overly quantitative in conversations surrounding climate change. The emphasis on numbers operates in the same cartesian perspective of rationality that created the framework for ecological destruction. ${ }^{41}$ As a result, it is necessary to transcend purely technological and engineered solutions. However, rejecting scientific contributions altogether would be equally unwise, and therefore this work advocates for a balance of science and ancient wisdom. To do this, Arturo Escobar proposes "changing the the Future We Want / Summary for Policymakers (UN Environment Programme, 2019), 4.

41 Timothy Morton, Being Ecological (Morton: MIT Press, 2018). 
way we change" by focusing on ontological design centered on dualistic perspectives in the pluriverse. ${ }^{42}$ Facing the climate crisis with design requires the return of oppressed wisdom to create solutions that respect unity (human/non-human, living/non-living, science/mythology, logic/ intuition).

Unifying Earth/Architecture to a transcendent whole, agriculture/ architecture become one. In tandem with modernist architectural methods, industrial agricultural practices of monoculture and tilling cause soil erosion by removing the earth's topsoil. "Although soils are essential for human well-being and the sustainability of life on the planet, they are threatened on all continents...the Food and Agricultural Organization (FAO) said on World Soil Day [in 2019], calling for their protection." ${ }^{.43}$ The FOA equates unsustainable agricultural practices, land-use, and deforestation to accelerating natural soil erosion up to a thousand times. ${ }^{44}$ Erosion causes soil to release its carbon stores by interrupting sequestration processes, contributing to increased atmospheric carbon dioxide levels and intensifying global temperature rises. Therefore, the way we build/farm is intimately connected to the deterioration of the environment. Through viewing architecture/agriculture as a single being, we can begin to find unified ways of working within geographies to address the climate crisis.

After the oil crisis of the 1970s, and the psychedelic movement of the 1960s, a re-emergence of natural building methods in North America coincided with the creation of political ecology. Social scientists began

42 Escobar, Designs for the Pluriverse.

43 UN News, "Soil Erosion Must be Stopped to 'Save Our Future', says UN Agricultural Agency," December 5, 2019. 44 Ibid. 
36 analyzing society and nature through marxism and systems theory. Sociology started to view Earth(Nature) as either a social production or cultural construction. Material-energetic analyses emerged with the creation of ecological economics. ${ }^{45}$ The current state of theories combining ecology, politics, and sociology developing from this perspective turns towards the ontological. Considerations like "nonhumans, matter and materiality (soil, energy, infrastructures, weather, bytes), emotions, spirituality, feelings, and so forth"46 begin to describe the ontological. Ontology necessitates an intersectional approach focused on "class, gender, race, coloniality, ${ }^{177}$ capitalism, and decolonization. Broadly, this phase can be titled neo-materialist and post-dualist. Post-dualism recognizes that euro-centric colonization was largely at the expense of nondualist cultures. Therefore, a decolonial perspective requires "the return of the repressed side of dualisms-the forceful emergence of the subordinated and often feminized and racialized side of the above binaries. ${ }^{148}$ Combining the recent resurgence of natural construction in North America, such as the straw-bale movement, with intuitive understandings of materials can help start conversations that seek to address the impact of modern architecture on the psyche and the environment.

45 Escobar, Designs for the Pluriverse, 63.

46 Ibid.

47 Ibid, 58.

48 Ibid, 64. 
Conventionally, embodied energy is "typically defined as the sum of all energy required to extract raw materials and then manufacture, transport, and assemble the materials into a building." ${ }^{\prime 9}$ David Benjamin asserts "a 'zero energy' house is now attainable, though the term is misleading because it actually involves zero percent operational energy and 100 percent embodied energy." ${ }^{250}$ The current approach to sustainable design becomes paradoxical. In seeking to resolve this contradiction, an etymological analysis proposes an alternative definition to embodied energy which may change methodologies for working with material in the built environment. The Oxford English Dictionary defines embody as "to invest or clothe (a spirit) with a body" and energy as "a general concept: power, strength, force." ${ }^{.52}$ This etymological study relates to the contemporary theory of neo-materialism in which material is given agency in a system of commodified economies, and the Indigenous philosophy of Place-Thought, where the Earth's material is seen as alive and thinking. Seeing material as a spiritual agent transforms the way we exist with and within constructed space and provides the foundation for contemporary discourse to merge with Indigenous teachings.

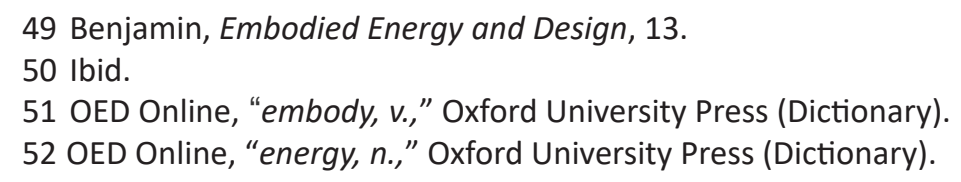




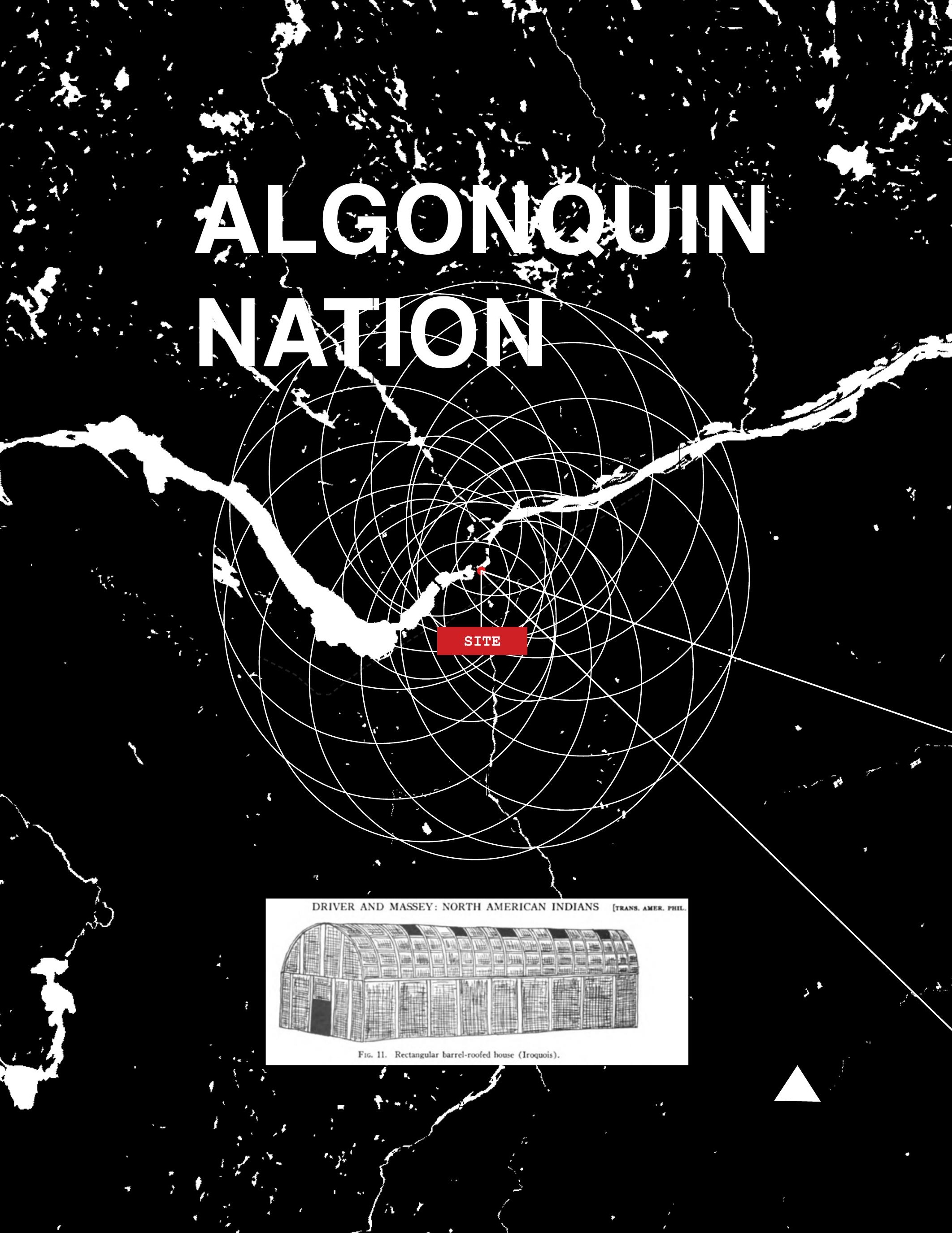




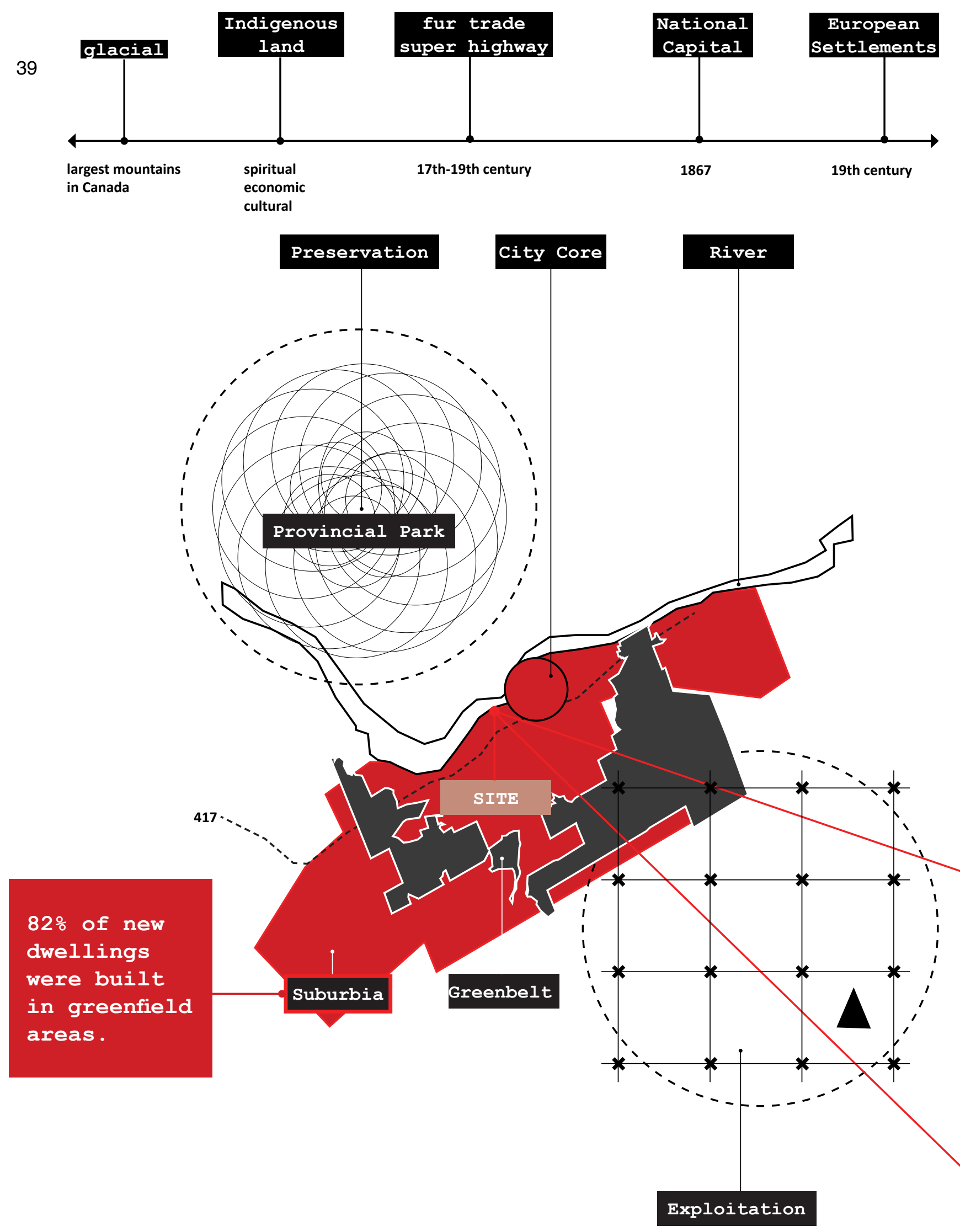

Fig. 7

Odawa 
Earth is the oldest known construction material. Ronal Rael explains, "the hegemony of the industrialized world has for decades been directly responsible for causing an inferiority complex among Earth-building cultures...classifying [Earth buildings] as 'alternative', or worse 'primitive."'"53 Conversations on the vernacular, meaning local to a region, generally refer to old colonial building typologies - homesteads, wood barns, everyday housing. ${ }^{54}$ Despite humans having built with earth and other locally sourced organic materials for millennia, the paradigm of grown materials and Indigenous[vernaeular] architecture is still "largely ignored within architectural education, research, and practice." ${ }^{55}$ In this respect, architecture becomes the physical manifestation of colonized thought patterns. Arch: Master; tecture: of material/Earth. Fundamentally, discussions on sustainability in the built environment need to address the historical context of architecture's role in suppressing Indigenous knowledge through colonization and the intersectional and multidisciplinary impacts of this reality.

53 Ronald Rael, Earth Architecture (New York: Princeton Architecture Press, 2009), 13. 54 As exemplified in Dell Upton and John Michael Vlach's Common Places: Readings in American Vernacular Architecture, which does not discuss earthen building strategies except one mention of adobe used in Sante Fe, New Mexico.

Dell Upton and Michael Vlach, Common Places: Readings in Vernacular Architecture (London: The University of Georgia Press, 1986).

55 Rael, Earth Architecture, 2. 
Part III

$\bullet$ 

2) 3 ry 400202 1 3 . -) - $x y 3$ 4. $130 \%$ 111. (3)yp $x$

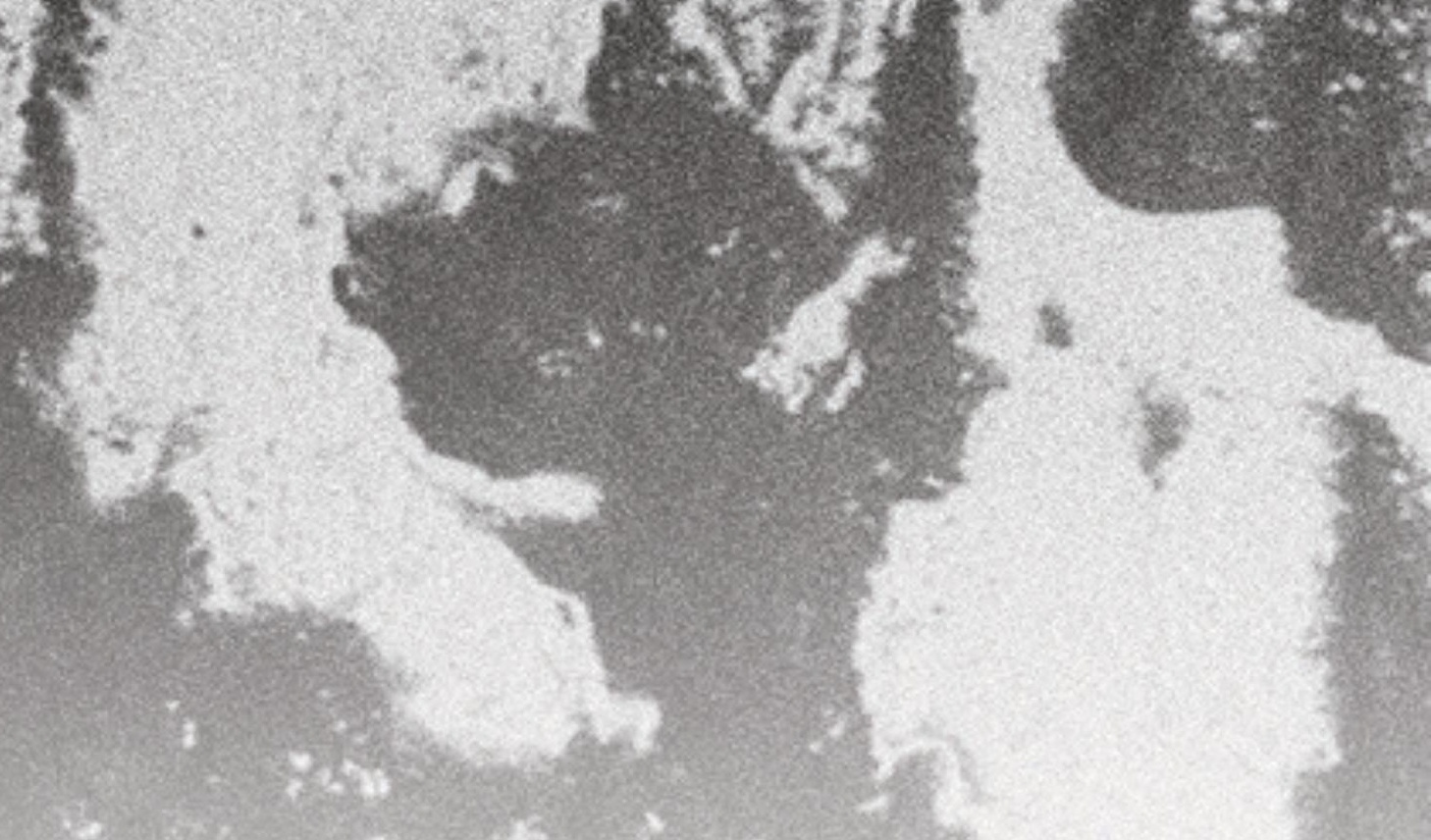

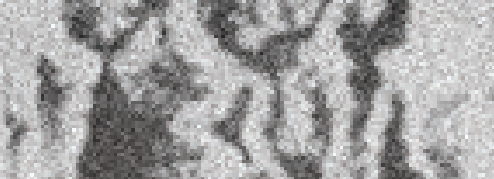

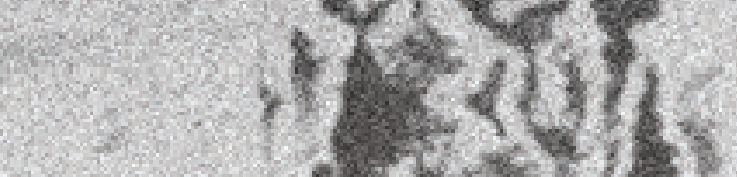

is

10.5 and c.
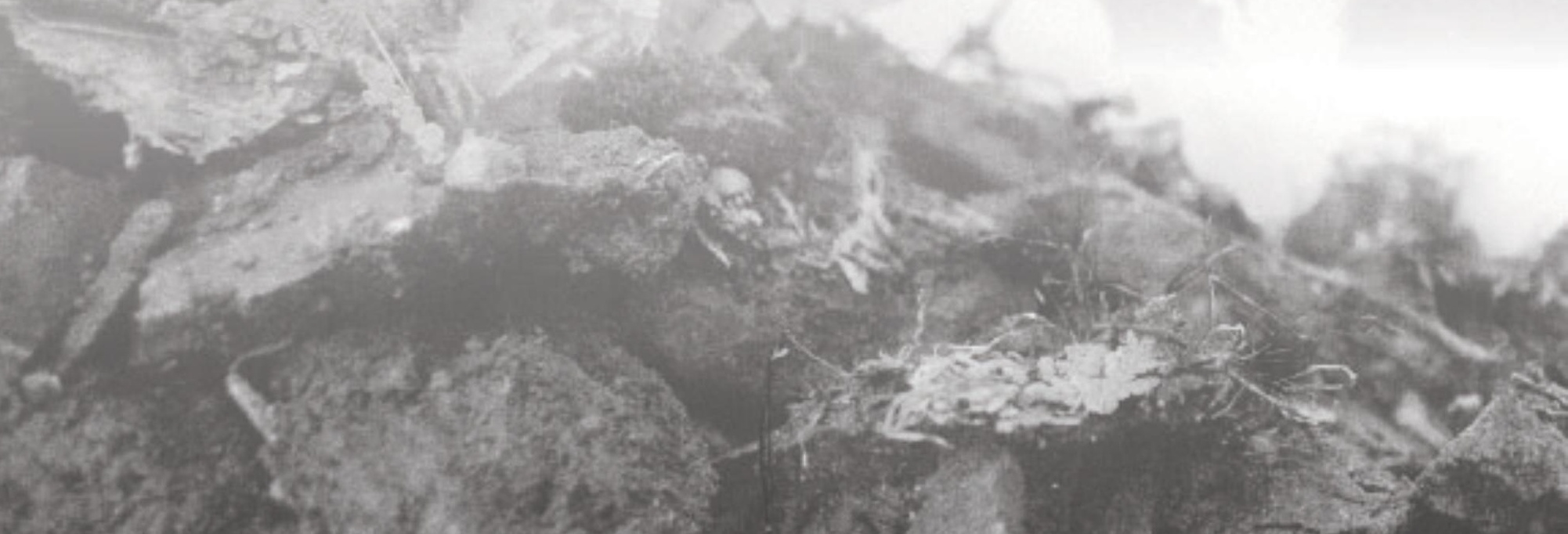

- $x^{2}$ c. c 2.5.

1500 . on 7.jowinges 

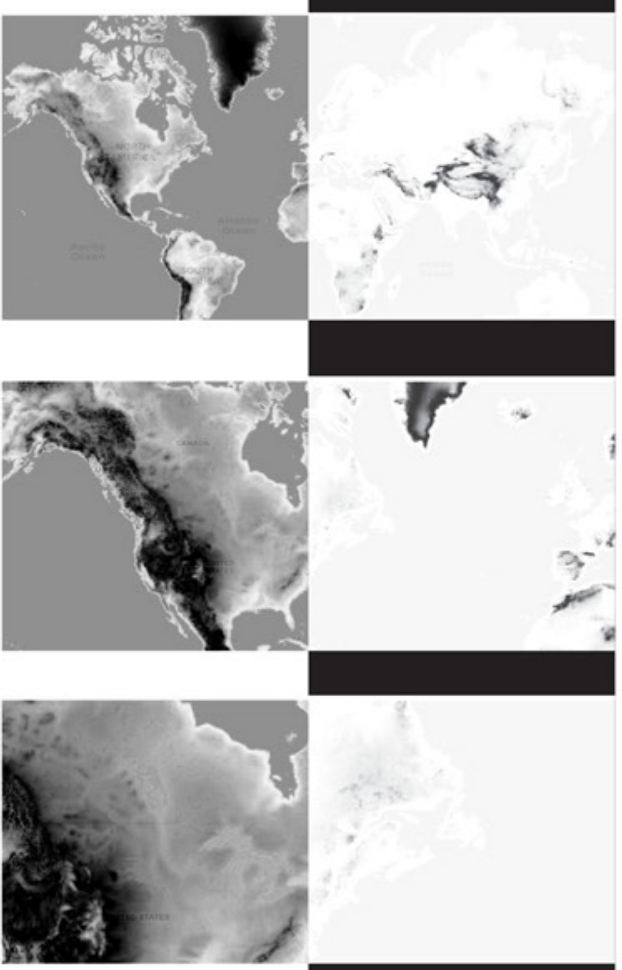

Fig. 9
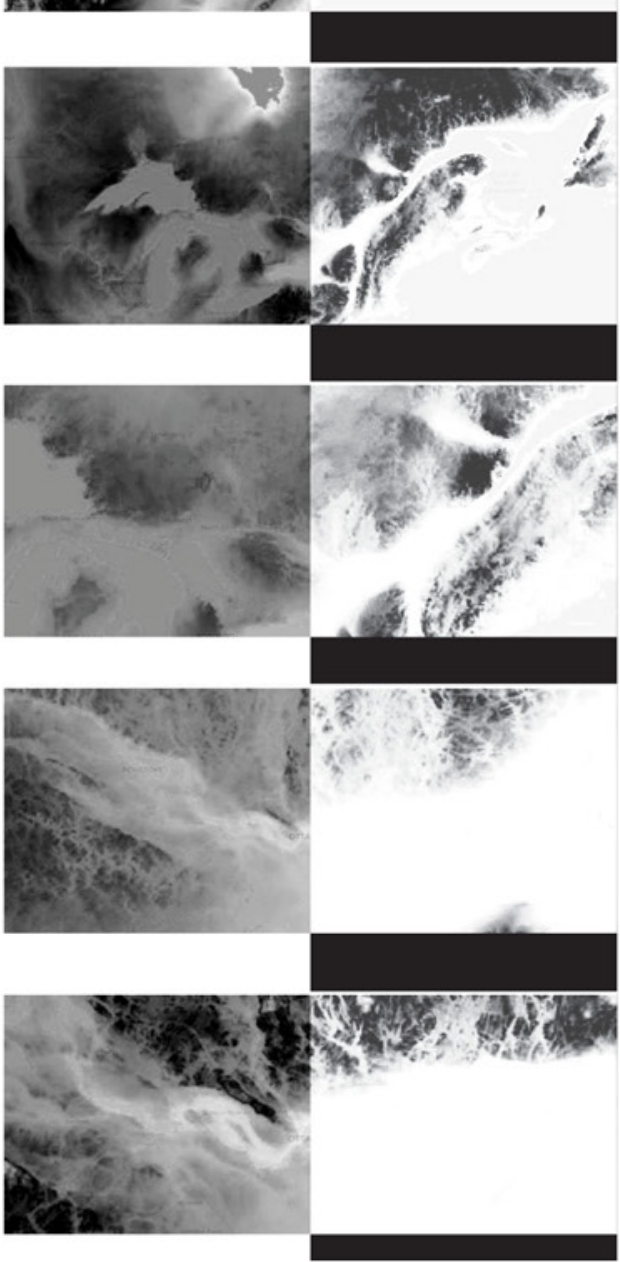
Symbiosis, defined by the Oxford English Dictionary in biological terms, details two entities growing attached to one another, "whether mutually beneficial or not." ${ }^{156}$ Currently, Architecture is growing at the expense of Earth; the relationship is not mutually beneficial. The prioritization of growth as a measure of success resulted in taller buildings, larger cities, and more pollution. Instead of fixating on growth, perhaps expansion, "the action or process of spreading out or unfolding; the state of being spread out or unfolded, the opening of a bud, flower, etc., also, a spreading out to view, a display" ${ }^{\prime \prime 7}$ offers an opportunity to explore growing in unity. Radical Indigenism and speculative fabulations/feminisms may suggest an alternative future where Earth/Humanity unfold together like a flower. Unifying Earth/humanity necessitates the unification of above/below, where healthy living requires healthy soils. This relates to the second Hermetic Principle of Correspondence: "As above, so below; as below, so above." ${ }^{58}$

Philip Steadman, Emeritus Professor of Urban and Built Form Studies from the Bartlett School of Environment and Resources, relates Charles Darwin's Evolutionary Theory ${ }^{59}$ to design in the book The Evolution of Designs: Biological Analogy in Architecture and the Applied Arts(1979) ${ }^{60}$

56 OED Online, "symbiosis, n.," Oxford University Press (Dictionary). 57 OED Online, "expansion, n.," Oxford University Press (Dictionary).

58 The Three Initiates, The Kybalion: A Study of the Hermetic Philosophy of Ancient Egypt and Greece (London: The Yogi Publication Society, 1908), 13.

59 Darwin's survival of the fittest prioritizes aggression in evolutionary theory. The 1975 Essay "Woman the Gatherer" by anthropologist Sally Slocum challenged the axiom of 'Man the Hunter' by asking the simple question of "what were women doing while men were out hunting."

Caroline Criado-Perez, Invisible Women: Exposing Data Bias in a World Designed for Men (New York: Harry N. Abrams, 2019), 2.

60 Philip Steadman, The Evolution of Designs: Biological Analogy in Architecture and the Applied Arts (London: Routledge, 1979). 
46 Viewing architecture with a biological perspective challenges the modern axiom proposed by Le Corbusier of "the city as a machine for living" to "the city as an organism." From a biological perspective, Earth construction is the most evolutionarily successful building species, as it is the oldest and most widely used culture[technology]. 
47 The city as an organism of Place-Thought transforms urbanity into a geo-place. A geo-place becomes the Earth thinking in space and time and reads across multiple scales from site to planet, with the language of soil, water, communities, energy, and beings. Rural communities become celestial bodies orbiting around the gravitational pull of urban masses.

Geo-Place[Urban] Indigenous agriculture restores water and life to our soils, animals, and peoples. Industrial agriculture, forestry, and land-use practices that removed the soil's ability to store carbon become practices of the past as soils begin to stabilize global temperatures. Agricultural by-products are integrated within the development of architectural materials. Extracting, sourcing, and producing material is elevated to an architectural act of growing and harvesting.

sourcing $=$ growing $/$ producing $=$ harvesting

This makes up the first quadrant of materialization (growing) and the fluid horizontal dimension of expansion (geoplace) and proposes the unification with the second quadrant of materialization (harvesting) through the fixed vertical dimension of culture. 


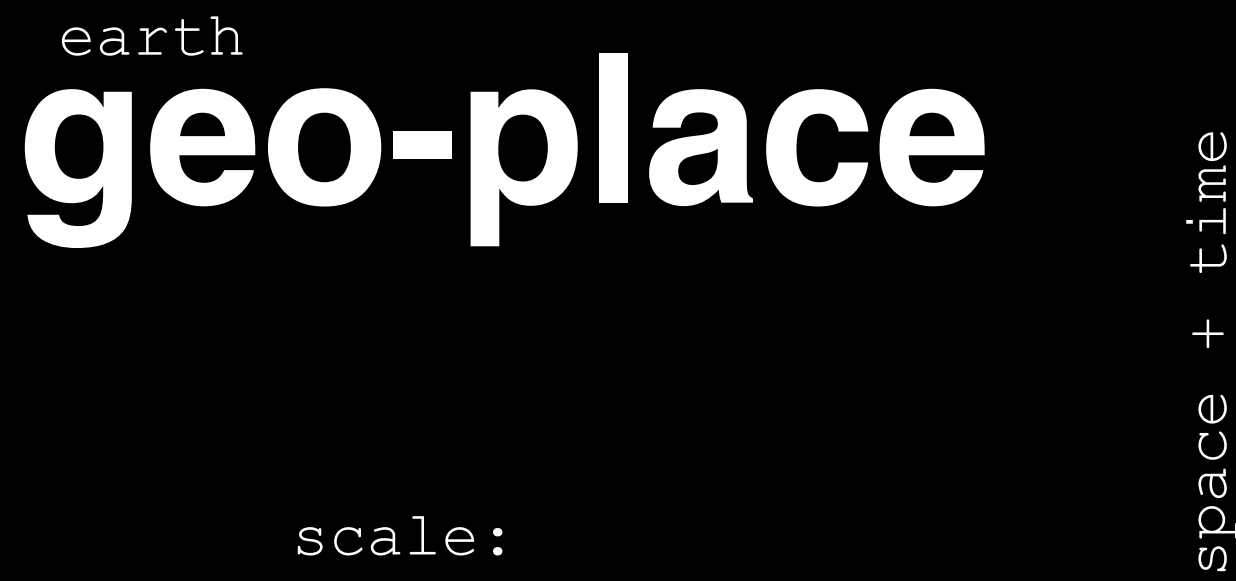

site, city, country, Earth, cosmos

Legend
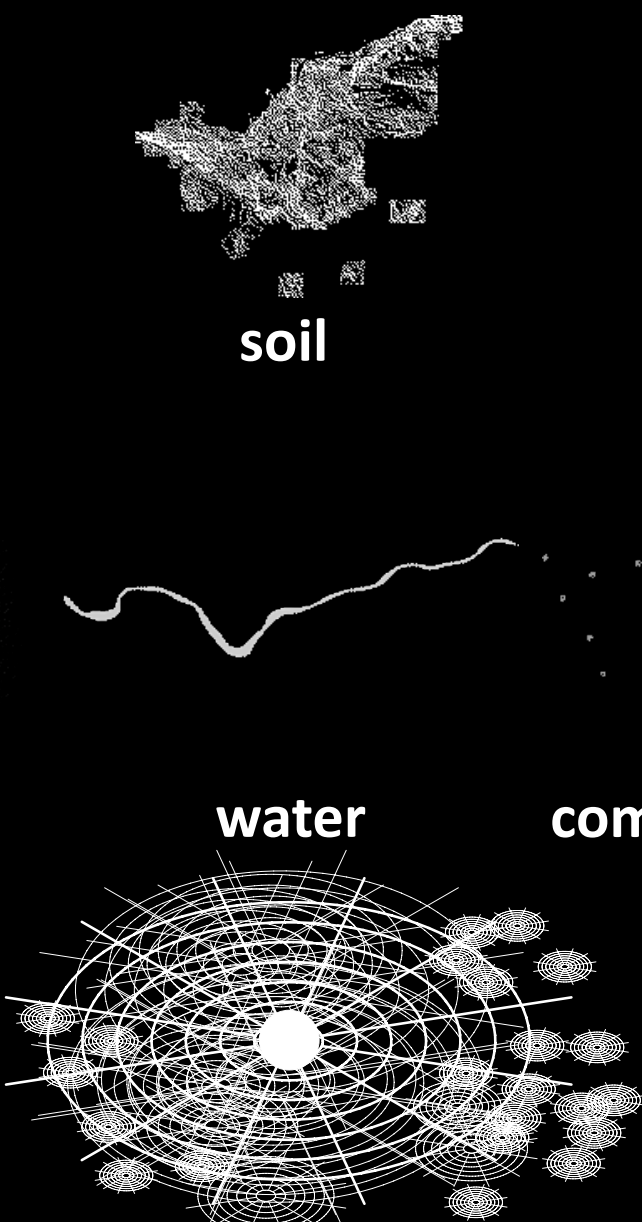

beings 


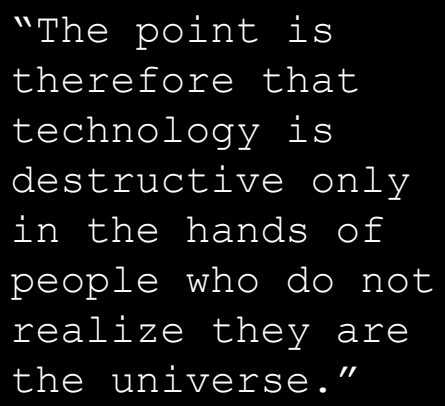

Alan Watts and Chungliang Al

Huang, Tao: The Watercourse Way, (New York: Pantheon Books, 1975), 194. 
"Buildings are a result of building cultures." ${ }^{61}$ As a result, "architecture should be explicitly treated as a cultural process rather than as merely a material production." ${ }^{62}$ Ronald Lewcock's chapter in Vernacular Architecture for the $21^{\text {st }}$ Century explains Indigenous[vernacular] architecture as fundamentally conceptual. This hinges on the first Hermetic law, The Principle of Mentalism. ${ }^{63}$ "Buildings must exist in the mind before they exist externally. In this way, works of architecture naturally reflect the structure of the mental models that formed them." ${ }^{44}$ Donna Haraway says,

It matters what matters we use to think other matters with; it matters what stories we tell to tell other stories with; it matters what knots knot knots, what thoughts think thoughts, what descriptions describe descriptions, what ties tie ties. It matters what stories make worlds, what worlds make stories. ${ }^{65}$

Science is the predominant culture of our time. The creation of science has ties to epistemological origin. In other words: science seeks to know. Science understands dirt as a revelation of unity. Dirt Acts. As such, soil can become the fulcrum to our reconnection to the planet - Our planet, the spherical object floating in time and space, titled The Earth. As the skin of the earth, science explains the ground as a formative member of the hydrological cycle: home to the atmosphere and the biosphere. The Geo(Earth)-sphere is defined as the collective name for the Hydrosphere(Water), Atmosphere(Air), and Biosphere(Organisms). The Smithsonian Environmental Research Center explains, "soils are

61 Ronald Lewcock, Generative Concepts in Architecture in Vernacular Architecture of the $21^{\text {st }}$ Century by Asquith, $\mathrm{L}$ and Vellinga, $\mathrm{M}, 36$.

62 lbid.

63 Three Initiates, The Kybalion, 13.

64 Lewcock, Generative Concepts, 36.

65 Haraway, "Tentacular Thinking, Anthropocene, Capitalocene, Chthulucene,"in Staying With the Trouble, 39. 
51 alive. They are born, they age, they breathe...Living soils sustain life on Earth." ${ }^{\prime 66}$ Can architecture discourse talk to biospheres, geospheres, and hydrospheres as it speaks of atmospheres?

David Gissen's book Subnature:Architecture's Other Environments (2009) speaks to the repressed elements of Earth(nature) in Architecture as mud(Earth) is defined as:

The viscous mixture of soil and water, appear[ing] in architecture in several ways. It is one of the original materials of architecture, central to concepts of the Indigenous [primitive] in architecture. Mud is also a type of unstable ground that must be overcome in the construction of foundations. In the development of modern cities, rather than discussing mud as something wanted or desirable, it was identified as a product of poor drainage and ineffective engineering. ${ }^{67}$

Understanding soil as the host to life can help support architecture's ontological reunion with the Earth, as an element of the divine. Unifying Earth/Architecture requires a transcended narrative. Geo-Stories: Another Architecture for the Environment (2018) by the collaborative practice DESIGN EARTH led by El Hadi Jazairy and Rania Ghosn, asserts that "stories and ideas matter for the Earth. Stories are a means for understanding the world, for nurturing the habits of seeing, and, ultimately, for projecting alternative forms of organizing life. They are means of world making." ${ }^{68}$ In comparison, Joseph Campbell explains Jungian archetypes in his interview with Bill Boyer as, "elementary ideas, what could be called 'ground' ideas" that Jung explores as coming from the unconscious, meaning it "comes from below." ${ }^{69}$ Relating Earth, below, to

66 The Smithsonian Environmental Research Center, "The Skin of the Earth."

67 David Gissen, Subnature: Architecture's Other Environments (New York: Princeton University Press, 2009), 118.

68 Rania Ghosn and El Hadi Jazairy / DESIGN EARTH, GeoStories: Another Architecture for the Environment (New York: Actar Publishers, 2018), 13.

69 Campbell, The Power of Myth, 59. 
52 the unconscious, suggests that Earth stories are grounded to speak to the most elemental parts of our being. Archetypes are universal, they can be understood across place (time and space) and may become necessary to develop an ecological worldview.

Earth myths become urban through combining Agrest's psychoanalytic perspective of cities as the unconscious with Jungian conceptions of Earth as the archetypal below. Telling Earth mythologies through cities is distinctly relevant today, with the global mass movement of peoples into urban centers as farming becomes increasingly industrialized. In essence, Earth requires not only a new story but new archetypal mythologies: Earth-Myths for an Earth-Culture. "We need new myths to serve the old stories." ${ }^{70}$ To begin, Place-Thought shows that the Earth is alive and thinking. The unification of scientific understandings and mythology opens conversations for ecological processes to merge with being. The task becomes planting different seeds to cultivate better building practices that support the Earth.

70 Ibid, 22. 
53 Harvesting[produetion] Earth alters the political, economic, and cultural realities of today. Earth harvesting locations in cities create urban regeneration through diversified planning strategies that prioritize healthy green jobs, incentivizing political support. Premanufacturing facilities generate reliable and testable earth materials, a product that is not yet industrialized. With testable

"Building Codes are colonized. They need

to be rewritten in ways that are appropriate. Can they be stories?"

Chris Cornelius at the Harvard Indigenous Design

Collective Round Table on Native Housing, April 9, 2021 products, natural building materials enter the building code. Circular economy and de-growth development emerge as natural building materials rely on the by-products of various other local industries such as agriculture and composting. The "industrialization" of Earth materials increases the likelihood of cultural norm disruption, allowing Earth products to become a standard rather than an exception.

geo-Culture[teehnology] uses the adaptive re-use of existing structures, such as the abandoned government buildings at Tunney's Pasture, permanently deserted due to the COVID-19 Pandemic ${ }^{71}$, to harvest agricultural by-products and create Earthen assemblies. A brutalist campus becomes a node for growing materials on available urban land, harvesting materials in existing industrial buildings, and locally producing premanufactured building assemblies to adapt existing post-war structures(housing) at the end of their life cycle.

building $=$ culture $/$ culture $=$ science $/$ science $=$ unity

71 "The president of one of Canada's major public sector unions says working from home could be a viable option for a great deal of federal public servants going forward, even as lockdowns lift across the country."

Ted Raymond, "Working From Home Could be a Viable Option for Federal Public Service: Union," Ottawa CTV News, May 22, 2020. 


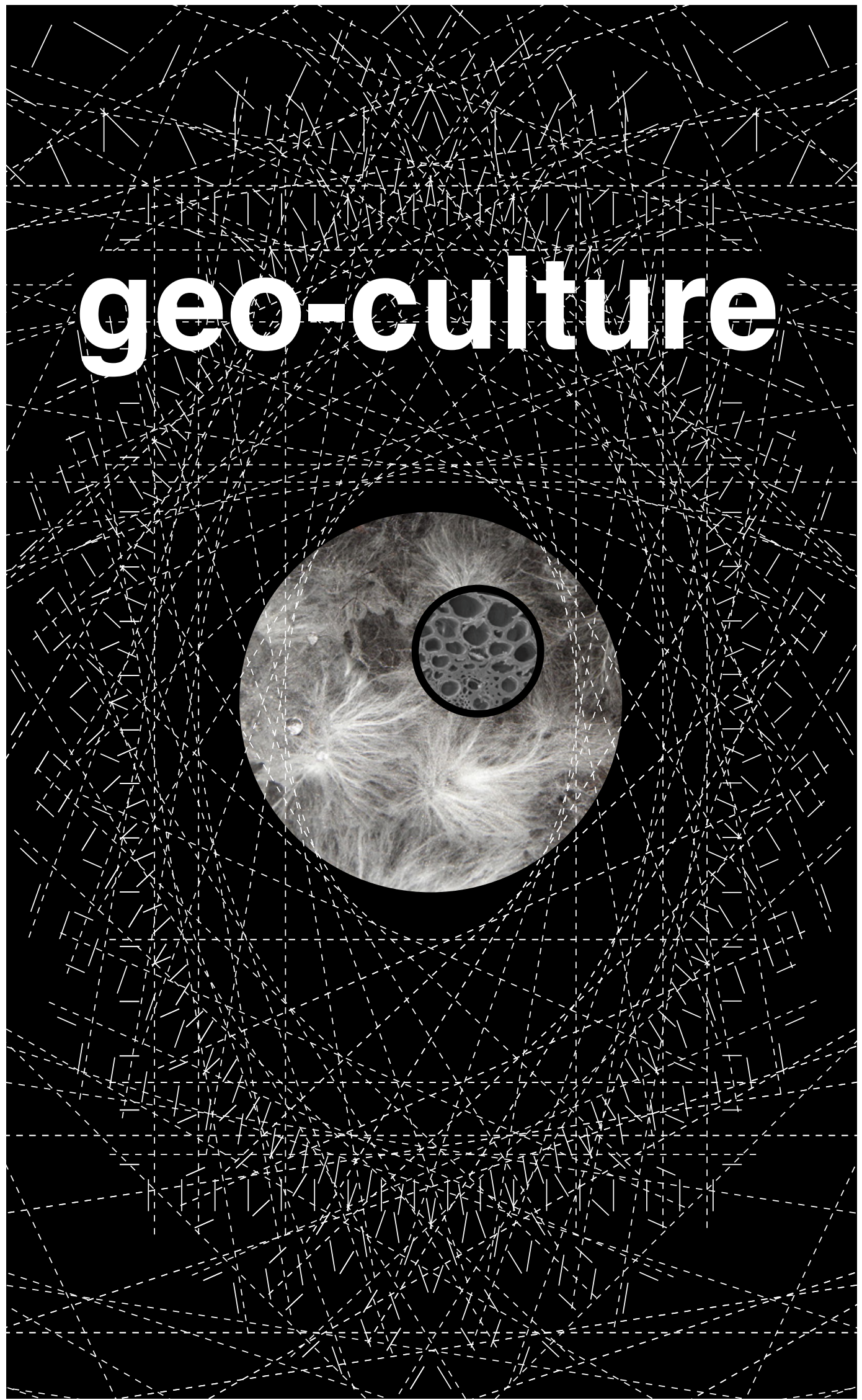


scale: liminal, int/ext, healing

The envelope as the skin of the building relates to the skin of the planet: The Earth. Indigenous writer Vanessa Watts explains "Our truth, not only Anishnaabe and Haudenosaunee people but in a majority of Indigenous societies, conceives that we (humans) are made from the land; our flesh is literally an extension of soil."72 Watts articulates Indigenous Place-Thought as "'the non-distinctive space' where place and thought were never separated because they never could or can be separated. Place-Thought is based upon the premise that the land is alive and thinking and that humans and non-humans derive agency through the extensions of these thoughts." ${ }^{\text {73 }}$ Watts demonstrates transcending dualism between place/ thought, Earth/mind, human/non-human in Indigenous philosophies native to the Algonquin Nation [Ottawa]. With Place-Thought, humanity becomes geo-Bodies.

As geo-Bodies, we become equal to the soil, plants, animals, minerals, and building assemblies. The housing crisis becomes the living crisis. The question moves from 'how are we housing' to 'how are we living?'

72 Vanessa Watts, "Indigenous place-thought \& agency amongst humans and nonhumans (First Woman and Sky Woman go on a European world tour!)," Decolonization: Indigeneity, Education \& Society 2: no.1 (2013): 24.

73 Ibid. 
56 "The façade is a technical system for cultural engagement with the natural world that explicates a social relationship to climate, represents it. It is a liminal space between the interior and the exterior, between the building's program and the region's climate; it contains both."74 The façade as a negotiator between realms becomes the agent for technical, cultural, and meta-physical analysis of the built environment's engagement with the natural world. Architecture's current separation and aversion to nature appears in drawings and constructions of building envelopes. This dualism is enforced perhaps most adversely in the vapour barrier that seeks a complete seal from the environment.

Culture's relationship with the external as an inside/outside separation dissolves as Geo-bodies transcend duality. Geo-bodies recognize contemporary conceptions of building assemblies related to a dualist mindset from colonization seeking construction and subsequent domination of the external or the other (race, gender, religion, nature, etc). Instead, Geo-bodies see the built environment as the Earth and our skin breathing.

envelope $=$ skin $/$ skin $=$ Earth $/$ Earth $=$ envelope

\section{This makes up the third quadrant of} materialization (living) and proposes weaving with the fourth quadrant (rooting).

74 Daniel Barber, "Architecture, Media, and Climate," in Modern Architecture and Climate: Design Before Air Conditioning (Barber: Princeton University Press, 2020), 9. 
57,

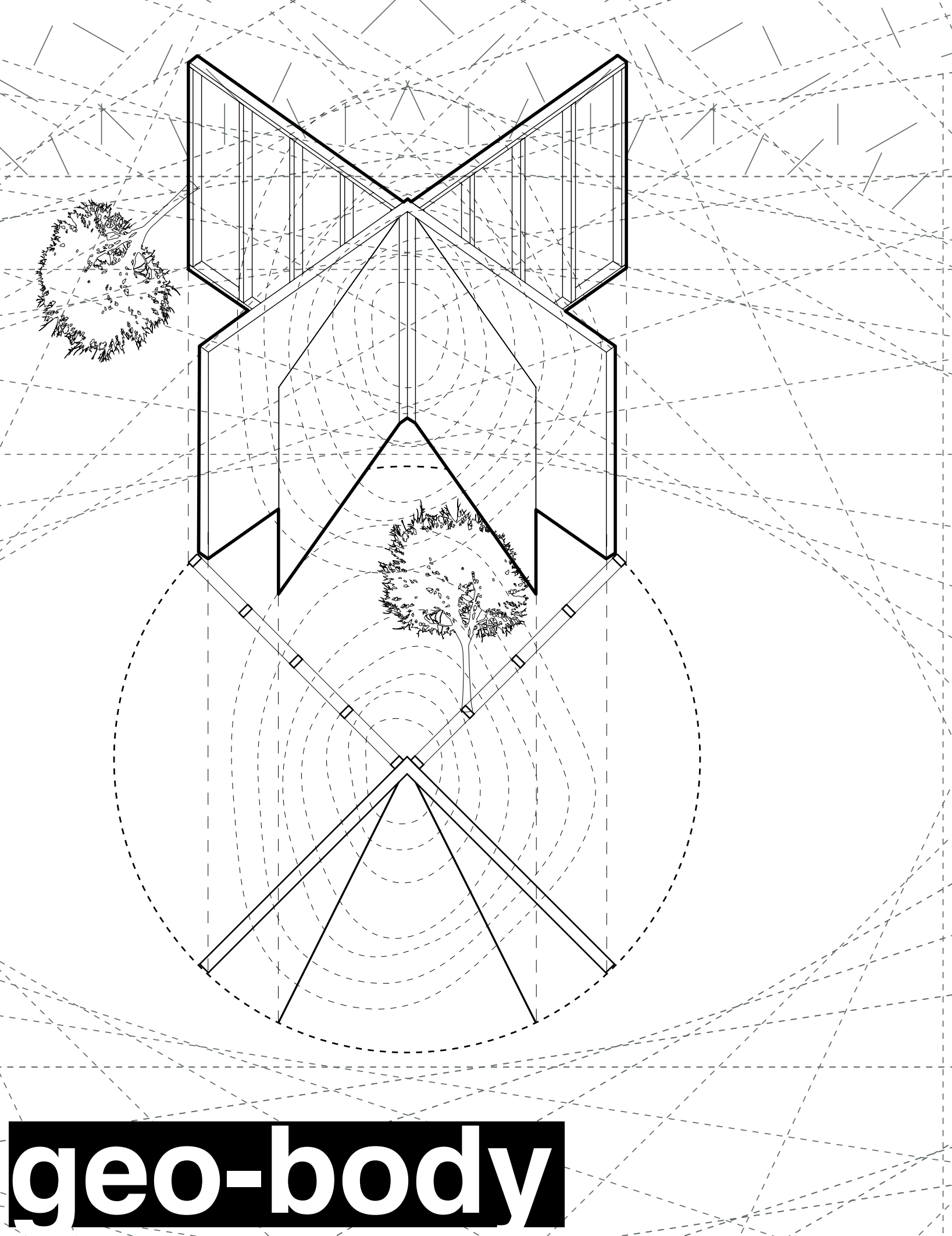


"It is not science that has
diminished human beings or
divorced us from divinity.
On the contrary, the new
discoveries of science
"rejoin us to the ancients"
by enabling us to recognize
in this whole universe a
"reflection magnified of our
own most inward nature;
so that we are indeed
its ears, its eyes, its
thinking, and its speech".

Joseph Campbell, The Power of Myth, 194. 
scale: biodiversity, optimism, myceliums

Living well requires an examination of labour and work, and the racialized and gendered boundaries historically associated with each. Hannah Arendt's labour, work, and action are separated across space and are further separated through gendered and racialized containers compounded by car-centric planning resulting from the Second World War. (World War $=$ Geo-War $=$ War with Self)

The postwar prioritization of automobile-dependent planning resulted in the urban sprawl phenomenon still in-place today. ${ }^{75}$ As a typology, housing represents $90 \%$ of North American Cities and therefore becomes the prevalent question related to living. Although, going beyond typologies shows every program as intimately connected to the way we live. Currently, the domestication of built space reinforces capitalist consumption, racial, gender, and class segregation, ${ }^{76}$ and is intimately connected to the deterioration of the environment.

Claude Levi-Strauss advocates for the house as the "quintessential phenomenological object" where the personal experience reaches its epitome. ${ }^{77}$ Paul Oliver speaks directly to Dwellings as the focus of Indigenous architecture. An epistemic approach identifies housing as the primary concern, while ontology points to questioning how we live. Both housing and living are victim to gendered and racialized unpaid labour and work silently supporting the patriarchal, hegemonic, and white nuclear

75 The City of Ottawa, Ontario is developing an Official New Plan for the urban planning direction of the city for the next 50 years, which was officially tabled in December 2020 . The plan is largely based on an expansion model of automobile-dependent and private-interest driven housing built on greenspace.

76 Irene Cheng, Mabel O.Wilson, and Charles L. Davis. Race and Modern Architecture: A Critical History From the Enlightenment to the Present (Pittsburgh: University of Pittsburgh Press, 2020), 222.

77 Claude Levee Straus, Myth and Meaning (Toronto: University of Toronto Press, 1978), 38. 
family model. This model resulted in undiversified urban conditions where realms of labour(life), work(care), and action(politics) ${ }^{78}$ became separated across Place-Thought.

Unearthing systemic oppression in our living practices exposes the ultimate duality of birth/death held in practice with linear time. Circular time unifies birth/death, making Now the liminal space. Seeking the liminal by embracing temporality merges Arendt's philosophical position with Joseph Campbell's mythological realms. Campbell defines the mythological as:

mystical, "about, realizing what a wonder the universe is, and what a wonder you are, and experiencing awe before this mystery"...

cosmological, "the dimension with which science is concerned-showing you what the shape of the universe is, but showing it in such a way that the mystery again comes through"...

sociological, "supporting and validating a certain social order. And here's where the myths vary enormously from place to place."79

Seeking to unify philosophical and mythological spheres makes life products an act of mystical labour, work becomes a cosmological service of care, and every action becomes a political/sociological interaction in place. Honouring decay through appreciating the mystical, cosmological, and sociological capacity of maintenance(cleaning-up) is central to environmental stewardship. A feminist reading of care-work displays the labour women do for free. ${ }^{80} \mathrm{An}$ intersectional lens exposes unjust and inequitable racialized product-creation. Respecting the Earth, the Other, and the Self through service [sustainability, conservation and preservation] attempts to unsettle unjust systems and not sustain, conserve, or preserve inequitable foundations. 
61 Housing's(living's) relationship to labour, work, and action is unified through diversification and material agency. Through unifying housing/living, residential zoning becomes the principal legal determinant related to infrastructure, transportation, and land-use policies structuring geo-places. Transportation emissions, green space development, and socio-cultural consumerist pressures disintegrate with the return of Earth assemblies. Maintenance/service works with North-American housing to care for existing buildings by keeping structural material already produced and replacing industrial materials (vinyl siding, gypsum board, dangerous insulation) at the end of their life-cycle with Earth. Geo-folds compost industrial materials in the garden, as earthen assemblies build equity and justice. Office towers and shopping malls transform into living centers. Diversifying living unifies product creation, care work, and political/sociological spheres. Making a living is done with and in Earth through housing.

Rooting into the Earth folds out decay. Decaying as the birth of our buildings makes every act of creation also an act of destruction. Embracing cycles of polarity transforms landfills into gardens. Can we compost our mess? Can we grow from it? 


\section{geo- folds}

Legend

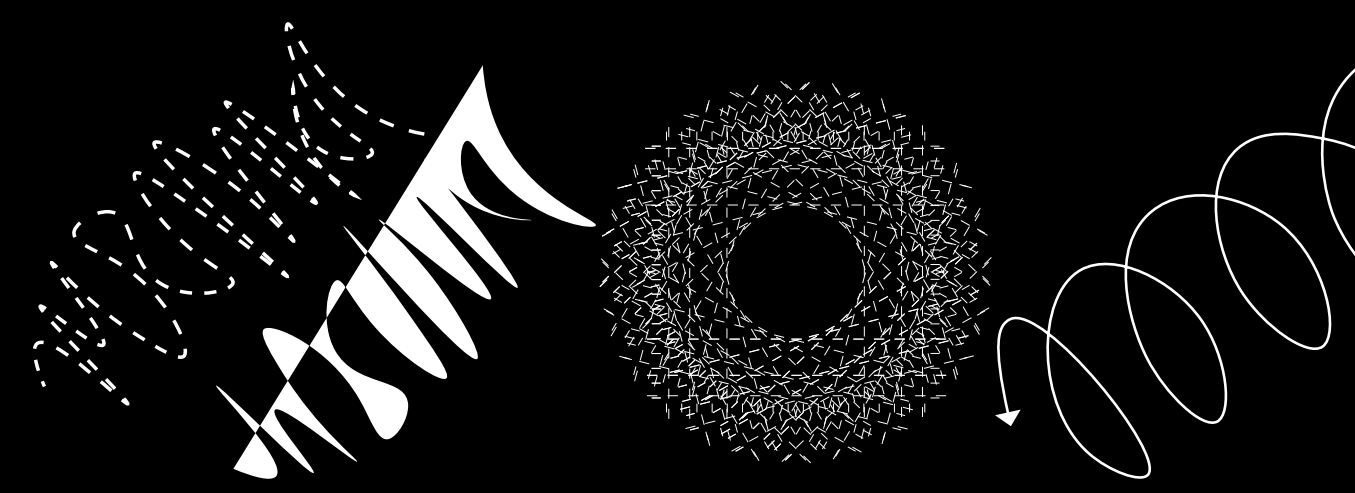

energy magnetism organism time

Ottawa Topography Satelite + Section 

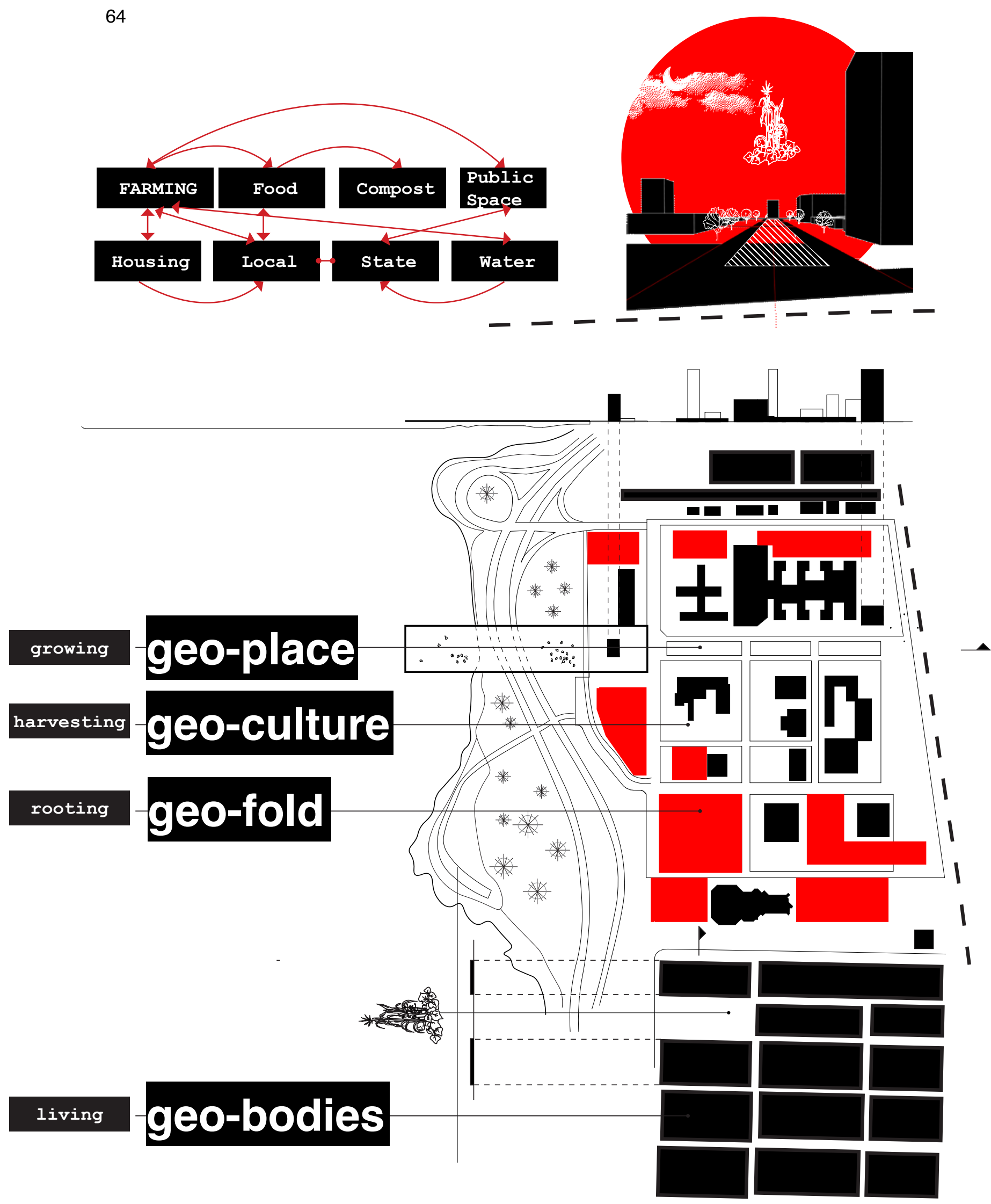
Part IV 


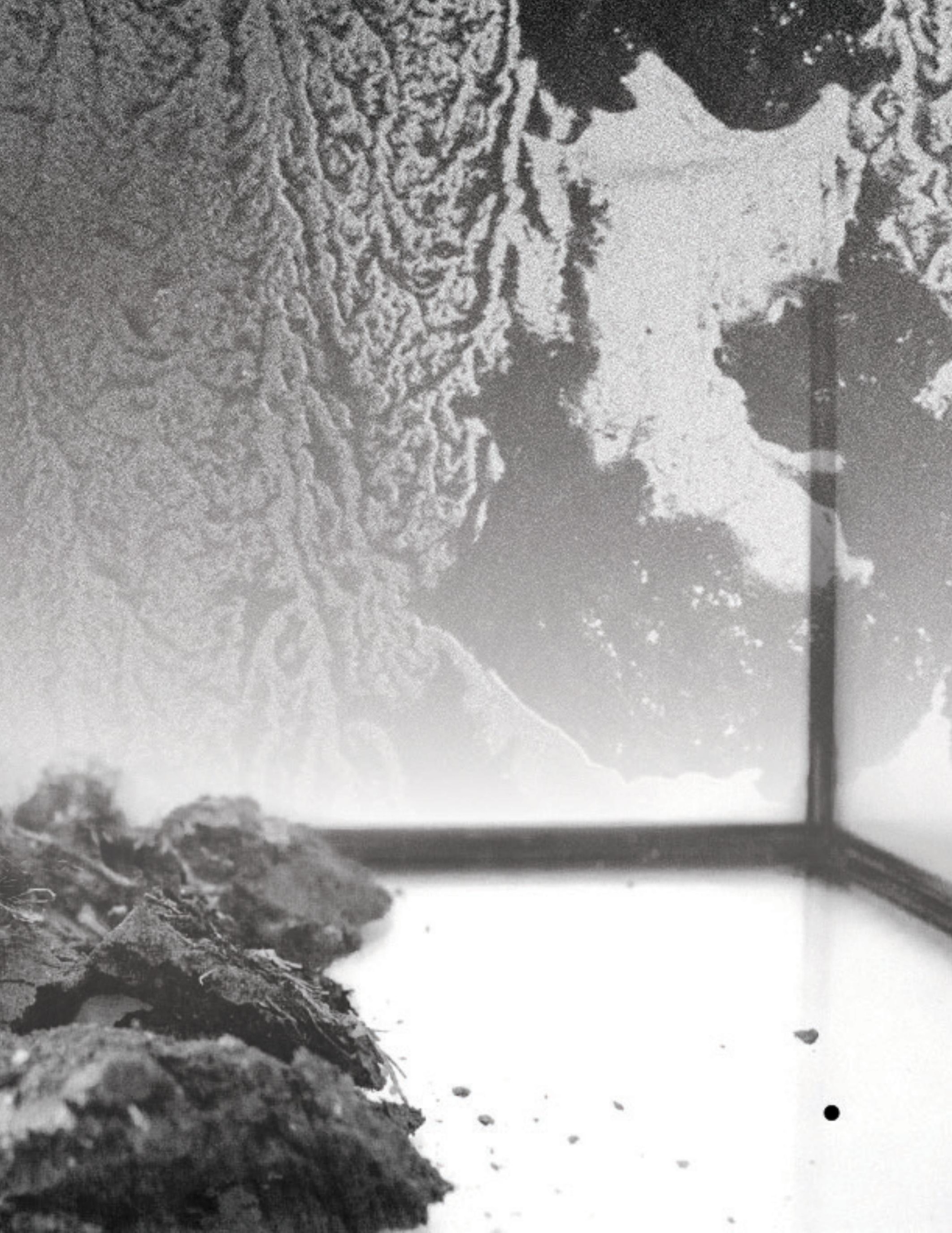




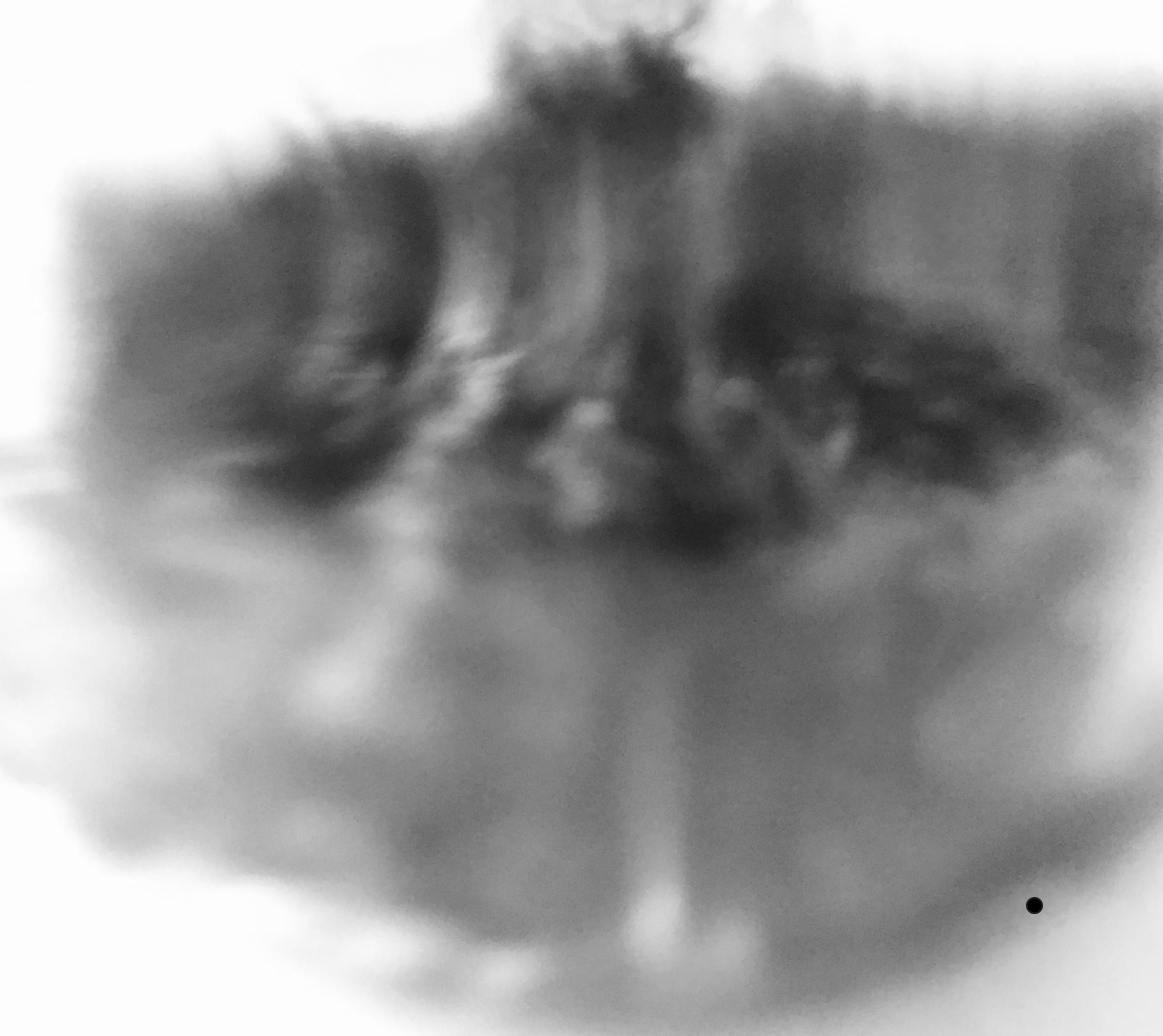


The story of Humanity's fall from grace, which has been told in the story of Adam and Eve's exile from the Garden of Eden, relates to utopias. Utopia is said to have been coined by Thomas More in 1516, developed from the Greek ou "not" + "topos," meaning "no place."81 Myths surrounding unattainable equity in economic, political, and cultural systems traces to the Old Testament book of Genesis, where humanity fell from perfection and is set to live their life in sin seeking redemption from God. ${ }^{82}$ Reconciling the myth of humanity's exile from its Mother, Earth, questions dualist philosophies underpinning academia and politics. Robin Wall Kimmerer explains in Braiding Sweetgrass, "look at the legacy of poor Eve's exile from Eden: the land shows the bruises of an abusive relationship. It's not just land that is broken, but more importantly, our relationship to land." ${ }^{83}$ In this way, utopias are directly antithetical to this works' advocacy to work with place, therefore this project engages with radical optimism $>$ [utopias].

81 Online Etymology, "Utopia, n.," March 2021, Online Etymology Dictionary.

82 Campbell, The Power of Myth, 54.

83 Robin Wall Kimmerer, Braiding Sweetgrass: Indigenous Wisdom, Scientific Knowledge, and the Teachings of Plants (Canada: Milkweed Editions, 2013), 9. 


\title{
garden of \\ eden
}

\begin{abstract}
"God is separate from
nature, and nature is

condemned of God. It's right

there in Genesis: we are

to be the masters of the

world. But if you will think

of ourselves as coming out

of the earth, rather than

having been thrown in here

from somewhere else, you see

that we are the earth, we

are the consciousness of the

earth. These are the eyes of

the earth. And this is the

voice of the earth."
\end{abstract}

Joseph Campbell, The Power of Myth, 39. 


\section{This is not a Utopic project.}

The project of modernity as a utopic exercise resulted in the International Style, hegemonizing the globe, destructing cultures, and enforcing dualist separations. As such, this work sits within the precarious history of modernist utopic projects such as The Garden City ${ }^{84}$, Le Corbusier's Plan Voisin, The Broadacre City by Frank Lloyd Wright, and most recently, the perpetuation of AgriHoods in American Cities. ${ }^{85}$ Furthermore, deep time shows the collapse of civilizations has occurred throughout history, as empires have risen and fallen throughout the ages. Thus, utopic "visions for the future" sit within the cyclical trend of attempts to dominate the external environment.

Furthermore, utopic thinking relates to greenwashed modernist sustainability projects. For instance, the Cradle-to-Cradle axiom thinking "all resources are recirculated and never wasted was comforting to a broad, wellintentioned audience, yet it defies the complexities present in both environmental science and creative design. Its critics argue that it dwells on wishful thinking, on the idea of holism and the idealization of the world as a round field where all resources can be effortlessly regenerated." ${ }^{\prime 66}$ Additionally, it creates a perception of "Earth holding," that positions a superiority between humanity and nature, ${ }^{87}$ creating a complex (Earth-savior/white-savior). This over-simplification in design thinking led to a "representational language for ecological simulation models, derivative of electronic circuits" visualized "almost exclusively with the use of arrows." ${ }^{88}$

84 The City of Ottawa's urban plan is a result of the City Beautiful design produced by Jacques Greber in 1950. A greenbelt and the Gatineau provincial park surround the previously industrial city.

85 Benjamin Berger, "Understanding Agrihoods: An Exploration into the Growing Trend of Farm-to-Table Communities Across the United States," Master's thesis, University of Massachusetts, 2020.

86 Lydia Kallipoliti, The Architecture of Closed Worlds: Or, What is the Power of Shit? (New York: Lars Muller Publishing, 2018), 22.

$87 \mathrm{Ibid}, 23$.

$88 \mathrm{Ibid}$. 
71 Instead of seeing ourselves holding the Earth, should we perhaps realize the Earth holds us? Reversing Earth-holding has intimate implications for design. Are we the authors, or is it the Earth? Do we seek epistemic solutions or ontological revelations? Can proposals for organisms/ place[arehitecture/urbanism] root themselves into ways of being with the Earth (ontological transition-oriented design ${ }^{89}$ )?

Agrarian lifestyle as the epitome of surplus and the development of capital questions the foundations of our relationship with land. "For one thing, peasants with a stake in the stability of the world were turned into day laborers entirely absorbed in the struggle to satisfy their bodily needs. For another, stable property was converted into fluid wealth-capital, in fact-with the dynamic effects that Marx had described so well. ${ }^{90}$ Food (land + animals) becoming property and property becoming capital birthed capitalism. Uncapitalizing the source may then offer solutions to re-address land-use. What if we uncommodified agriculture and instead treated it as a gift from the Earth? Robin Wall Kimmerer explains this concept as gift economies as she references Lewis Hyde's declaration that "objects... will remain plentiful because they are treated as gifts." 1 Clean Water, Air, and Food become Earth's gift to all.

89 Escobar, Designs for the Pluriverse.

90 Hannah Arendt, "Introduction," in Human Condition, ed. 2, Margaret Canovan, (Chicago: University of Chicago Press, 1958, 1988) 1.

91 Wall Kimmerer, Braiding Sweetgrass, 30. 
Susan Stewart's writings on the Miniature and the Gigantic investigates scale and language as a mechanism to communicate ontological investigations into spectrums of time and space to an infinite and definable degree. Stewart relates this to Raymond Roussel's "verse technique of parathentical sentences, sentences that sometimes involve as many as five parathentical expressions $(((((?))))) .{ }^{" 92}$ Stewart demonstrates that the relationship between scale, time, and language are directly proportional and can help orient our existence within place.

Moving through various scales and times with language questions our relationship to Earth. Earth as a deep time entity represents a scale notunderstandable to our short human-life perception. Thinking with Earth scales questions the relationship between the cosmos and the quantum, which physicists are currently exploring as the multiverse through string theory. "String theory posits perhaps multiple parallel dimensions of space and time, amid the perhaps millions of galaxies and billions of solar systems, stars, and planets." ${ }^{33}$ Working with multiverses, pluriverses, and pluralities shows infinite opportunities and possibilities, as well as limitless agents and worlds. "Designers become the harbingers of the transition toward plural ways of making the world." 94 Optimism coupled with the belief in infinite possibilities, and the realization that the world is so complex that we may not be meant to understand it all, proposes working humbly to engage with Earth through rhythms and flows in Ecozoic times. ${ }^{95}$

92 Susan Stewart, On Longing: Narratives of the Miniature, the Gigantic, the Souvenir, the Collection (London: Duke University Press, 1993), 52.

93 Wangari Maathai, Replenishing the Earth (Toronto: Doubleday, 2010), 63. 94 Escobar, Designs for the Pluriverse, 7.

95 "The term "Ecozoic era" was coined by Thomas Berry in conversation with Brian Swimme for their book The Universe Story to describe the geologic era that Earth is entering when humans live in a mutually enhancing relationship with Earth and the Earth community." 


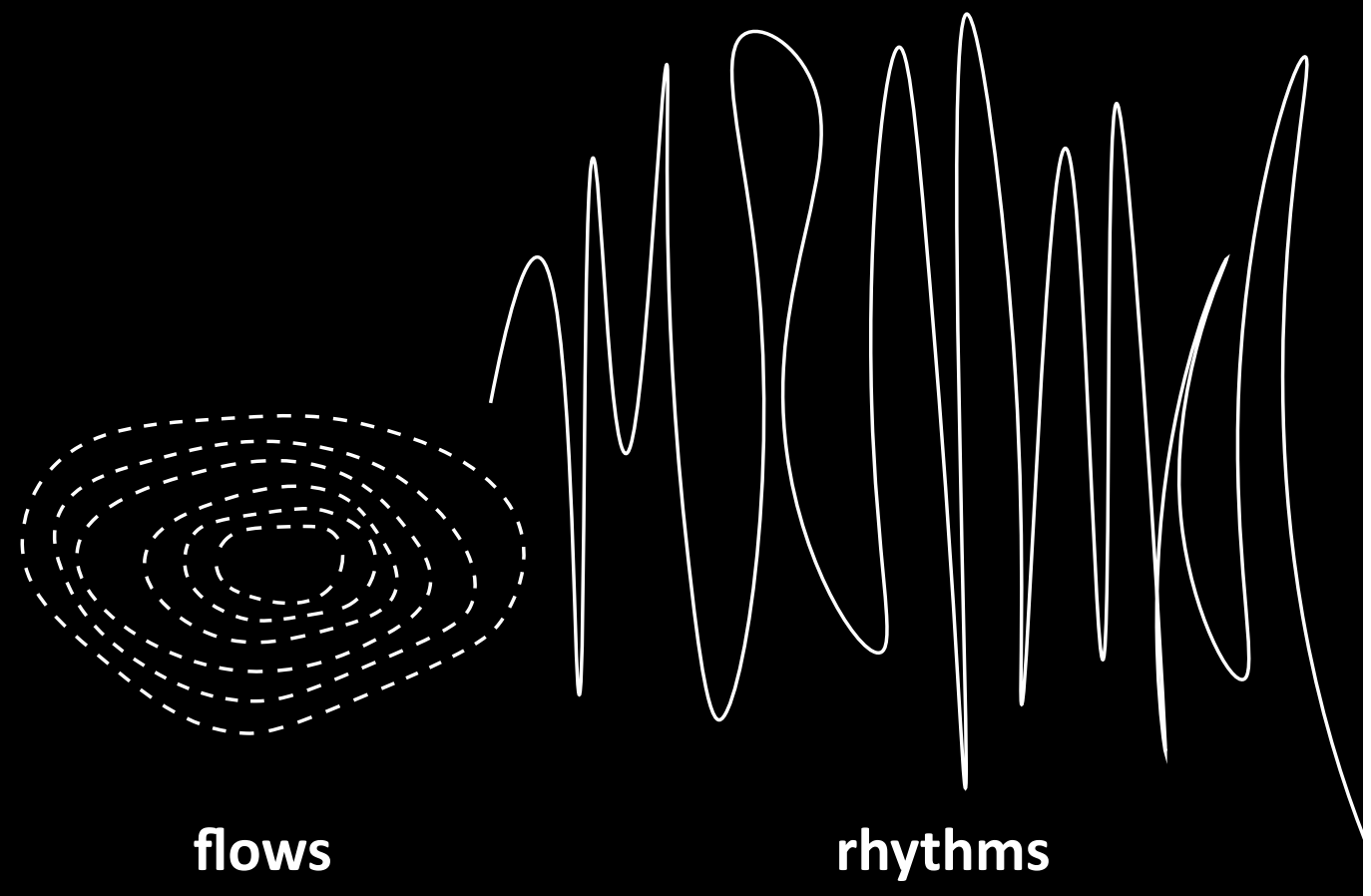




\section{SAche}
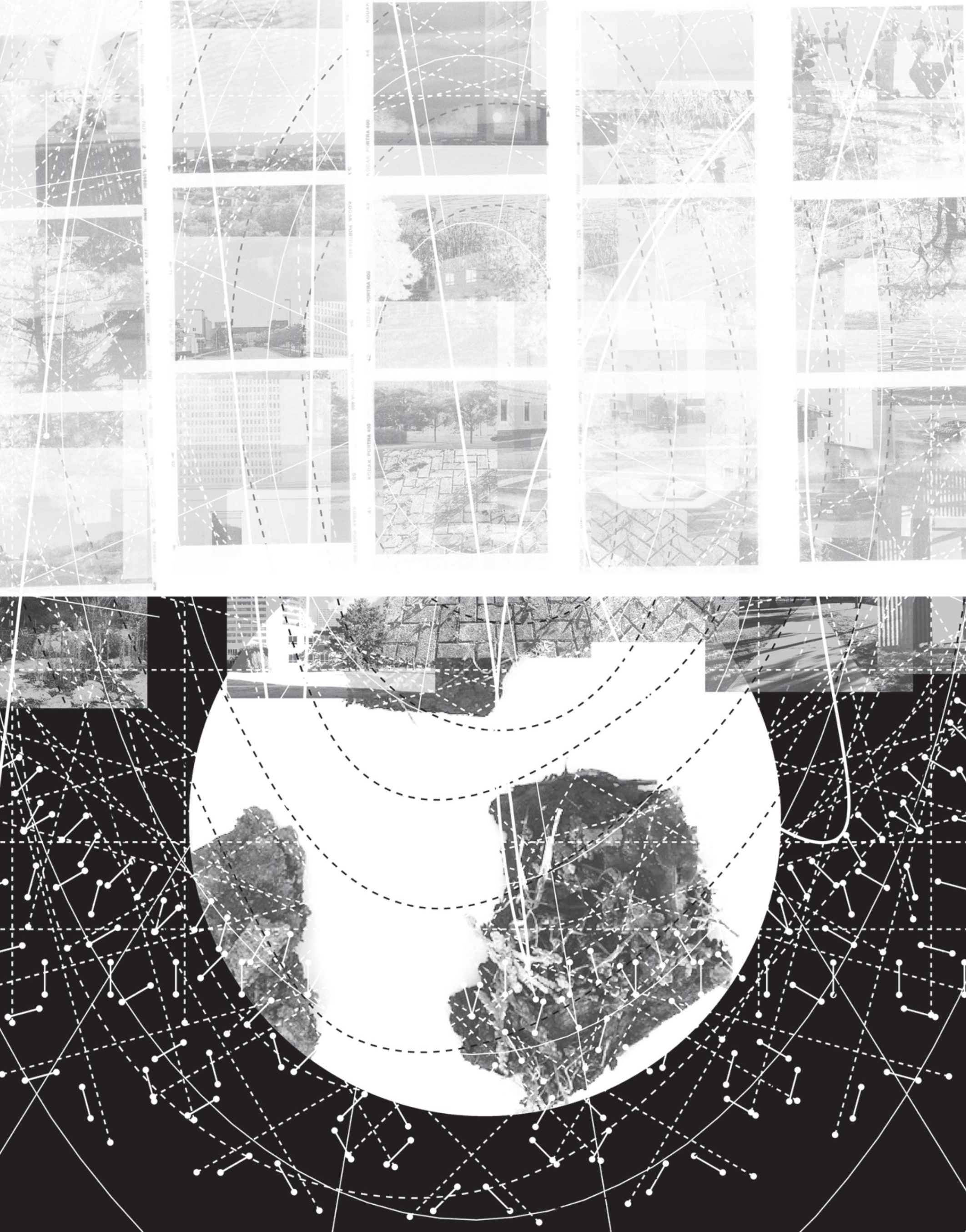
Conventional planes for architectural plans and maps $(X, Y)$ become fluid landscapes of mythology (Archetype to Land).

3dimensional elevations and sections ( $Z$ ) demonstrate movement of the 2D plan over the fourth dimension of time. (Sky and Earth continually interact).

Axonometric drawings operate in cartesian planes of $X, Y,+Z$ axis'. The dimension of time reveals a plurality of possibility, as everything folds together in rhythms. 
Finally, the relationship in the $X, Y, Z$ axis + time is conceptually transformed in a hyperbolic multiverse.

Designing without plans and sections reveals becoming architecture across scales and in time. Instead of drawing architecture, what if we drew the Earth as alive and thinking? 
Earth, Gaia, or Gaea - the Greek God embodying the Earth - speaks to the earth-bound condition, which Hannah Arendt explores as the Human Condition. Seeking to master the sky-bound (realm of the Gods) and the underground (realm of the dead) is rejecting the earth-bound nature that defines the human condition(life). Bruno Latour's Facing Gaia: Eight Lectures on the New Climatic Regime(2017) urges us to reconsider our relationship with Nature. Earth as a substitute for Nature calls us to reconsider our existence.

Ponderings on existence appear in Gaston Bachelard's Poetics of Space concluding chapter The Phenomenology of Roundness where Van Gogh concludes, "Life is probably round. "966 Roundness suggests unity, a cycle of dualism transcending divides. Bachelard writes, "outside and inside are both intimate-they are always ready to be reversed." ${ }^{\prime 97}$ The Kybalion: A Study of The Hermetic Philosophy of Ancient Egypt and Greece represents duality in the fourth Principle of Polarity, everything is "poles of the same thing." ${ }^{98}$ Campbell explains "all things in the field of time are pairs of opposites. So this is the shift of consciousness from the consciousness of identity to the consciousness of the participation in duality. And then you are into the field of time." 99

96 Gaston Bachelard, "The Phenomenology of Roundness" in The Poetics of Space (London: Penguin Books, 2014), 247.

97 Ibid, 233

98 The Three Initiates, The Kybalion, 78.

99 Campbell, The Power of Myth, 55. 


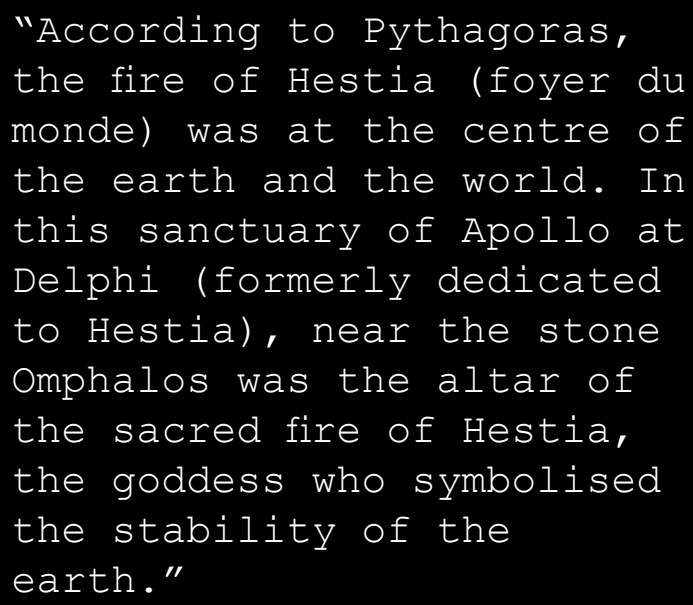

William Lethaby, Architecture, Mysticism, and Myth, (London: Percival \& Co, 1892), 80. 
79 Questioning our existence presents the importance of language. "Languaging" is the fundamental manner of existence of human beings; not only that, but language is intimately connected with the flow of emotions, and languaging and "emotioning" together provide the basis for the recursive coordination of behaviour through the creation of consensual domains." 100 Due to the scalar and time-based meditations on Earth, Place-Thought is found to need new languages founded on emotion. 
In conclusion, this work gives Earth worlding agency. But with caution, as Haraway writes, "a risky game of worlding and storying; it is staying with the trouble." ${ }^{101}$ In the way of this work, worlding is proposed as an ontological process merged with the spiritual and emotional capacity of material and language.

Exploring duality's epistemology revealed a prioritization on logocentric thinking, which catalyzed the separation between humanity and Earth (nature). Weaving dualities creates a focus on multiple quadrants of materialization, with the feedback between perception, creation, and emotion in language iteratively explored through the Indigenous philosophy of Place-Thought.

Growing materials with Indigenous agricultural practices in place (++), harvesting materials in urban premanufacturing facilities as cultures $(-+)$, living in existing post-war residential neighborhoods with Earth assemblies through geo-bodies (--), and finally, rooting building materials with mycelium and folds (+-), positions architecture within a polarity framework of cyclical regeneration in a post-war government campus and residential development at Tunney's Pasture in Odawa, Turtle Island.

Hannah Arendt's labour, work, and action are unified with Joseph Campbell's definition of the mythological. As a result, labour as a paradigm of mystical living for architectural pedagogy works with care to engage the practice of maintaining our cosmological world. Action unifies construction/ 
81 deconstruction as a political/sociological engagement. Intersectional eco-feminism becomes embracing duality to support explorations on maintenance and decay. Hybrids operating in hyperbolic space through scale and time fold realms of existing and proposed realities (industrial, organic, new, ruin, etc.) to orient a path forward.

Continuous work is required to identify the time of material state change. How long would it take to compost our garbage? Curiosities continue regarding the role of quantum physics and the impact Newtonian logic has on our structures and theories of space. Additionally, the relationship between the creation of Architecture/Anthropology and domestication creates many possibilities for future inquiry into the complexities of climate.

Ultimately, seeking to design with language, emotion, place, and polarity, the work aimed to develop a transition-methodology that privileges material as an agent and a gift through place (in space and time). The building envelope positioned as a liminal negotiator between dualities (inside/outside, internal/external) and a Place-Thought manifestation creates a mythological and intuitive counter-exploration on the perceptual shift to an organic Here+Now(history/future). 
Defence Intro Script:

Defended 04212021 on Planet Earth

Dissolving boundaries between Earth/Architecture inverts methodologies to study the subnatures of matter, time, and space experienced in sensorial dimensions. The illusion of boundaries reveals being with a consciousness of interconnectivity and unity. The void becomes the negotiation of metaphysical vessels manifest through edges, corners, and surfaces. Searching epistemics beyond cartesian planes meditates on the viscosity of material state change. Time is a thick present that liberates Earth from its container to negotiate with the spirit and soul of material through the messiness of scale. $\because 4$

\section{materials}

- (embodied)

energy

harvesting

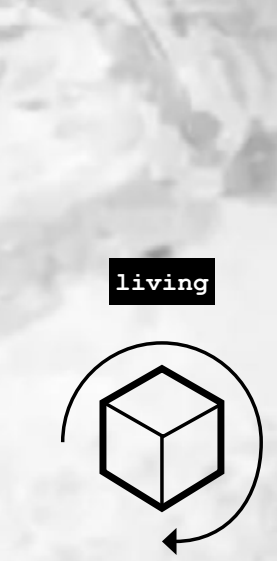

-
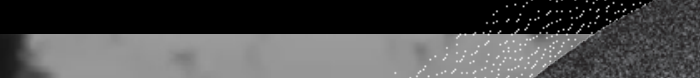

政 


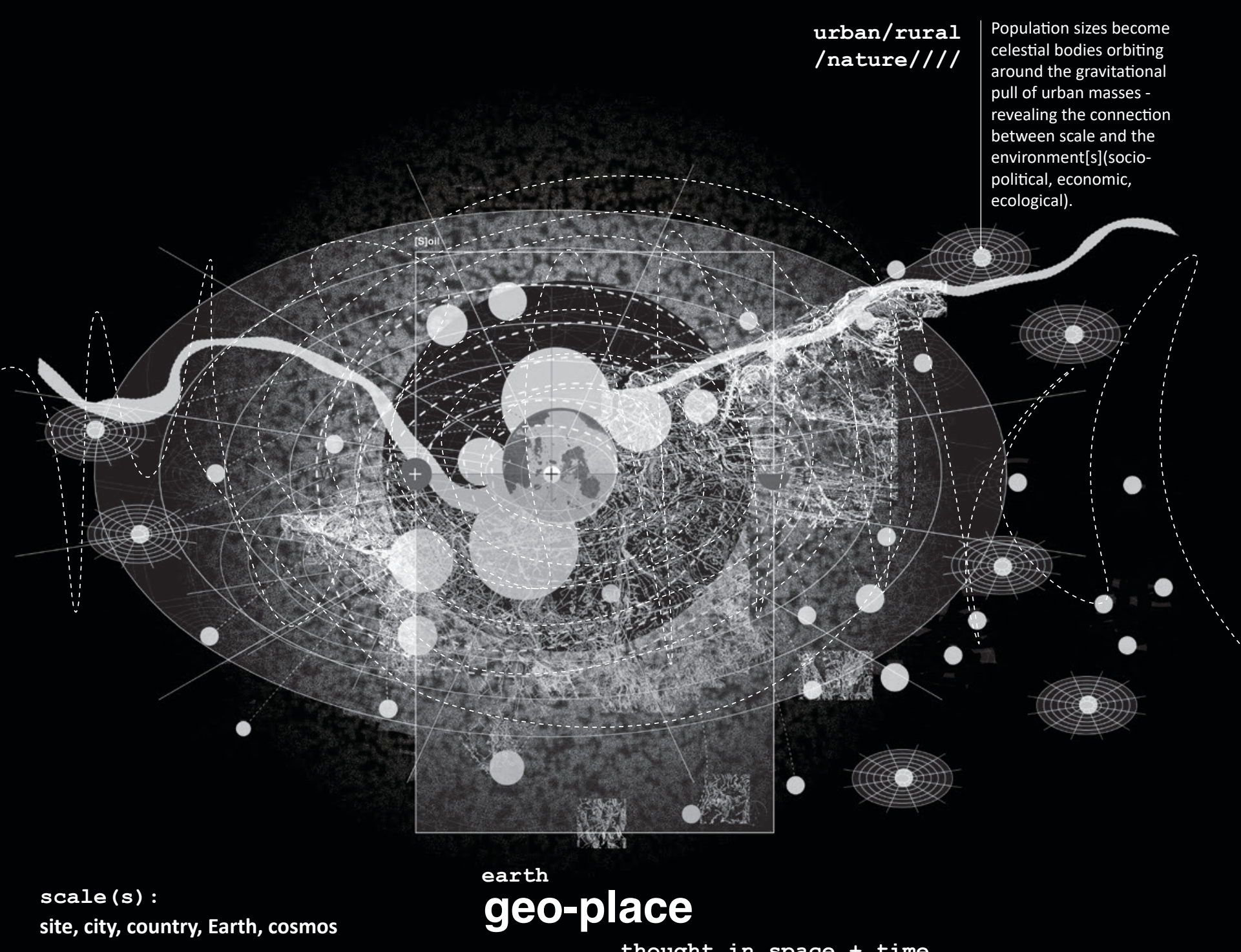

thought in space + time
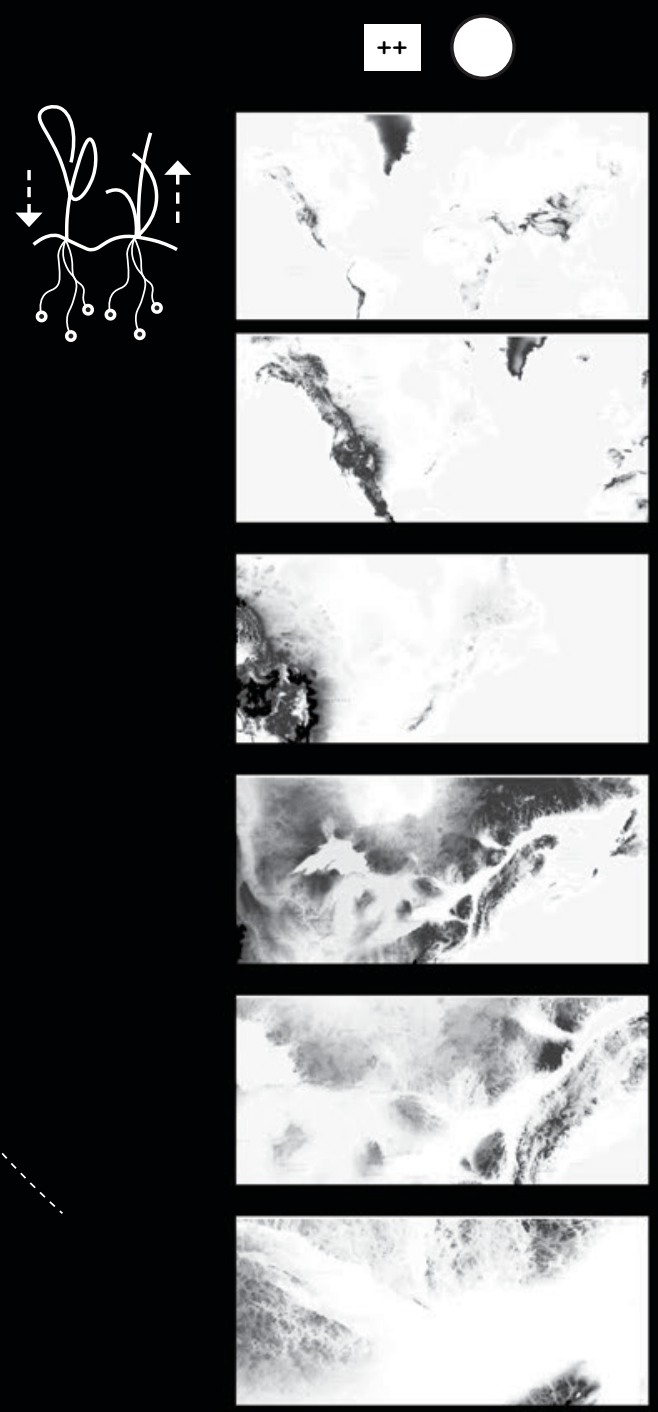

(x)

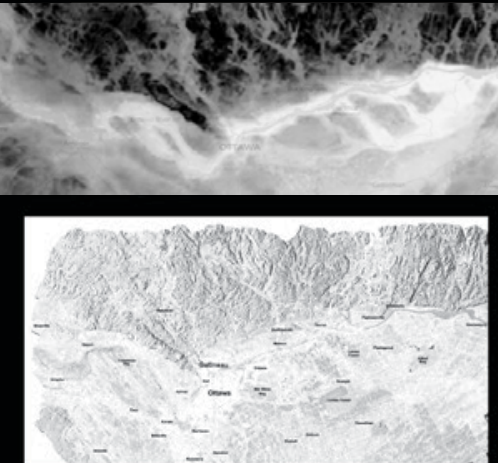

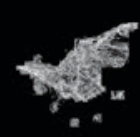

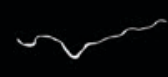

water
\%

communities

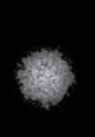

energy

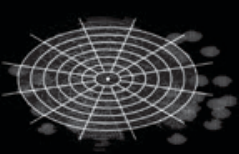

beings
GroWING 


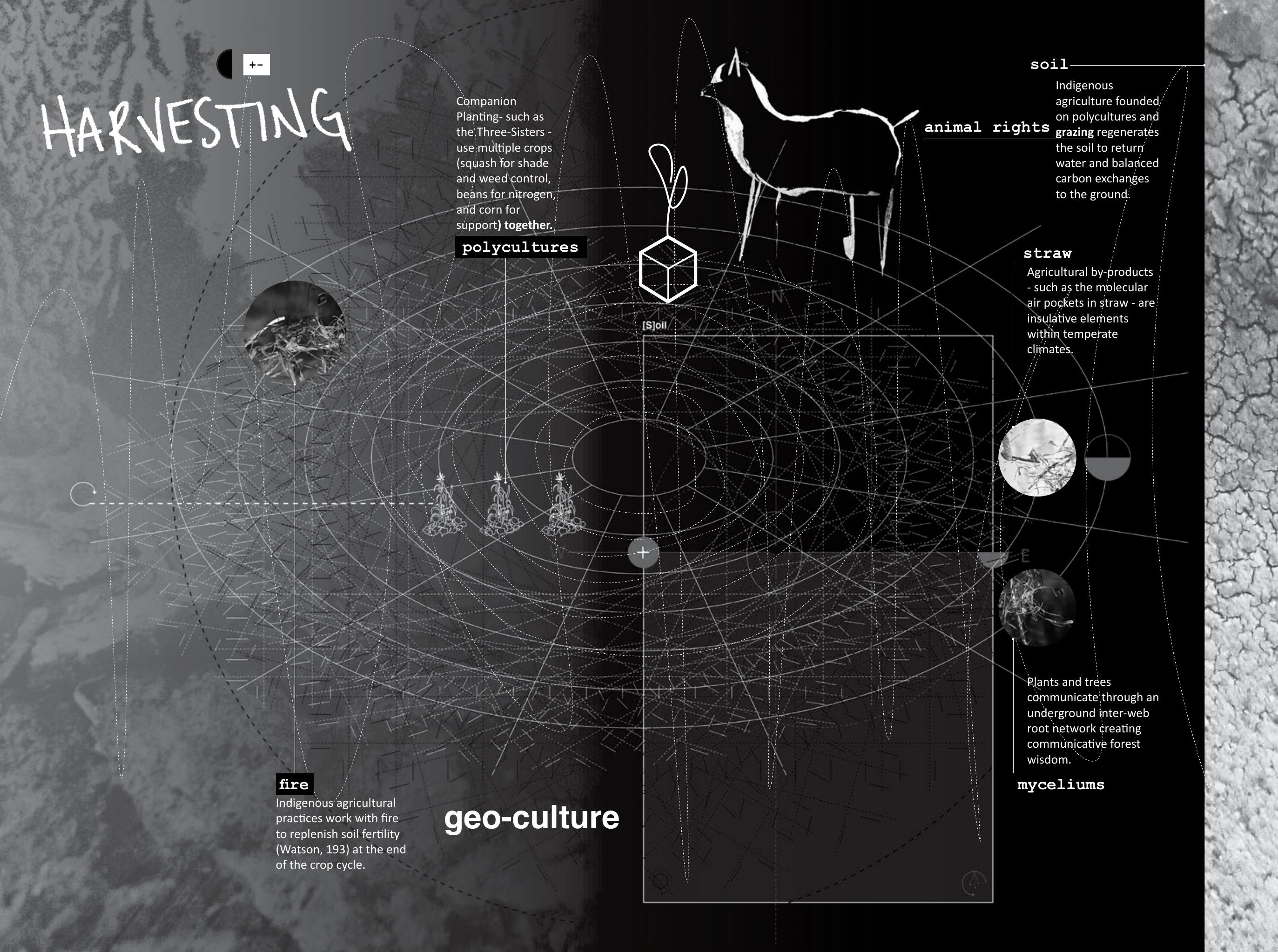




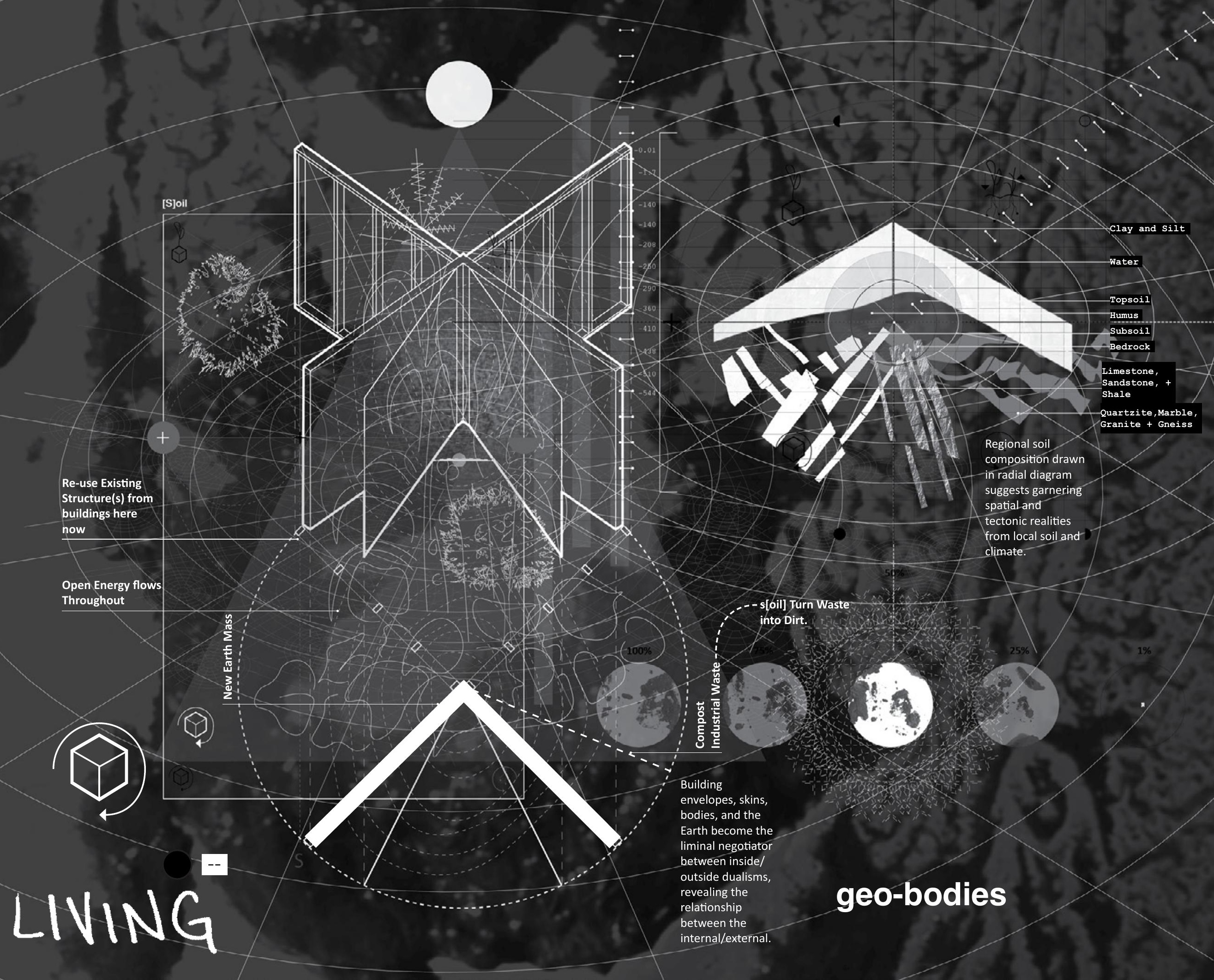


explores using

soil for worlding.

Every construction

and its inevitable

deconstructions

make all acts of

building political

and sociological.
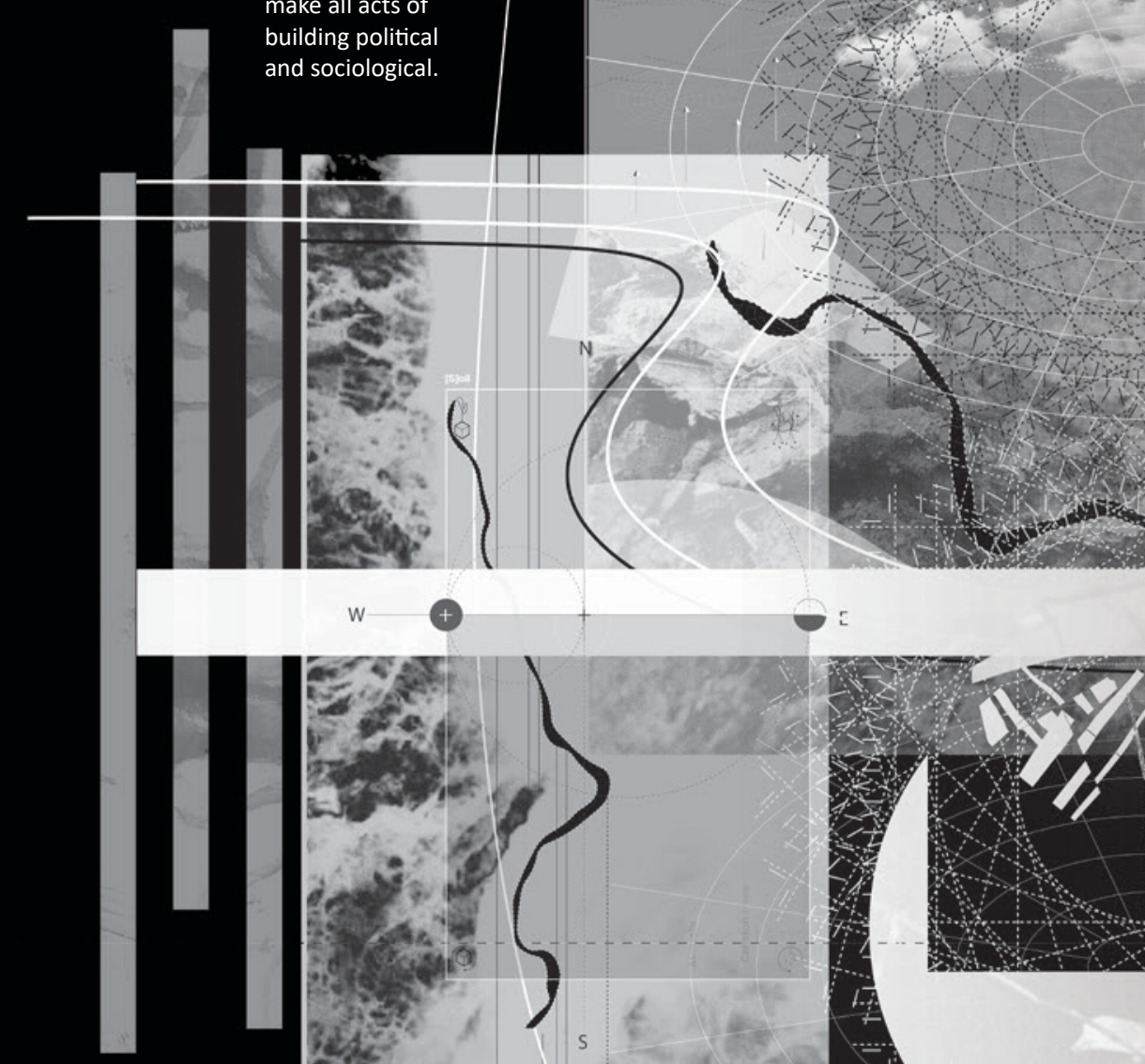

$38 \mathrm{~m}$

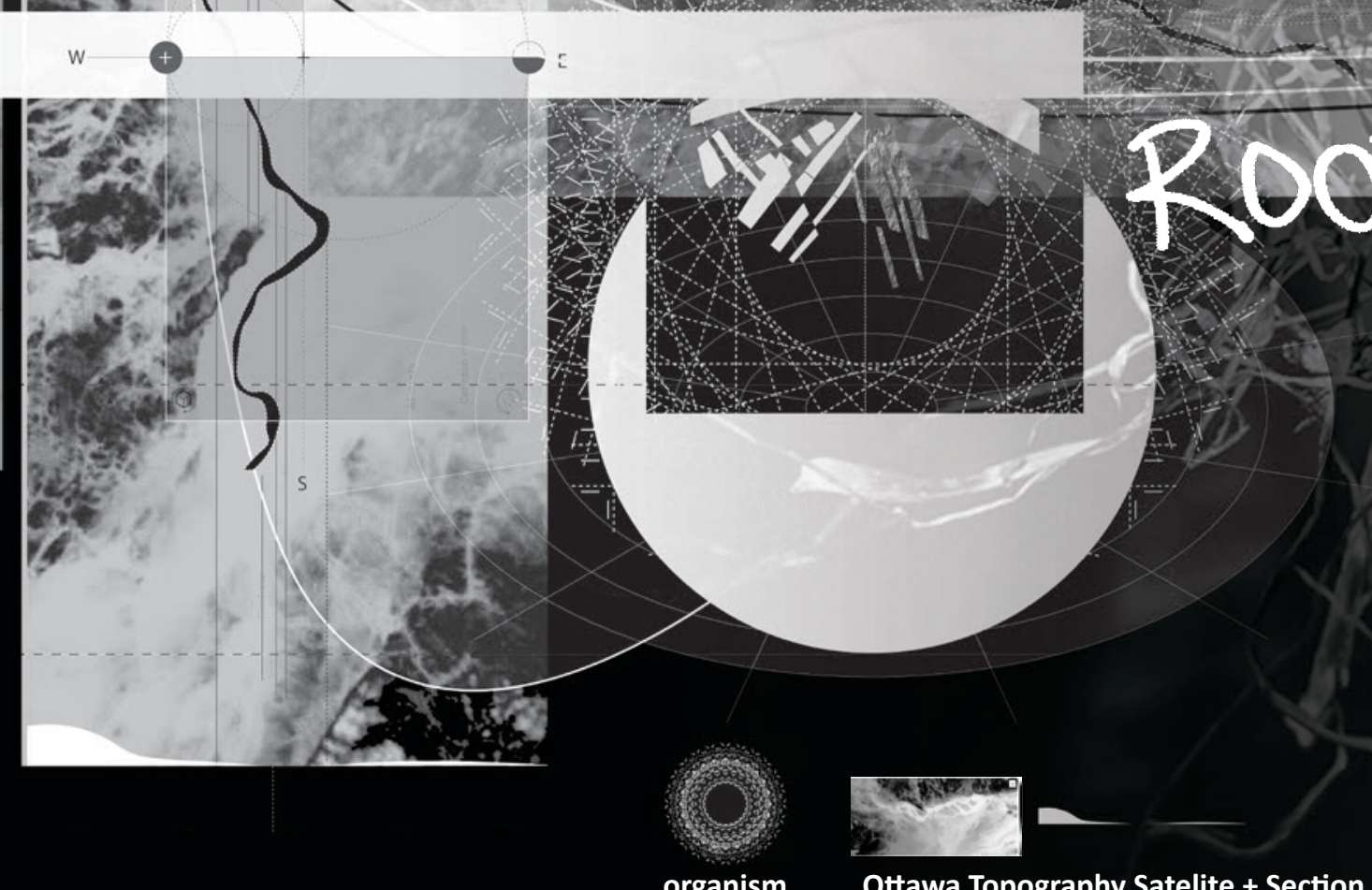




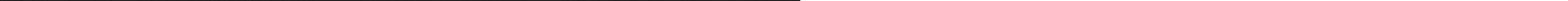



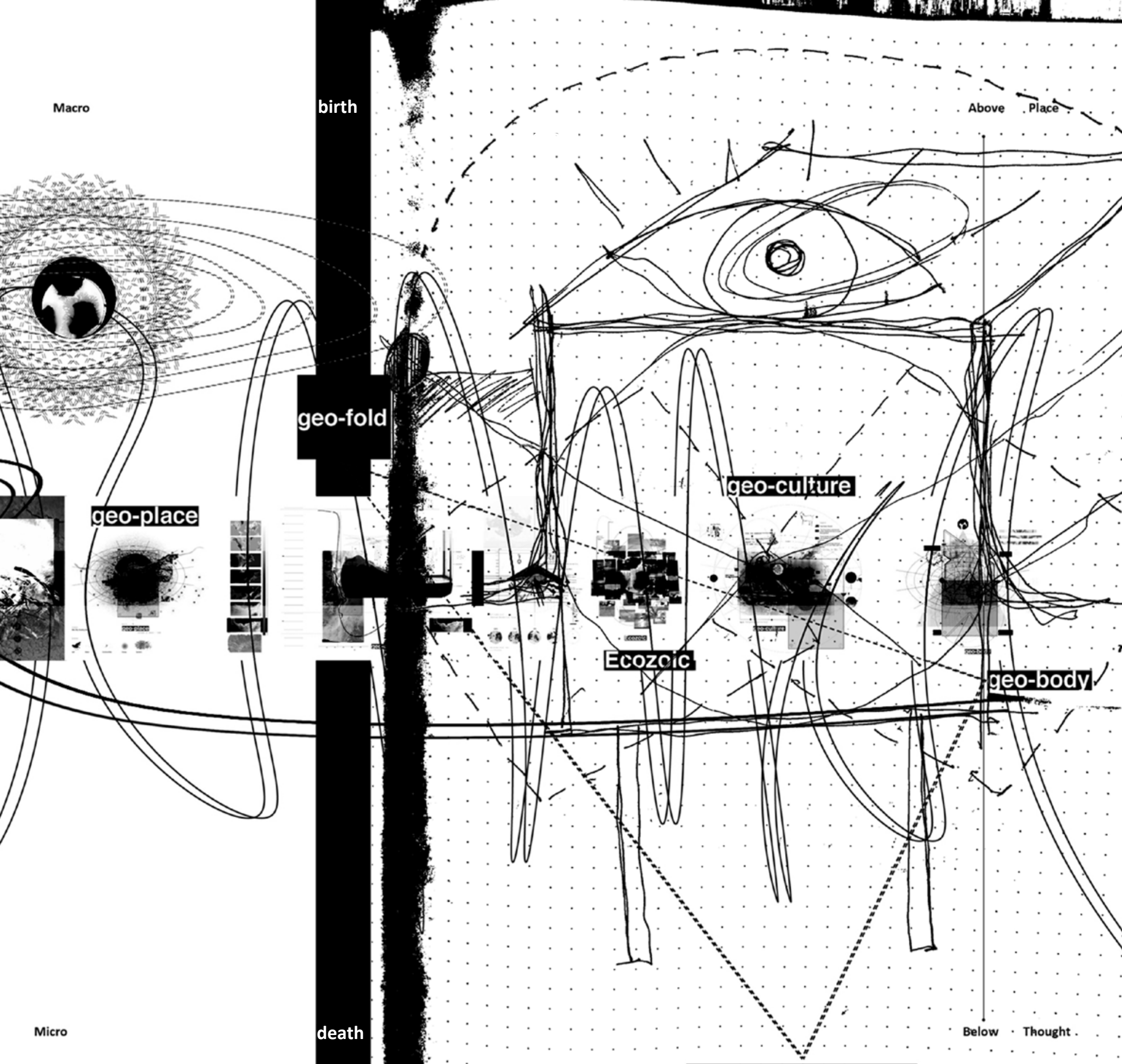

Epistemological/Heteronomy

\section{Earth-time}




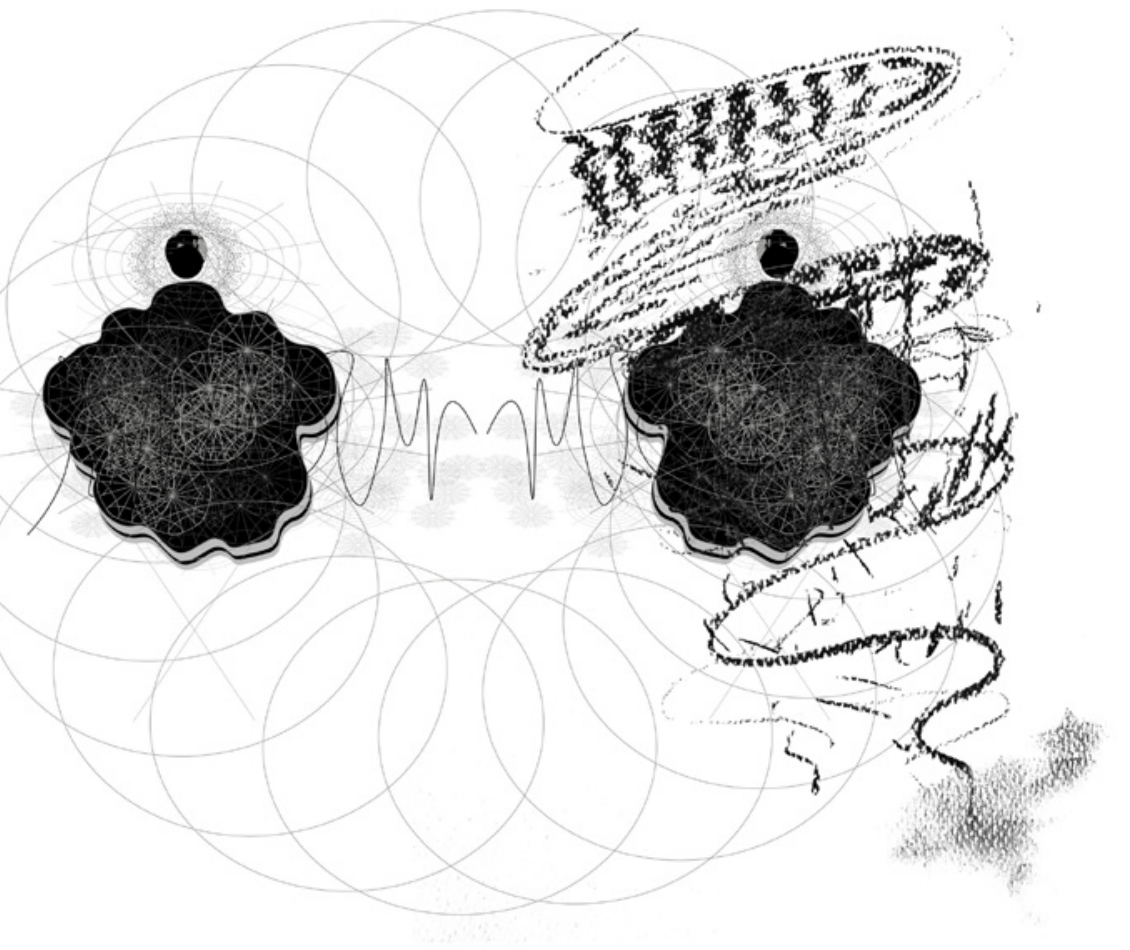

An architecture of pluriversal action makes space that helps us meet ourselves, and the other, through time.

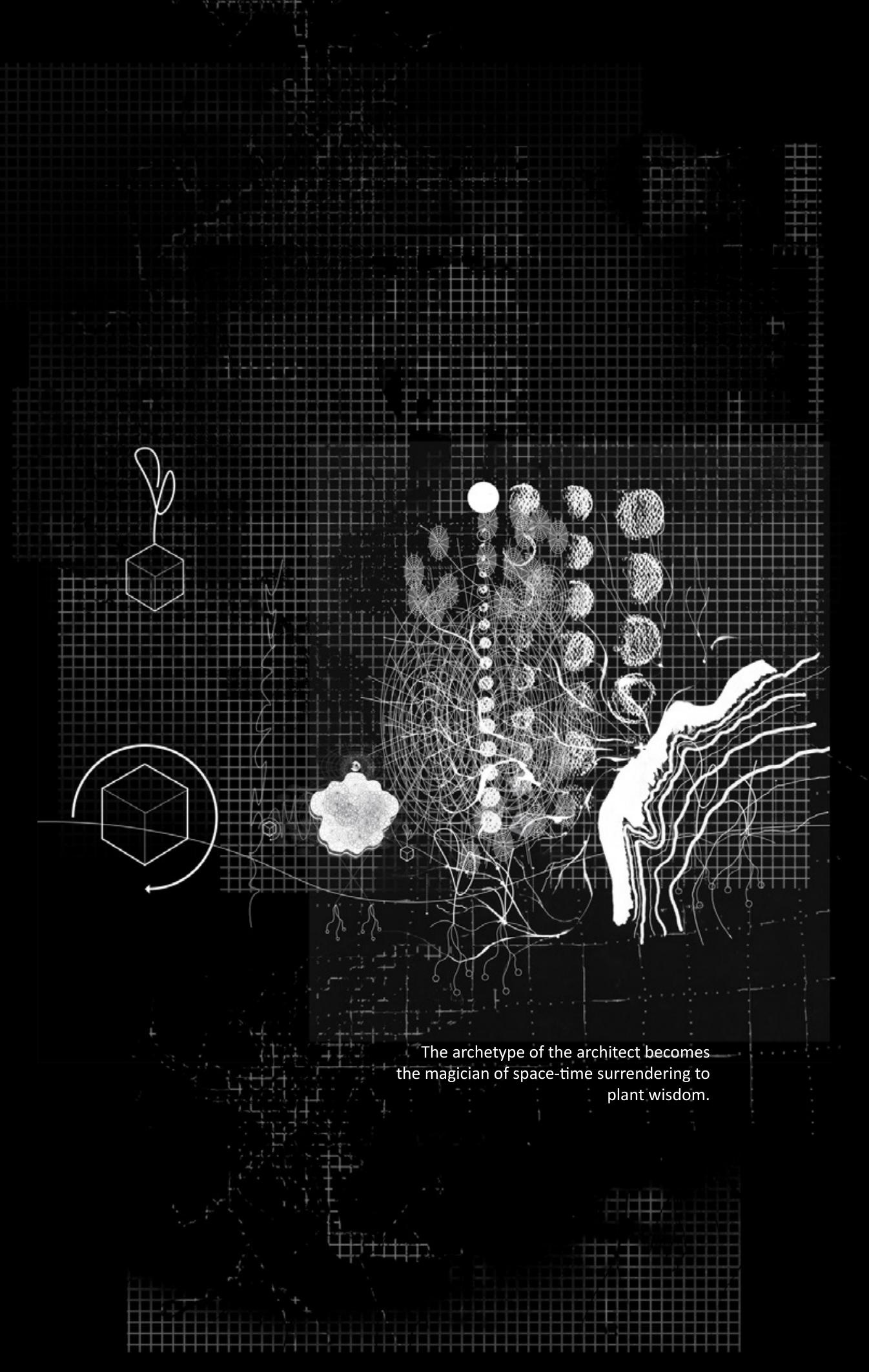




\title{
Being Care-ful
}

\author{
Duality / \\ subverts inside/outside \\ resolves paradoxes of nature/architecture \\ combines landscapes/bodies
}

building envelope;

cultural and programmatic

climate

transcend extractivism

liminality;

[sp/pl-ace] of now

in-between

growth/decay

folds;

interdependent cycles

of regeneration

in conclusion; let's begin

with patience +

positive knowledge(wisdom) 


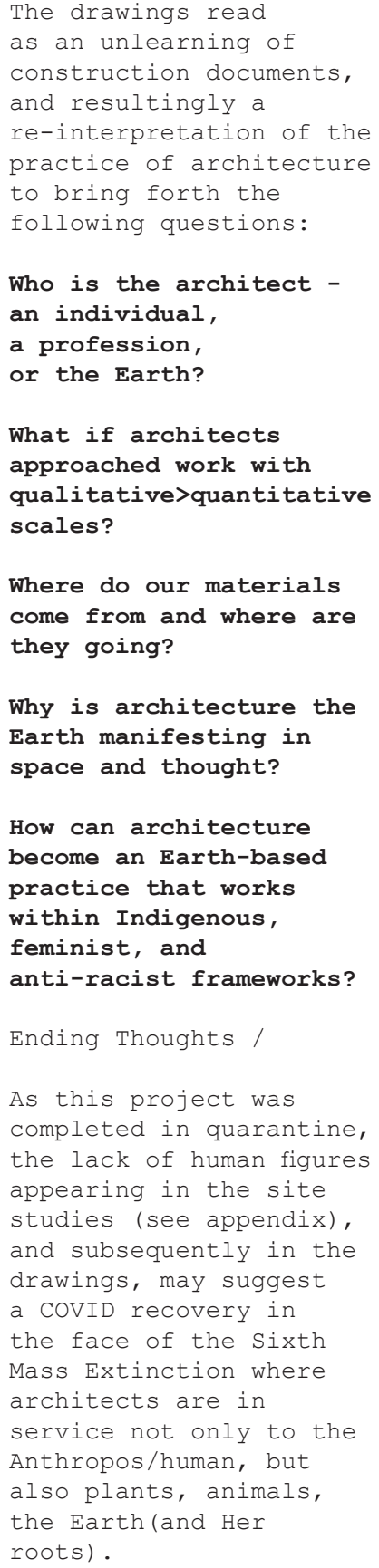

Speculative fabulation/feminism and radical Indigenism unifies Earth and architecture to combine all interactions with soil ranging from farming, composting, and dwelling. Indigenous agricultural methods regenerate soil to reverse climate change by stabilizing carbon dioxide inputs and outputs in the ground. A transition-oriented path beyond fossil-capitalism and extractive practices suggests harvesting farming byproducts for building materials to create ethical local work in the process of addressing the inequalities of racialized product creation, gendered care-work, and global exchanges. Living with earthen materials requires the continual maintenance of our built environment and necessitates a renewed relationship to time as a circular practice, rather than the planned obsolescence linear model that clogs landfills. Lastly, rooting material through composting celebrates the inevitable cycle where all material eventually returns to the Earth to be decomposed by the root network, creating soil that can be used to grow new vegetation. In essence, the design narrates a proposal to fold what is here now with a path forward where humanity lives in harmony with the Earth and her kin.

Moving beyond systems, which seeks to logically rationalize the interdependency in the network of living things, surrenders to the illogical and invisible forces that connect all beings. Rather than systems, perhaps relating to seasons (or phases) can more accurately express our relationship with our environment. Living in the Anthropocene as an era of decay, old systems begin to fall away - revealing new opportunities for growth and harmony. Having compassion in this crisis is extremely important to give rise to love rather than fear - to ultimately, let the Earth(and ourselves) heal. 
appendix 


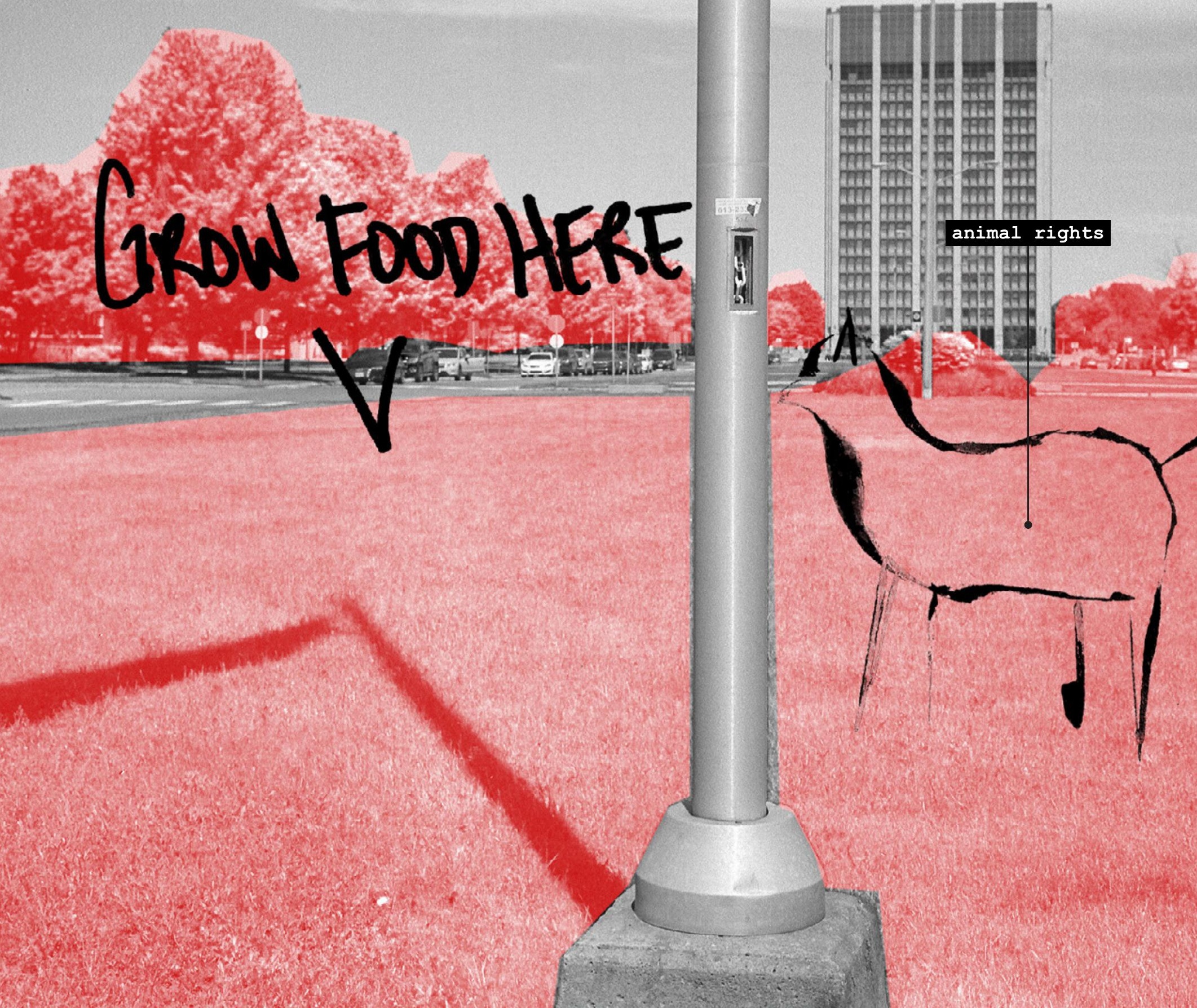



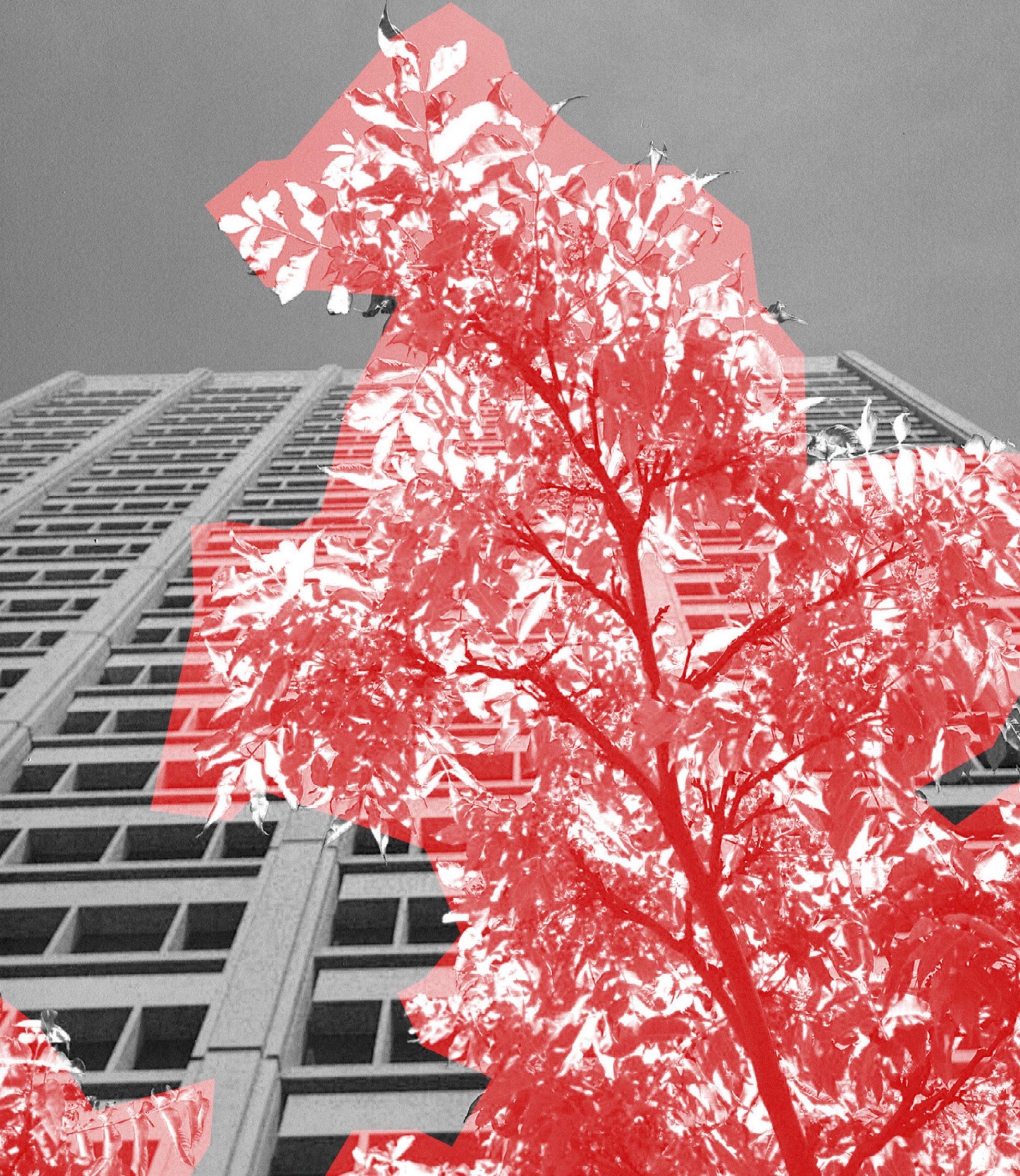



\section{as apove.}

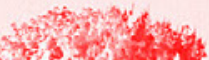

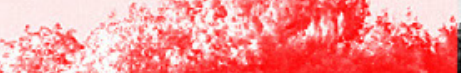

$\frac{2}{2}$
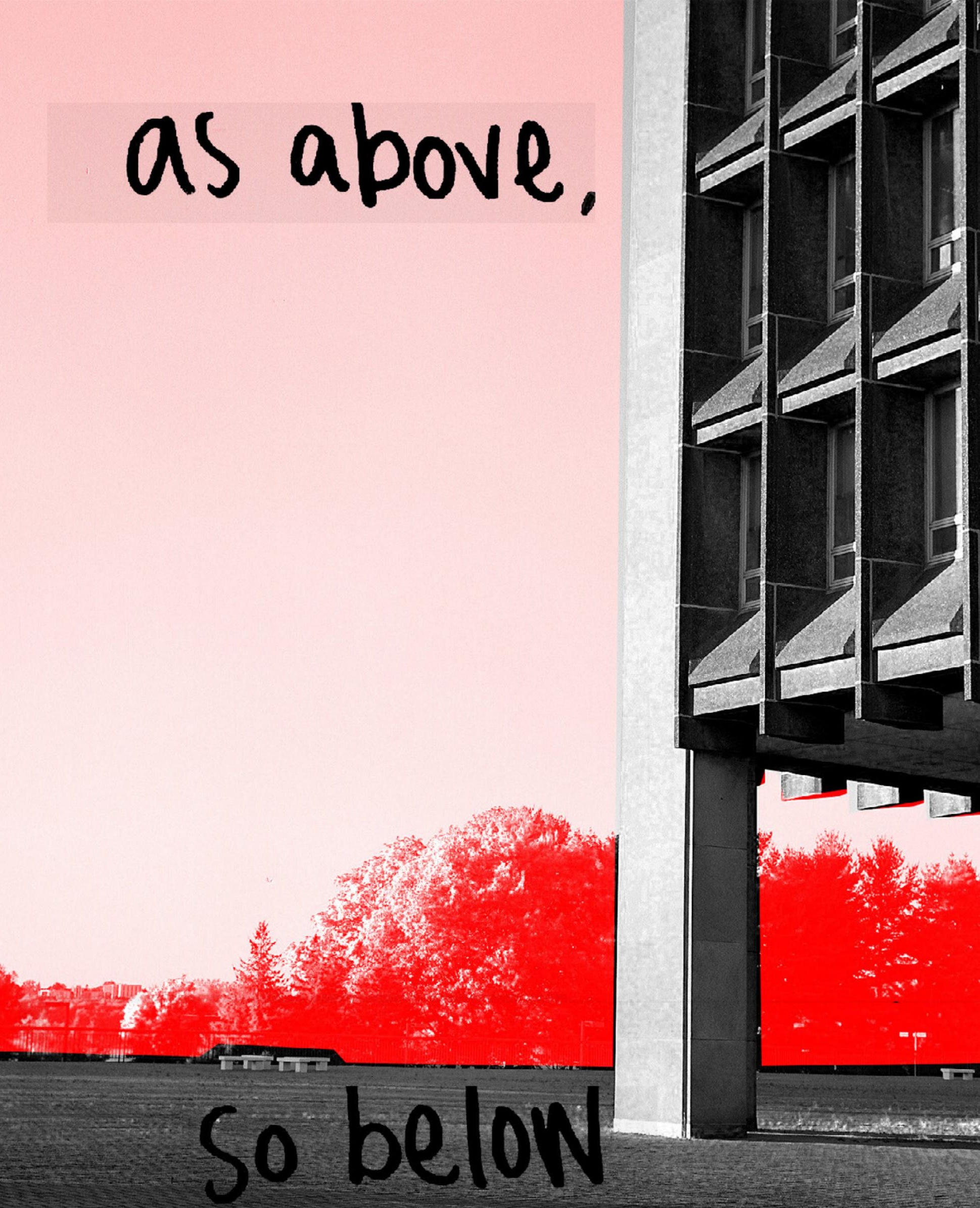


19

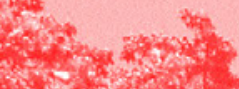

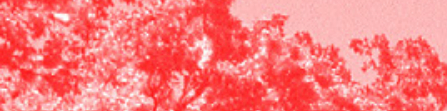

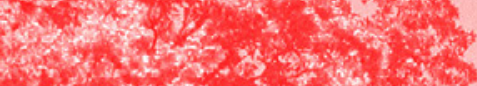

(3)

.

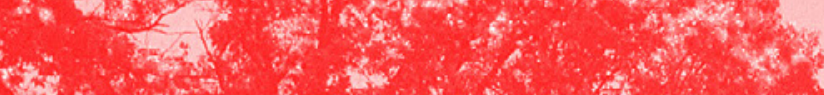

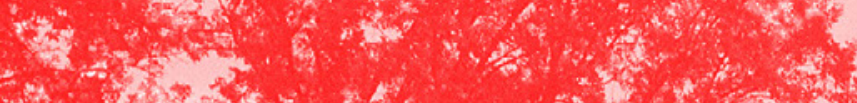

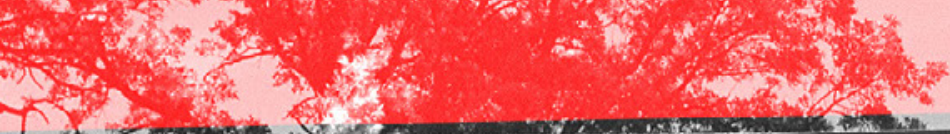

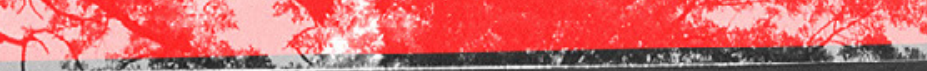

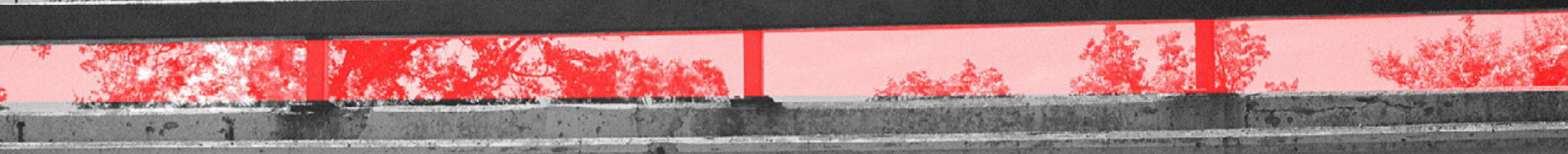

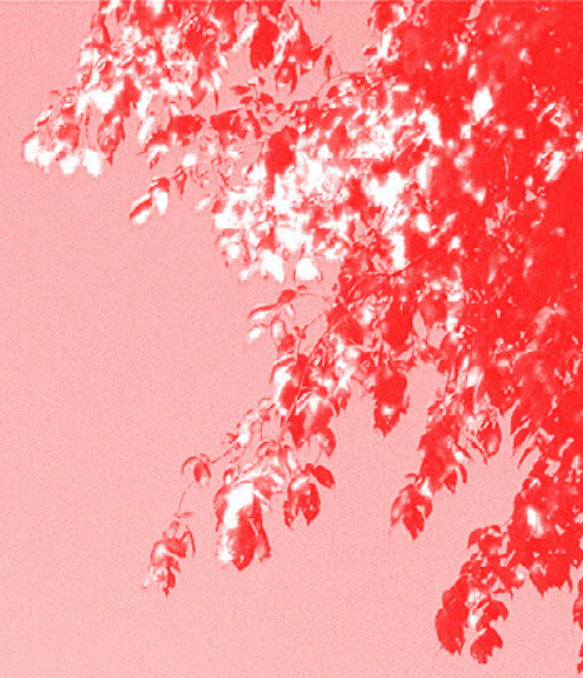
(5) 


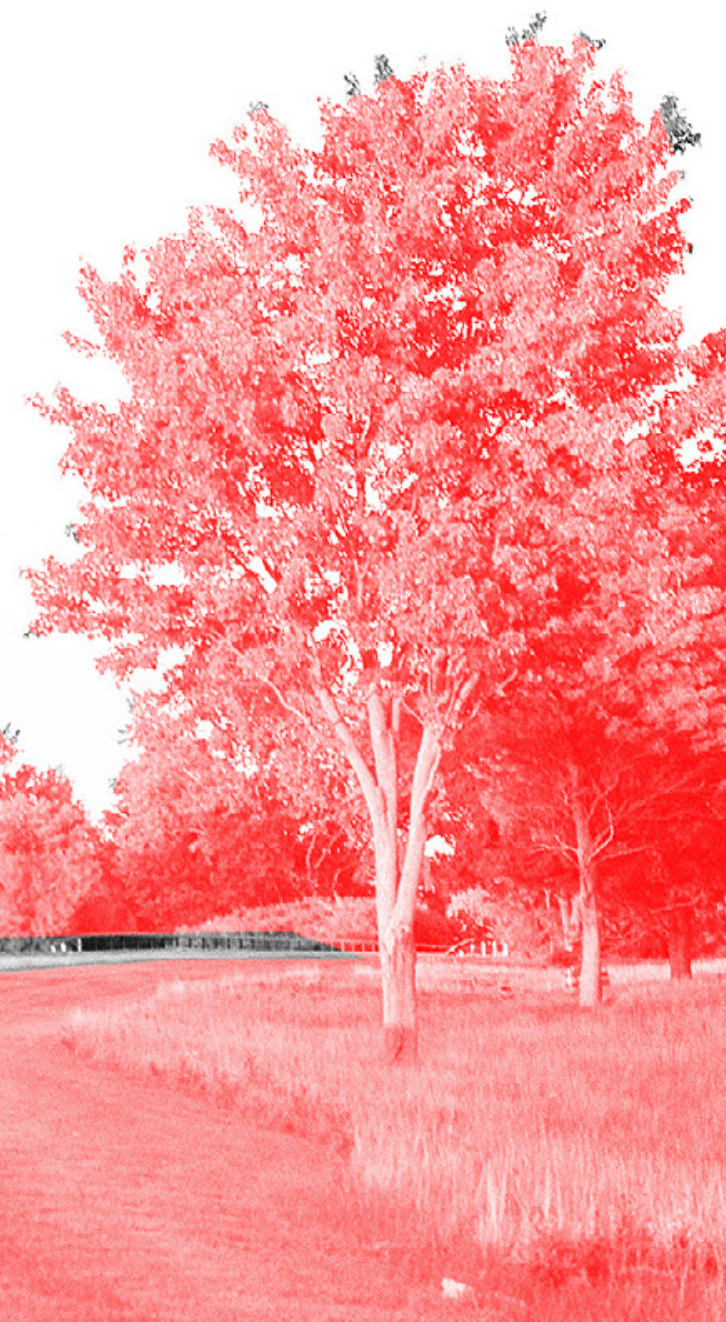




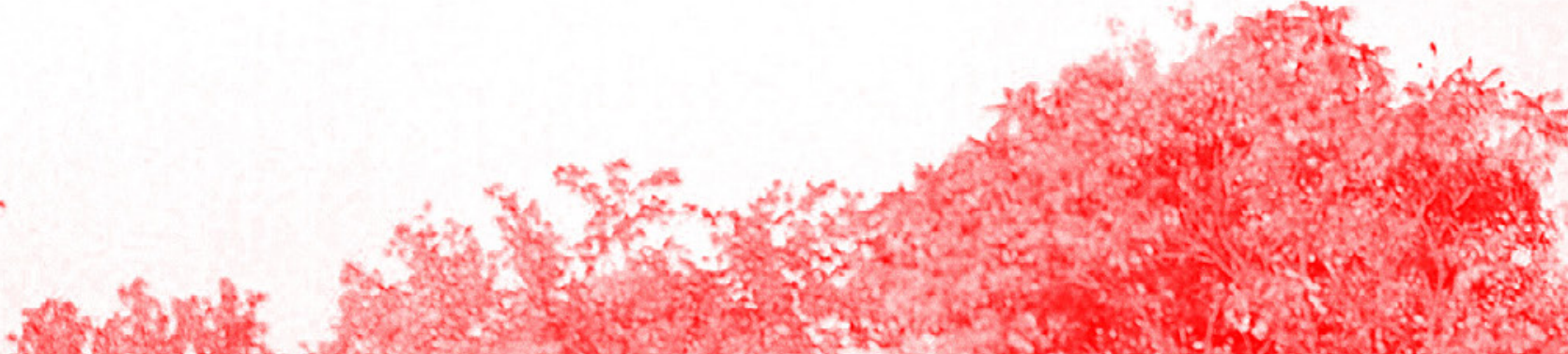

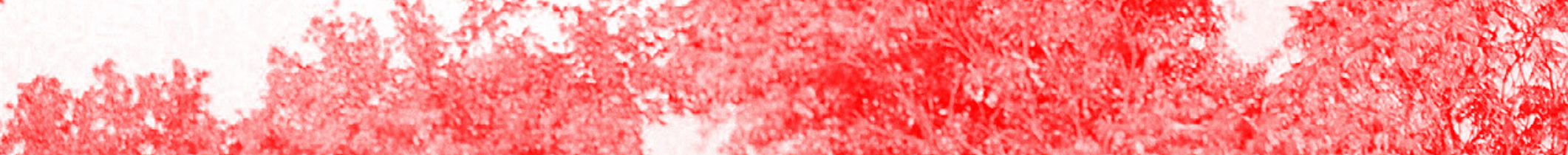

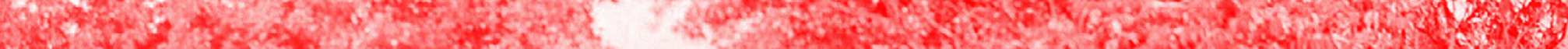

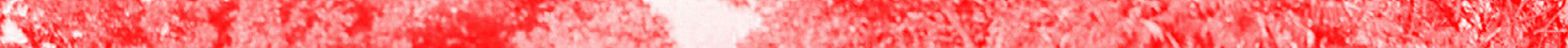

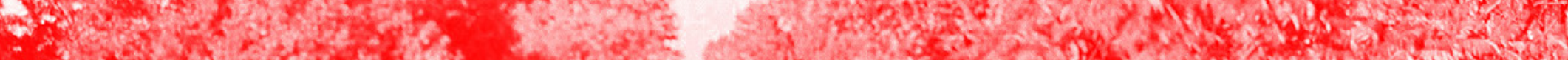

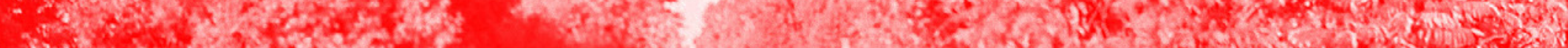

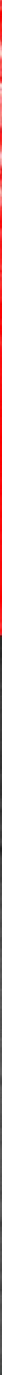




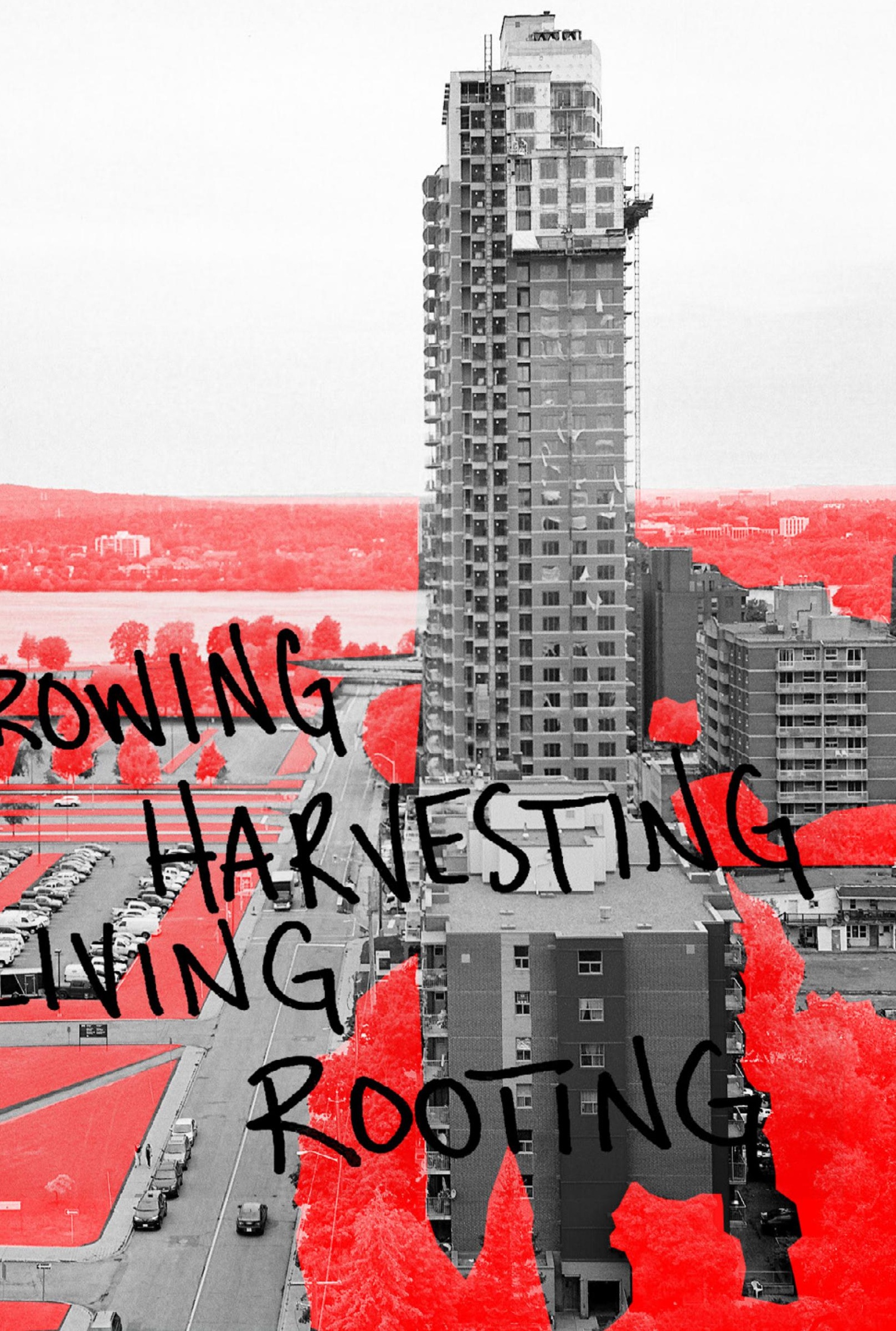




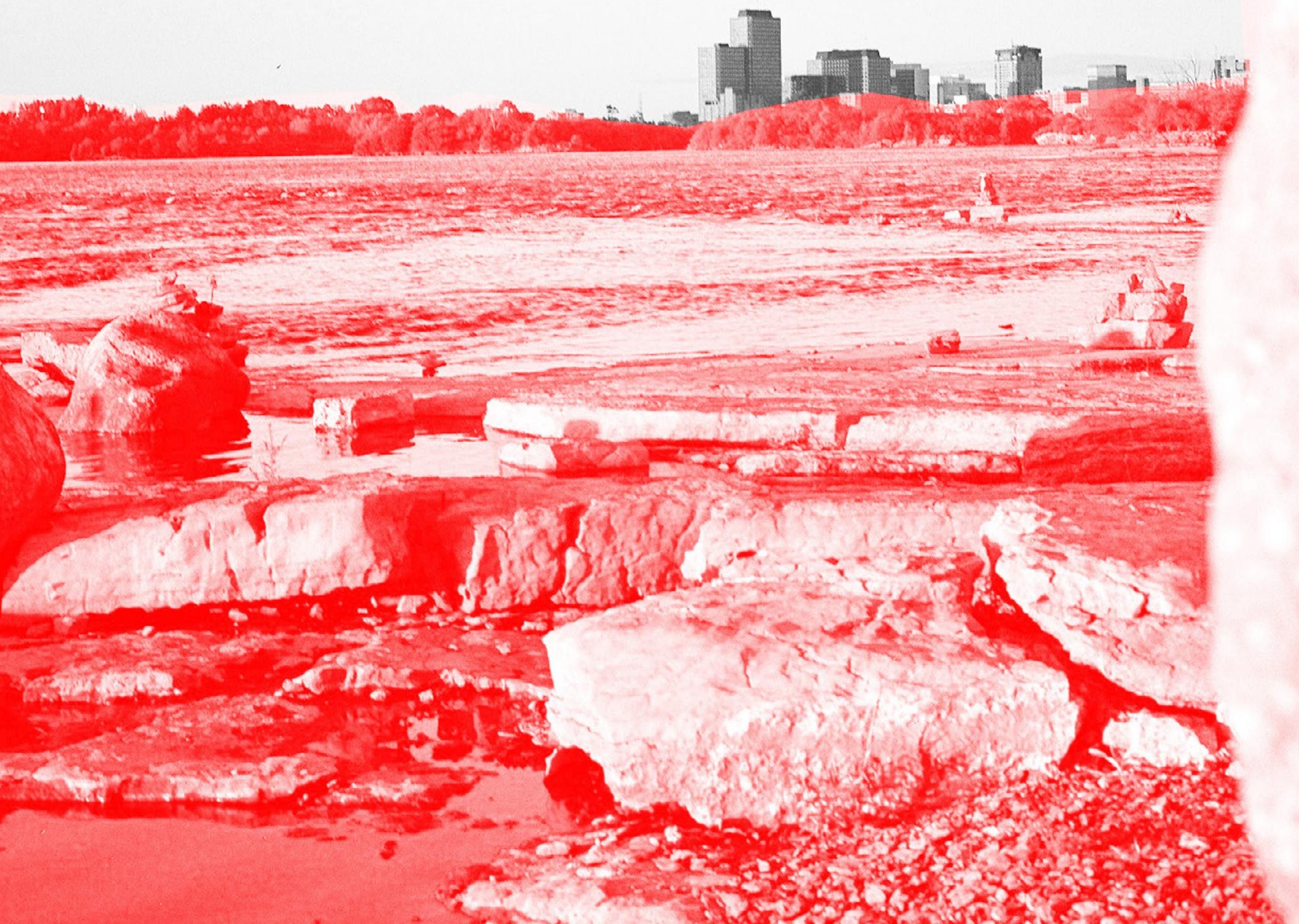





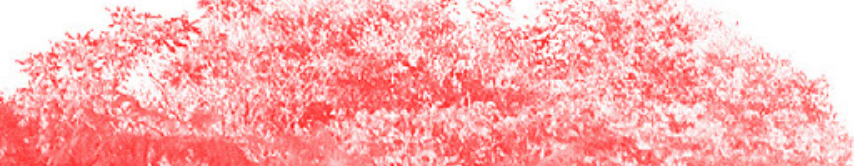

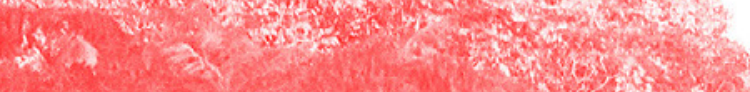




bibliography 
Agrest, Diana. Architecture from Without. Cambridge: MIT Press, 1993.

Agrest, Diana. Architecture of Nature: Nature of Architecture. New York: Applied Research and Design Publishing, 2018.

Arendt, Hannah. The Human Condition. Chicago: University of Chicago Press, 1958.

Bachelard, Gaston. The Poetics of Space. London: Penguin Books, 2014.

Barber, Daniel. "Architecture, Media, and Climate." In Modern Architecture and Climate: Design Before Air Conditioning, 2-23. Barber:

Princeton University Press, 2020.

Benjamin, David. Embodied Energy and Design: Making Architecture Between Metrics and Narratives. New York: Columbia University GSAPP, 2017.

Berger, Benjamin. "Understanding AgriHoods: An Exploration in the Growing Trend of Farm-to-Table Communities Across the United States." Master's Thesis. University of Massachusetts, 2020. https://scholarworks.umass.edu/masters_theses_2/934/

Blackfoot Dictionary. Algonquin Dictionaries Project. (Dictionary) https://dictionary.blackfoot.atlas-ling.ca/\#/help

Campbell, Joseph. The Power of Myth with Bill Moyers. New York: Anchor Books, 1988.

Cheng, Irene., Charles L Davis, and Mabel O Wilson. Race and Modern Architecture: A Critical History from the Enlightenment to the Present. Pittsburgh: University of Pittsburgh Press, 2020.

City of Ottawa. The New Official Plan. https://engage.ottawa.ca/the-newofficial-plan.

City of Ottawa: Research and Forecasting Unit, Planning, Infrastructure and Economic Development Department. Residential Growth Management Strategy for the New Official Plan. Ottawa: 2019.

Colbert, Elizabeth. The Sixth Extinction: An Unnatural History. New York: Henry Holt and Company, 2014.

Criado-Perez, Caroline. Invisible Women: Exposing Data Bias in a World Designed for Men. New York: Harry N. Abrams, 2019.

Davis, Heather., Todd, Zoe. "On the Importance of a Date, or Decolonizing the Anthropocene." An International Journal for Critical Geographies 16, No.4, (2017): 761-780. https://acme-journal.org/ index.php/acme/article/view/1539 

the Age of Climate Change. London: Verso, 2019.

Descartes, René. A Discourse on the Method Translated by John Veitch. Project Gutenberg, 1937. https://www.gutenberg.org/files/59/59h/59-h.htm.

Dorries, Heather, Robert Henry, David Hugill, Tyler McCreary, Julie Tomiak (Editors). Settler City Limits: Indigenous Resurgence and Colonial Violence in the Urban Prairie West. Winnipeg: University of Manitoba Press, 2019.

Escobar, Arturo. Designs for the Pluriverse: Radical Interdependence, Autonomy, and the Making of Worlds. London: Duke University Press, 2017.

Frampton, Kenneth. Modern Architecture: A Critical History. London: Thames and Hudson, 1985.

Ghosn, Rania., Jazairy, El Hadi., I DESIGN EARTH. GeoStories: Another Architecture for the Environment. New York: Actar Publishers, 2018.

Gissen, David. Subnature: Architecture's Other Environments. New York: Princeton University Press, 2009.

Gorsline, Marie., and Douglas Gorsline. North American Indians. New York: Random House, 1977.

Haraway, Donna. Staying With The Trouble: Making Kin in the Chthulucene. Durham: Duke University Press, 2016.

International Resource Panel. Global Resources Outlook: 2019 Natural Resources For the Future We Want / Summary for Policymakers. UN Environment Programme, 2019. https://www.resourcepanel.org/ reports/global-resources-outlook

Kallipoliti, Lydia. The Architecture of Closed Worlds: Or, What is the Power of Shit? New York: Lars Muller Publishing, 2018.

Kimmerer, Robin Wall. Braiding Sweetgrass: Indigenous Wisdom: Scientific Knowledge, and the Teachings of Plants. Milkweed Editions, 2013, 9.

Kruger, Barbara. I Shop Therefore I Am. New York: MoMA, 1990. https://www.moma.org/collection/works/64897

Latour, Bruno. Down to Earth: Politics in the New Climatic Regime. Cambridge: Polity Press, 2018. 
LeCain, Timothy James. "Against the Anthropocene: A Neo-Materialist Perspective." International Journal for History, Culture and Modernity 3, No.1, (2015): 1-28. DOI: 10.18352/hcm.474

Lethaby, William. Architecture, Mysticism, and Myth. London: Percival \& Co, 1892.

Maathai, Wangari. Replenishing the Earth: Spiritual Values for Healing Ourselves and the World. Toronto: Doubleday, 2010.

McKibben, Bill. The End of Nature. New York: Penguin Random House, 1989.

Morton, Timothy. Being Ecological. Morton: MIT Press, 2018.

OED Online. "Embody, v." Oxford University Press. (Dictionary) https://www.oed.com/view/Entry/60907?redirectedFrom=embody.

OED Online. "Energy, n." Oxford University Press. (Dictionary) https://www.oed.com/view/Entry/62088?redirectedFrom=energy.

OED Online. "Expansion, n." Oxford University Press. (Dictionary) https://www.oed.com/view/Entry/66424?redirectedFrom=expansion.

OED Online. "Symbiosis, n." Oxford University Press. (Dictionary) https://www.oed.com/view/Entry/196194?redirectedFrom=symbiosis.

Ontario Government. Map of Ontario Treaties and Reserves. https://www.ontario.ca/page/map-ontario-treaties-and-reserves

Ontario Government. The Algonquin Land Claim. https://www.ontario.ca/page/algonquin-land-claim.

Rael, Ronald. Earth Architecture. New York: Princeton Architecture Press, 2009.

Raymond, Ted. "Working From Home Could be a Viable Option for Federal Public Service: Union." Ottawa CTV News. May 22, 2020.

Rudofsky, Bernard. Architecture Without Architects: An Introduction to Non-Pedigreed Architecture. New York: The Museum of Modern Art, 1964.

Steadman, Philip. The Evolution of Designs: Biological Analogy in Architecture and The Applied Arts. London: Routledge, 1979.

Stewart, Susan. On Longing: Narratives of the Miniature, the Gigantic, the Souvenir, the Collection. London: Duke University Press, 1993.

Strauss, Claude Levee. Myth and Meaning. Toronto: University of Toronto Press, 1978. 
110 Tafuri, Manfredo. Architecture and Utopia: Design and Capitalist Development. Cambridge, MIT Press, 1977.

The Ecozoic Times. What does Ecozoic mean? https://ecozoictimes.com/what-is-the-ecozoic/what-doesecozoic-mean/\#: :text=The\%20term\%20\%E2\%80\%9CEcozoic\%20 era\%E2\%80\%9D\%20was,Earth\%20and\%20the\%20Earth\%20 community.

The Smithsonian Environmental Research Center. "The Skin of the Earth." https://forces.si.edu/soils/02_01_01.html\#: :text=Over\%20 most\%20of\%20the\%20Earth's,each\%20with\%20its\%20own\%20 story.

Three Initiates. The Kybalion: A Study of Hermetic Philosophy of Ancient Egypt and Greece. London: The Yogi Publication Society, 1908.

Tuck, Eve., and Yang, Wayne. "Decolonization is not a Metaphor." Decolonization, Indigeneity, Education \& Society, 1, no. 1. (2012): 1-40. https://jps.library.utoronto.ca/index.php/des/article/view/18630

UN News. "Soil Erosion Must be Stopped to 'Save Our Future,' says UN Agricultural Agency." December 5, 2019. https://news.un.org/ en/story/2019/12/1052831.

Upton, Dell., and John Michael Vlach. Common Places: Readings in American Vernacular Architecture. London: The University of Georgia Press, 1986.

Vellinga, Marcel., and Lindsay Asquith. Vernacular Architecture in the $21^{\text {st }}$ Century: Theory, Education and Practice. London: Taylor \& Francis, 2006.

Wanek, Catherine., Michael Smith, and Joseph F. Kennedy. The Art of Natural Building: Design, Construction, Resources. Second Edition. Gabriola Island, BC: New Society Publishers, 2005.

Watson, Julia. Lo-TEK Design by Radical Indigenism. Italy: Taschen, 2020.

Watts, Alan., and Chungliang Al Huang. Tao: The Watercourse Way. New York: Pantheon Books, 1975.

Watts, Vanessa. "Indigenous place-thought \& agency amongst humans and non-humans (First Woman and Sky Woman go on a European world tour!)." Decolonization: Indigeneity, Education \& Society 2, No.1, (2013): 20-34. https://jps.library.utoronto.ca/index.php/des/ article/view/19145 
D

O 